Universidad de Lima

Facultad de Ciencias Empresariales y Económicas

Carrera de Economía

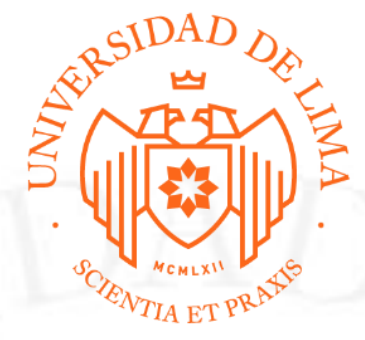

\title{
EFECTO DEL DESARROLLO DEL MERCADO DE CAPITALES EN EL CRECIMIENTO ECONÓMICO DE LOS PAÍSES DEL MILA EN EL PERIODO 1994 - 2016
}

Trabajo de investigación para optar el título profesional de Economista

\section{Valeria Jeanette Aguirre Bravo}

Código 20120033

\section{Asesor}

Yuri Landa Arroyo

Lima - Perú

Julio de 2019 


\section{EFECTO DEL DESARROLLO DEL MERCADO DE CAPITALES EN EL CRECIMIENTO ECONÓMICO DE LOS PAÍSES DEL MILA EN EL PERIODO 1994 - 2016}




\section{TABLA DE CONTENIDO}

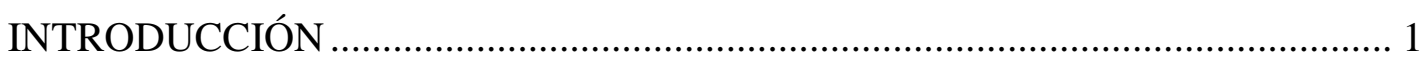

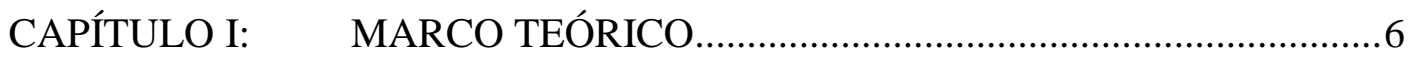

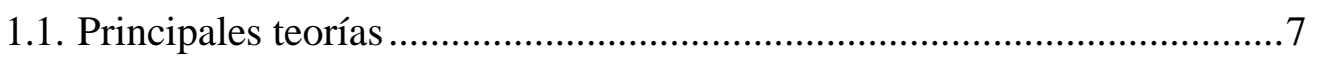

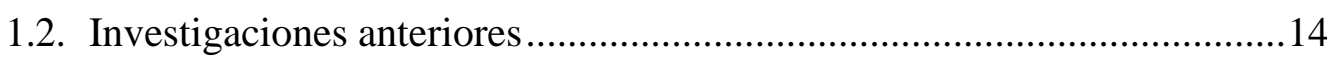

CAPÍTULO II: $\quad$ SISTEMA FINANCIERO PERUANO ...................................20

2.1. Historia del sistema financiero peruano................................................20

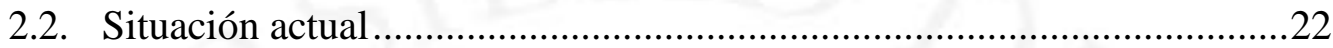

2.3. Principales leyes que regulan el mercado de capitales ..........................26

CAPÍTULO III: MEDIDAS Y REFORMAS EN AMÉRICA LATINA ............28

3.1. Reformas liberales en América Latina....................................................28

3.2. Mercado Integrado Latinoamericano .................................................. 31

CAPÍTULO IV: COSTOS DE EMISIÓN DE DEUDA EN LOS PAÍSES DEL

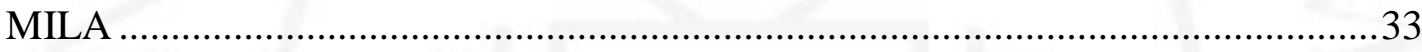

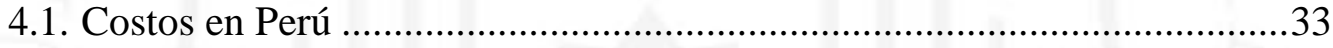

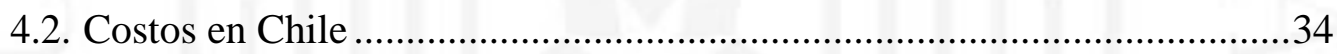

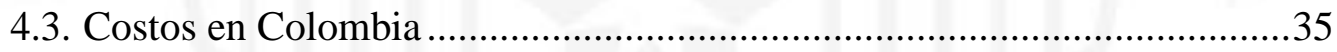

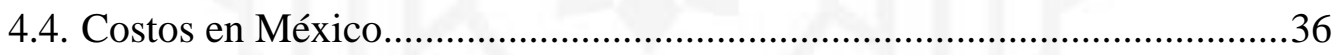

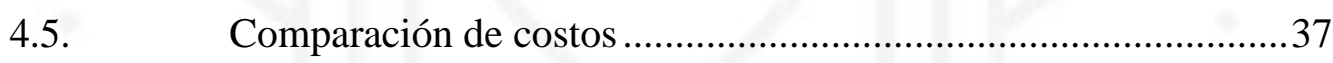

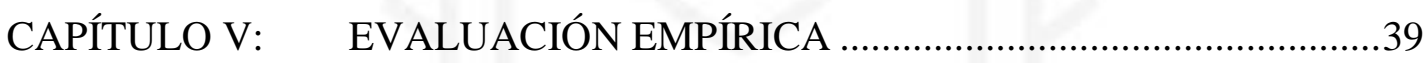

5.1. Modelo de mínimos cuadrados completamente modificados (FMOLS) ...43

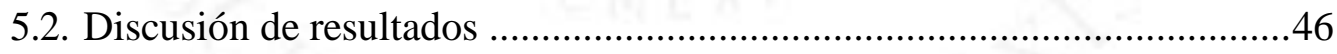

5.3. Modelo de corrección de errores (VECM) ..................................48

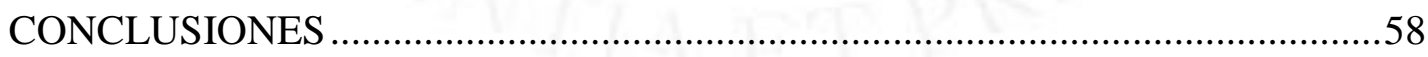

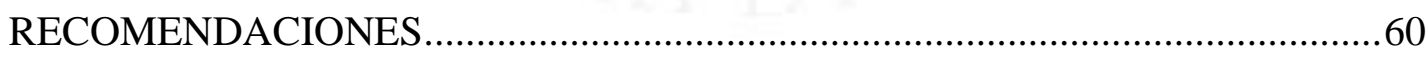

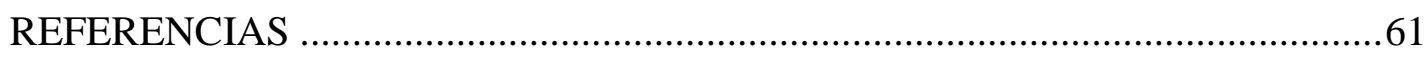




\section{ÍNDICE DE FIGURAS}

Figura 1 Valores de deuda pública doméstica (\%PBI) 1

Figura 2 Diferencias de tasas de interés: tasa activa menos tasa pasiva $(\%)$................ 2

Figura 5.1 Gráficos de las variables para Chile (1) y Colombia (2): PBI per cápita, Crédito Interno, Spread de Tasas de Interés, Capitalización de Mercado y Valor Total de Acciones

Tranzadas 40

Figura 5.2 Gráficos de las variables para México (3) y Perú (4): PBI per cápita, Crédito Interno, Spread de Tasas de Interés, Capitalización de Mercado y Valor Total de Acciones Tranzadas .41

Figura 5.3 Matriz de correlación de las variables ....................................................... 42

Figura 5.4 Prueba de cointegración de Kao .............................................................. 44

Figura 5.5 Estimación del modelo con el método de FMOLS....................................45

Figura 5.6 Prueba de normalidad de los residuos para el modelo FMOLS .................. 45

Figura 5.7 Gráficas de la variable PBIPC respecto a las variables explicativas ............ 47

Figura 5.8 Estimación del modelo con el método de VECM ....................................... 49

Figura 5.9 Test de autocorrelación de los residuos para el modelo VECM....................50

Figura 5.10 Test de heterocedasticidad para el modelo VECM .....................................51

Figura 5.11 Test de normalidad de los residuos para el modelo VECM .......................52

Figura 5.12 Funciones impulso-respuesta para la variable PBIPC ............................. 53

Figura 5.13 Funciones impulso-respuesta para las variables CRED y SPREAD $\quad 54$

Figura 5.14 Funciones impulso-respuesta para las variables CAP y SMVT ..................55

Figura 5.15 Respuesta del crecimiento del PBI per cápita ante un shock en el crédito al sector privado (1980 - 2007) 


\section{ÍNDICE DE TABLAS}

Tabla 2.1 Perú: principales reformas financieras (1990-2004)

Tabla 2.2 Comparación de la profundidad del Mercado de Capitales en los países del MILA

Tabla 4.1 Costo de emisión de bonos corporativos en el Mercado de Capitales peruano

Tabla 4.2 Costo para el listado de valores de deuda en México..................................... 36

Tabla 4.3 Costos de mantenimiento de valores de deuda en México. 37

Tabla 4.4 Costos de emisión de valores de deuda privada en los países del MILA (en US\$) 38

Tabla 5.1 Resultados de pruebas de raíz unitaria para las variables del modelo 42

Tabla 5.2 Resultado de las pruebas de longitud de rezagos 48 


\section{ÍNDICE DE ANEXOS}

ANEXO 1: PRUEBAS DE RAÍZ UNITARIA....................................................6

Prueba en niveles para la variable PBI per cápita .............................................67

Prueba en diferencias para la variable PBI per cápita .........................................6 67

Prueba en niveles para la variable Crédito interno ............................................68

Prueba en diferencias para la variable Crédito interno .......................................6 68

Prueba en niveles para la variable Spread de tasas de interés ..............................69

Prueba en diferencias para la variable Spread de tasas de interés .........................69

Prueba en niveles para la variable Capitalización de mercado................................70

Prueba en diferencias para la variable Capitalización de mercado ......................... 70

Prueba en niveles para la variable Valor total de acciones tranzadas ................... 71

Prueba en diferencias para la variable Valor total de acciones tranzadas ...............71

ANEXO 2: PRUEBAS DE SELECCIÓN DE NÚMERO DE REZAGOS .....................72

Prueba de selección de número de rezagos para la variable PBI per cápita ............ 72

Prueba de selección de número de rezagos para la variable Crédito interno .........72

Prueba de selección de número de rezagos para la variable Spread de tasas de

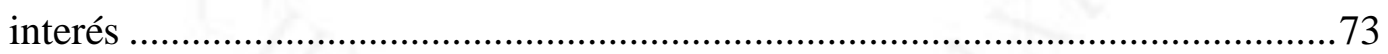

Prueba de selección de número de rezagos para la variable Capitalización de

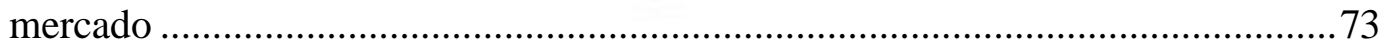

Prueba de selección de número de rezagos para la variable Valor total de acciones tranzadas .74 


\section{INTRODUCCIÓN}

En este trabajo se investiga la relación entre el mercado de capitales y el crecimiento económico de los países del Mercado Integrado Latinoamericano (MILA): Perú, Chile, Colombia y México. El periodo analizado está comprendido entre los años 1994 y 2016, después de la liberalización económica y después de la década perdida de los 80’s vivida en la región.

Según el Banco Central de Reserva del Perú (2010), “el mercado de capitales es el lugar donde se emiten y transan instrumentos financieros". Este mercado representa una alternativa de financiamiento, que permite a las empresas emitir títulos con un costo financiero menor que un préstamo bancario. Por otra parte, los inversionistas obtienen una mayor rentabilidad por sus inversiones.

Estas alternativas de inversión y financiamiento aplican tanto para el sector privado como para el público. En el Perú, el Gobierno tiene poca participación como emisor de deuda pública, a diferencia de otros países de la región. En la figura 1 se muestra que el país está por debajo del promedio del MILA en cuanto al uso de valores de deuda pública, y muy por debajo del promedio mundial. Este tipo de financiamiento es aplicable en todos los niveles de gobierno, los municipios podrían emitir bonos para financiar proyectos de infraestructura.

\section{Figura 1}

Valores de deuda pública doméstica (\%PBI)

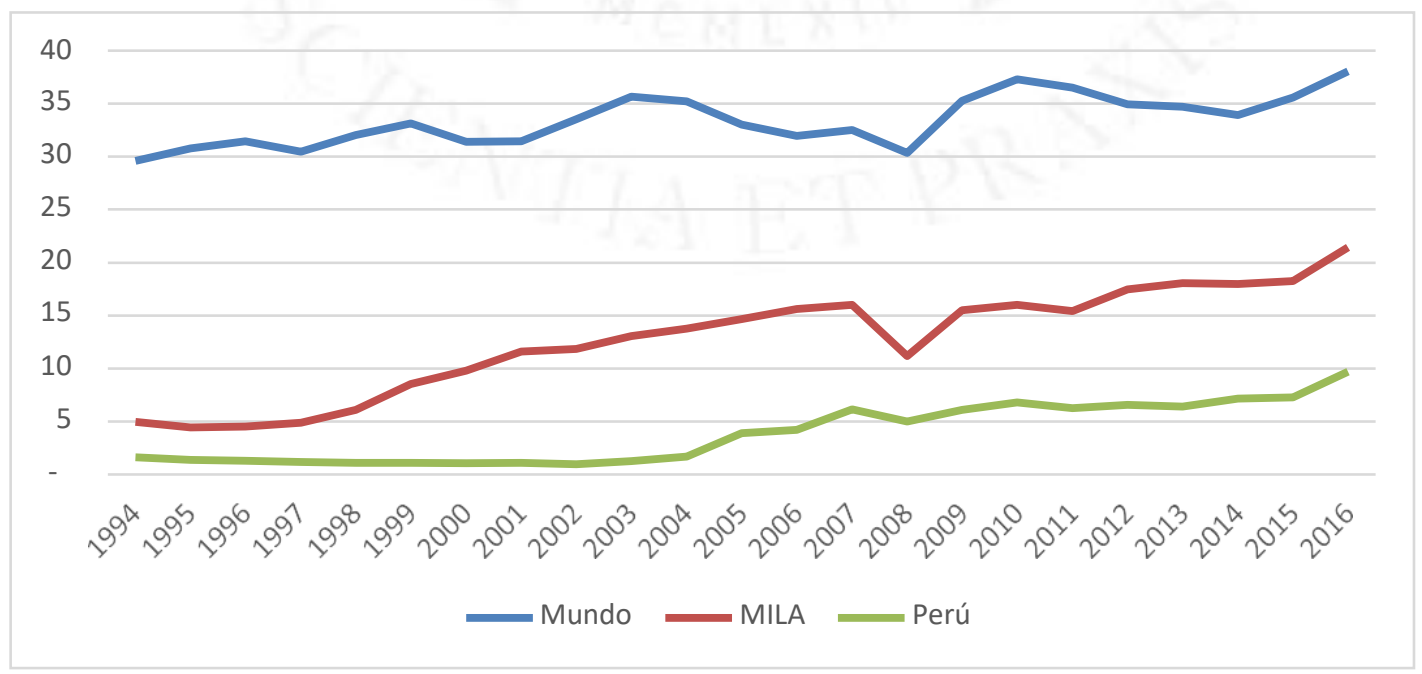

Fuente: Banco de Datos del Banco Mundial (s. f.). Recuperado de https://databank.bancomundial.org Elaboración propia 
Un obstáculo importante en el crecimiento del mercado secundario de valores es que no es líquido, lo cual se debe a los bajos volúmenes de negociación de acciones y porque muy pocas empresas peruanas cotizan en bolsa. Esto se da porque la gran mayoría de las empresas peruanas son microempresas. Según la publicación del INEI, Perú: Estructura Empresarial (2014), el 94,92\% de las empresas del país son microempresas, las cuales presentan ventas anuales menores a 570 mil soles (p. 1).

Estas empresas no tienen acceso al mercado de valores, ya que los costos de obtener financiamiento por este medio, son en gran parte fijos. Según el Ministerio de Economía y Finanzas, sólo son justificables las emisiones mayores a 10 millones de dólares, para compensar los costos de transacción. Más adelante, en el capítulo IV se detallan los costos de emitir bonos corporativos, que son instrumentos de deuda utilizados por empresas para sus necesidades de financiamiento.

Por otra parte, los créditos a las empresas en el país son caros, siendo las micro y pequeñas empresas a las que se les cobra una mayor tasa de interés. En el Perú, los bancos tienen un spread de tasas de interés bastante alto, lo que dificulta el dinamismo en la inversión y desalienta el ahorro. Al 2016, este spread es de 13.82 puntos porcentuales. En la figura 2 se observa que, el promedio de los países del MILA tiene el spread de tasas de interés similar al promedio mundial. Esto muestra que hay un amplio espacio de mejora para el Perú.

Figura 2

Diferencial de tasas de interés: tasa activa menos tasa pasiva $(\%)$

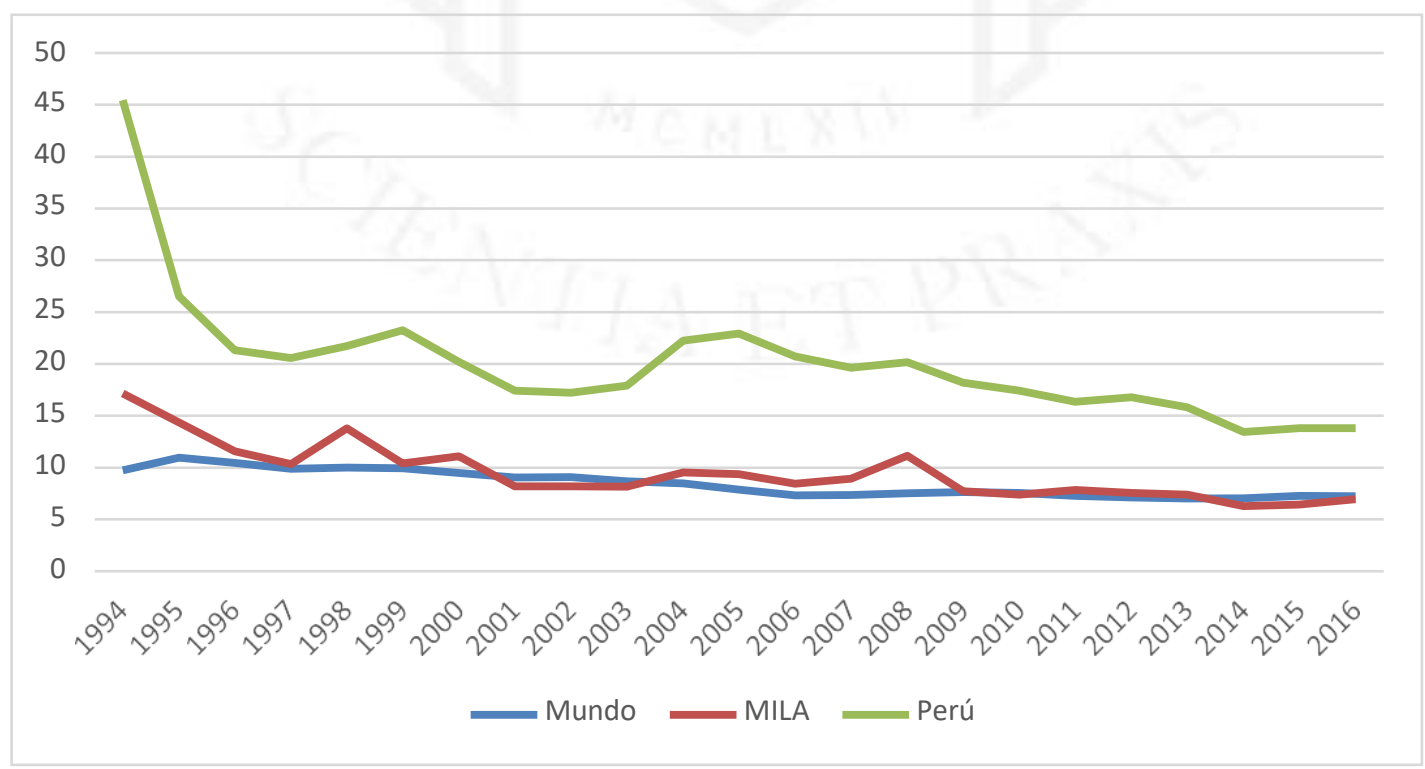

Fuente: Banco de Datos del Banco Mundial (s. f.). Recuperado de https://databank.bancomundial.org Elaboración propia 
El desarrollo del mercado de capitales es de gran importancia para el país, debido a que el Perú está muy rezagado en este tema, inclusive, comparado con los países de Latinoamérica. Este escenario es favorable para la introducción de políticas que se encarguen de dinamizar la inversión y mejorar la eficiencia en la asignación de recursos, por medio de este mercado.

Desde el punto de vista del Estado, el mercado de capitales es un medio para la redistribución del ingreso y la reducción de la pobreza. Existe una gran brecha de infraestructura en varios países de la región, como es el caso de Perú, la cual se puede financiar por medio de este mercado. Por otra parte, un mejor desarrollo de este mercado, favorece al crecimiento del sector financiero del país.

El mercado de capitales facilita el flujo de fondos de los inversionistas (superavitarios) a las empresas o instituciones estatales (deficitarios), lo cual mejora la eficiencia del sistema financiero. Desde el punto de vista de la empresa, este mercado representa una fuente de financiamiento para proyectos de inversión en infraestructura, innovación, desarrollo de nuevos productos, entre otros.

En una conferencia realizada por el Fondo Monetario Internacional (FMI) sobre el desarrollo de los mercados de capital en América Latina (2001), Eduardo Aninat, entonces Subdirector Gerente del FMI, explicó que, en los países de Latinoamérica, los mercados de capitales son poco desarrollados. Esto hace que a nivel sistémico sean más volátiles y que las crisis financieras puedan contagiarse con mayor facilidad. Por eso, afirmó que los mercados de valores requieren mejorar su infraestructura financiera y jurídica, para fomentar su desarrollo.

El objetivo general de este trabajo es determinar el impacto del desarrollo de los mercados de capitales en el crecimiento económico de los países del MILA: Perú, Chile, Colombia y México, para el periodo de 1994 a 2016. Los objetivos específicos son analizar el impacto de los costos de transacción en el desarrollo del mercado de capitales, y establecer la relación entre el acceso al financiamiento de las empresas y el crecimiento económico de los países estudiados.

Para lograr estos objetivos, se planteó como hipótesis general que existe un impacto positivo del desarrollo de los mercados de capitales en el crecimiento económico de los países del MILA, para el periodo de 1994 a 2016. Por otra parte, como hipótesis específicas se plantea que los costos de transacción ejercen un impacto negativo en el 
desarrollo del mercado de capitales; y que el acceso al financiamiento de las empresas tiene un efecto positivo en el crecimiento económico.

La investigación tiene un enfoque cuantitativo, ya que se centra en la medición del efecto del desarrollo del mercado de capitales en el crecimiento económico de los países del MILA. Se toma como periodo de análisis del año 1994 al 2016. El número de observaciones que se procesan es de 92 , ya que son 23 datos anuales de 4 países para cada variable.

Para ello, se utilizó un modelo econométrico de datos de panel para el proceso de validación de las hipótesis. A diferencia con otras investigaciones en las que se basa el trabajo, se realizó una comparación con los países del MILA en cuanto al nivel de desarrollo que presentan los mercados de capitales de cada uno de estos países. Se analiza cómo es que esto afecta al crecimiento económico en el largo plazo, lo cual se verifica con el modelo econométrico de cointegración para datos de panel. Adicionalmente, se analizó la reacción de las variables ante shocks en las otras variables del modelo, mediante funciones impulso-respuesta.

Primero se emplearon pruebas de cointegración para definir si las variables utilizadas presentan una relación de equilibrio en el largo plazo. Luego se procede a emplear un modelo de estimación de mínimos cuadrados completamente modificados, con cointegración para datos de panel. Después se estimó el modelo de corrección de errores para poder obtener las funciones impulso-respuesta.

Las variables empleadas son:

- PBI per cápita: Producto bruto interno dividido por la población a mitad de año, en dólares constantes del 2010.

- Crédito interno al sector privado: Incluye los créditos provistos al sector privado por parte de corporaciones financieras, como porcentaje del PBI.

- Spread de tasas de interés: Diferencia entre la tasa activa promedio menos la tasa pasiva promedio de cada país, en porcentaje.

- Capitalización del Mercado de acciones: valor total de las acciones listadas en la Bolsa de Valores del país, como porcentaje del PBI.

- Valor total de acciones tranzadas: Valor total de las acciones transadas en la Bolsa de Valores del país, como porcentaje del PBI. 
Las variables capitalización de mercado y valor total de acciones tranzadas son usadas para explicar el desarrollo de los mercados de capitales, mientras que las variables crédito interno y spread de tasa de interés reflejan el acceso al financiamiento y el costo del mismo en los países analizados. Estos datos fueron obtenidos del Banco de Datos del Banco Mundial, de los Indicadores del Desarrollo Mundial y Desarrollo Financiero Mundial.

En el capítulo I, el marco teórico, se explican las teorías más importantes del tema, iniciando con la teoría neoclásica de crecimiento económico. Más adelante, se analiza el enfoque funcional de la intermediación financiera, que es el enfoque en el que se basa la investigación, y se exponen algunas conclusiones de estudios anteriores sobre el tema. En el capítulo II, se detalla la evolución del Mercado de Capitales Peruano, luego se explica la situación actual y se describen las normas que lo regulan. En el capítulo III, se explican las medidas y reformas en el sistema financiero en América Latina y se realiza una descripción del Mercado Integrado Latinoamericano. En el capítulo IV, se explican los costos de emisión de bonos para los países estudiados, dando ejemplos para cada caso. Luego, en el capítulo V, se presentan las variables y el modelo empleado, terminando con la discusión de los resultados obtenidos. Para finalizar, se presentan las conclusiones y recomendaciones del trabajo. 


\section{CAPÍTULO I: MARCO TEÓRICO}

El desarrollo del mercado de capitales es un elemento esencial para la correcta asignación de capital. Según Bencivenga y Smith (1991), "una industria de intermediación le permite a una economía reducir la fracción de sus ahorros depositados en forma de activos líquidos improductivos, y así evitar una mala asignación de capital invertido, debido a las necesidades de liquidez" (p.196).

Gran parte del desarrollo financiero depende de los mercados de capitales, los cuales son una herramienta clave en el crecimiento económico, al asignar eficientemente los recursos de ahorro hacia los distintos proyectos de inversión. Esto se puede ver en los países desarrollados, los cuales tienen estos mercados muy avanzados. Según Ouandlous (2010), el objetivo principal de los mercados de capitales es facilitar los recursos disponibles a los inversionistas para financiar proyectos de largo plazo, a un costo de capital competitivo (p. 11).

Se podría pensar que los bancos cumplen esa función al ser intermediarios financieros, sin embargo, estos no suelen financiar proyectos de muy largo plazo, muchos de los cuales no tienen un retorno asegurado y son riesgosos. En cambio, los mercados de capitales sí facilitan la obtención de fondos de largo plazo, ya sea por medio de emisión de acciones o de bonos. Esto incentiva la innovación y la implementación de nuevas tecnologías.

De esta manera, los mercados de valores pueden promover el crecimiento de largo plazo, ya que fomentan la especialización, la adquisición y difusión de información, además de reducir el costo de movilización del ahorro, facilitando la inversión (Arestis, Demetriades y Luintel, 2001, p. 17).

Además, en el caso del mercado de acciones, los empresarios que reciben los fondos no están obligados a pagar cuotas fijas, sino que pagan un porcentaje de las ganancias de la empresa. Esto ayuda a financiar proyectos en los que las ganancias se dan de manera irregular a lo largo del tiempo. Un ejemplo de este tipo de proyectos son los que están relacionados con la investigación y desarrollo de nuevos productos, por medio de los cuales se puede alcanzar un incremento en la productividad. 
Por el lado del sector público, este mercado brinda una fuente de financiamiento no inflacionario del déficit fiscal (Borges, Landaberry y Licandro, 2012, p. 2). Esto es importante para economías como la del país, que tienen un rango de inflación meta. Al otorgar una mayor diversidad de instrumentos en cuanto a vencimiento, permite realizar operaciones de mercado abierto y ampliar la capacidad de transmisión de las políticas (p. 3).

Varios países de América Latina han sufrido de tasas de inflación altas debido a la emisión de dinero por parte del Estado para cubrir el déficit fiscal. Financiar los gastos del gobierno de esta forma es sumamente regresivo, ya que los agentes económicos más pobres son los que se ven perjudicados al no tener acceso a mecanismos de pago alternativos, como el crédito (Bucacos, 2003, p. 3).

Además, la inflación corroe la base imponible del impuesto debido al cambio en la base monetaria, haciendo que sean necesarias tasas cada vez más altas para asegurar un determinado nivel de recaudación. Esto podría traducirse en un incremento pronunciado en el ritmo de crecimiento de los precios, lo que podría llevar a la hiperinflación (p. 4). Es por esto que la existencia de un mecanismo alternativo para financiar el gasto del gobierno, como la emisión de bonos soberanos, es importante, ya que contribuye a la estabilidad de la economía.

\subsection{Principales teorías}

La relación entre el crecimiento económico y la acumulación de capital ha sido analizada por diversos autores a lo largo del tiempo. Las teorías que se presentarán a continuación se dividen en dos grandes grupos, las de crecimiento exógeno y las de crecimiento endógeno. Los modelos de crecimiento exógeno son los neoclásicos. Estos tienen una función de producción con rendimientos de capital decrecientes. Son exógenos porque el crecimiento de largo plazo se explica por factores externos al modelo. Por el contrario, los modelos de crecimiento endógeno tienen una función de producción con rendimientos constantes de capital. Estos modelos tienen variables que sí explican el crecimiento de largo plazo.

La teoría neoclásica plantea que el crecimiento económico está en función a la productividad del capital y del trabajo, lo cual depende de la tecnología disponible. Mediante este modelo, en el largo plazo se llega a un estado estacionario, en el que el 
ratio de crecimiento económico es igual al ratio de crecimiento de capital. Este depende de la tasa de ahorro y de crecimiento poblacional: mientras más alta sea la tasa de ahorro, más alto será el nivel de ingresos en el estado estacionario (Solow, 1956).

En el modelo planteado por Solow, parte de la producción de cada periodo se consume, mientras que el resto se guarda y se invierte. La fracción del ingreso que se ahorra está dada por una tasa constante. El stock de capital toma la forma de la acumulación del bien compuesto, cuya tasa de aumento es la inversión neta. La producción, que presenta rendimientos constantes a escala, se da mediante dos factores: capital y trabajo, mientras que las posibilidades tecnológicas están representadas por una función de producción (p. 66).

El resultado es un perfil temporal del capital de la población, que empleará plenamente la mano de obra disponible. Una vez que se conoce la trayectoria temporal del capital y de la fuerza de trabajo, se puede calcular, a partir de la función de producción, la producción real. La ecuación de la productividad marginal del trabajo determina la trayectoria temporal de la tasa de salario real. Además, en cualquier punto del tiempo se suministra de forma inelástica el stock preexistente del capital, el cual es el resultado de la acumulación anterior. El rendimiento real de los factores se ajustará para lograr el pleno empleo de mano de obra y el capital se puede utilizar en la función de producción para encontrar el nivel actual del producto (p. 68).

A continuación, la propensión a ahorrar muestra qué parte de la producción neta será ahorrada e invertida, por lo que se conoce la acumulación neta de capital durante el período actual. Es así como se obtiene el capital disponible, con lo que se puede determinar el capital futuro. De esta manera, se puede proyectar el nivel de producción real (p. 68).

En el largo plazo, el sistema se desarrollará hacia un estado de crecimiento a la tasa natural, el cual es el equilibrio del estado estacionario. Aquí, la relación entre capital y trabajo se mantendrá. En este estado, el trabajo crece a la misma tasa que el crecimiento poblacional (n), y como la relación entre capital y trabajo se mantiene, ambos crecen a la tasa " $n$ ". Esto lleva a que la producción crezca de forma balanceada a la tasa natural (p. $70)$.

Por otra parte, Romer (1986) plantea un modelo de crecimiento endógeno, donde la producción per cápita puede crecer sin límite, a una velocidad que se incrementa con 
el tiempo. La tasa de inversión y el rendimiento del capital se incrementan con el aumento del stock de capital. Este modelo se desvía del supuesto habitual de los rendimientos decrecientes y propone un modelo de equilibrio de cambio tecnológico endógeno. Plantea que el crecimiento a largo plazo es impulsado principalmente por la acumulación de conocimiento por parte de agentes que maximizan sus beneficios de manera intertemporal.

El enfoque de Romer del conocimiento como forma básica del capital, genera que el modelo de crecimiento agregado se formule de una manera diferente. En contraste con el capital físico, los nuevos conocimientos son el producto de una tecnología de investigación que muestra rendimientos decrecientes. Eso quiere decir que, dado el stock de conocimientos en un punto en el tiempo, duplicar los insumos para la investigación no duplicará la cantidad de nuevos conocimientos producidos.

Además, la inversión en conocimiento genera una externalidad natural. La creación de nuevos conocimientos por una empresa tiene un efecto externo positivo sobre las posibilidades de producción de otras empresas, porque el conocimiento tiende a difundirse. Lo más importante en el modelo es que la producción de bienes de consumo, como función del stock de conocimientos y otros insumos, presenta rendimientos crecientes. Esto quiere decir que el conocimiento puede tener un producto marginal creciente (p. 1003).

Estos tres elementos, externalidades, rendimientos crecientes en la producción de bienes y rendimientos decrecientes en la producción de nuevos conocimientos, se combinan para producir un modelo de equilibrio competitivo bien especificado de crecimiento. A pesar de la presencia de rendimientos crecientes, existirá un equilibrio competitivo con factores externos, el cual es capaz de explicar el crecimiento histórico en ausencia de la intervención del gobierno (p. 1004).

Otro modelo de crecimiento endógeno es el de Lucas (1988), quien desarrolla un modelo similar al neoclásico, una economía cerrada cuya población crece a una tasa constante. La principal diferencia es que incorpora al capital humano y su acumulación mediante cambios en la tecnología. La tasa de crecimiento del stock de capital se incrementa con la efectividad de inversión en capital humano, y se reduce con el incremento de la tasa de descuento (p. 23). 
Hay dos tipos de capital, el capital físico que se acumula y utiliza en la producción bajo una tecnología neoclásica, y el capital humano, el cual incrementa la productividad del capital físico. El capital humano se acumula por medio de "learning by doing" o aprendizaje en el trabajo. La acumulación de este tipo de capital humano crece cuando se incrementan los esfuerzos por producir un determinado producto (p. 28).

Según el modelo, un nivel constante de esfuerzo produce una tasa de crecimiento constante para el stock de capital, independientemente de su nivel actual. El producto marginal del capital físico tiende a un nivel constante, determinado por la tasa de preferencia temporal. De esta manera, una economía que inicia con niveles bajos de capital humano y físico permanecerá siempre debajo de otra economía con mejores niveles iniciales de capital (p. 39). Es por esto que el modelo no explica las diferencias en el crecimiento entre economías con condiciones iniciales similares.

Rebelo (1991) desarrolló un modelo de crecimiento económico en el que no es necesario que la tecnología tenga rendimientos crecientes de escala para que haya un crecimiento sostenible en el largo plazo. Para que esto sea posible, debe existir un grupo de bienes de capital "core" que se produzcan sin usar factores no reproducibles, que son aquellos factores que no se pueden acumular y permanecen constantes en el tiempo, como la tierra. Este grupo de bienes de capital se puede producir con tecnologías que tengan rendimientos constantes de escala (p. 502).

Según Rebelo, un incremento en la tasa impositiva de los ingresos reduce la tasa de rendimiento de las actividades de inversión del sector privado. Esto lleva a una reducción permanente en la acumulación de capital, resultando en menor tasa de crecimiento. Sin embargo, Rebelo afirma que cobrar impuestos a la producción de bienes que no son los bienes de capital "core", no genera efectos en la tasa de crecimiento (p. $501)$.

En base a estas teorías, se puede afirmar que las funciones desempeñadas por el sistema financiero afectan el crecimiento económico en el estado estacionario, ya que inciden en los niveles de acumulación de capital. Además, el sistema financiero influye en la tasa de ahorro, lo cual afecta la inversión (CEFP, 2010, p. 3). Como se mencionará más adelante, el mercado de capitales también facilita el financiamiento de proyectos de investigación e innovación, lo cual contribuye a la generación de conocimientos. En los modelos explicados, la investigación impulsa el desarrollo del capital humano, lo cual 
genera crecimiento económico. A continuación, se presentan modelos en los que el sistema financiero influye en la innovación tecnológica, lo cual afecta el crecimiento económico de largo plazo al mejorar la productividad.

En 1990, Romer desarrolla un modelo en el cual las decisiones de inversión tomadas por agentes que maximizan beneficios impulsan el crecimiento económico. Aquí, el cambio en la tecnología genera incentivos para la acumulación de capital, lo que incrementa la velocidad de producción. (p. 72)

Estos cambios en la tecnología se producen gracias a los proyectos de investigación que se realicen. Estos proyectos intercambian costos en el periodo actual por beneficios en periodos futuros, lo que hace que los cambios tecnológicos sean sensibles a las tasas de interés. De esta manera, los mercados más desarrollados tenderán a realizar más investigaciones que lleven a mejoras tecnológicas, por lo que crecerán más rápido. (p. 99)

Grossman y Helpman (1991) proponen un modelo en el que el crecimiento depende de los beneficios esperados en el sector de investigación y desarrollo. Aquí, el equilibrio se caracteriza por una tasa agregada de innovación que es determinada y constante en el estado estacionario. En el modelo, cada producto puede ser suministrado en un número infinito de calidades. Estas calidades mejoran gracias a las investigaciones que realizan las empresas. (p. 60)

Según los autores, la innovación incrementa la productividad total de los factores en la producción de bienes de consumo y de capital, además de hacer posible la producción de nuevos bienes. Los empresarios de cada industria compiten simultáneamente para tener la mejor tecnología, con la cual buscan mejorar la calidad de sus productos. La probabilidad de tener éxito es proporcional a la cantidad de recursos destinados a mejorar ese producto, por medio de la investigación. La recompensa de tener éxito en las investigaciones en una industria específica es un flujo de ganancias, el cual durará hasta que se logre el próximo éxito en la misma industria. (p. 44)

Los empresarios que logran mejorar sus tecnologías e innovar se vuelven los líderes de la industria. Ellos generan una externalidad positiva para los consumidores, ya que pagan el mismo precio que antes de la innovación, pero reciben un producto de mayor calidad. Sin embargo, también generan una externalidad negativa para los líderes 
anteriores de la industria, ya que los consumidores preferirán los nuevos productos de mejor calidad, reduciendo su demanda por los productos de las otras empresas. (p. 52)

Otro modelo es el de Aghion y Howit (1992), donde el crecimiento económico depende del progreso tecnológico, el cual se da mediante la competencia entre las empresas, que investigan para generar innovaciones. En este modelo, las innovaciones consisten en nuevos productos intermedios, los cuales hacen que la fabricación de un producto final sea más eficiente que antes. (p. 349)

Sin embargo, los autores demuestran que la cantidad de investigación en un periodo tiene una relación negativa con la cantidad de investigación esperada para el siguiente periodo, porque reduce los ingresos esperados de las empresas. Esto se da a través de dos efectos: la destrucción creativa y un equilibrio general que funciona a través del salario de mano de obra calificada, que puede utilizarse tanto en investigación como en fabricación.

El primer efecto, la destrucción creativa, se refiere al proceso de innovación en el que, por medio de la investigación, las empresas crean nuevos productos que reemplazan a los existentes, lo que destruye a las empresas que no innovan. En este contexto, el incentivo de investigar en este periodo es la expectativa de rentas de monopolio para el siguiente periodo, las cuales solo duran hasta que ocurra la siguiente innovación. El valor presente de las rentas del siguiente periodo depende de forma negativa de la innovación futura esperada, por lo que un incremento de la investigación esperada desalienta la investigación en este periodo (p. 324).

En el segundo efecto, la expectativa de mayor investigación en el siguiente periodo va a la par con la expectativa de mayor demanda de mano de obra calificada. Esto genera que se espere un incremento en el salario de este tipo de mano de obra, lo que reduce los ingresos esperados de la empresa que innova (p. 324).

Por otra parte, Greenwood y Jovanovic (1990) plantean que la intermediación financiera impulsa el crecimiento económico porque permite que el capital gane una tasa de rendimiento más alta. El crecimiento, a su vez, facilita la implementación de estructuras financieras costosas, las cuales contribuyen a mejorar la asignación de recursos. Además, el crecimiento económico fomenta la inversión en capital, lo que genera mayor crecimiento (p. 1078). 
Los intermediarios financieros recopilan y analizan información, con lo cual determinan la asignación más eficiente de los recursos. Las instituciones surgen para facilitar las transacciones en la economía, al permitir obtener una mayor rentabilidad y al reducir los riesgos. Estas instituciones agrupan los riesgos y los distribuyen entre un gran número de inversores, lo que hace que las inversiones sean más seguras (p. 1078).

Según los autores, en las primeras etapas de desarrollo de una economía, sus mercados financieros son pequeños y crecen a un ritmo lento. A medida que el crecimiento empieza a acelerarse, surgen estructuras financieras más desarrolladas. En esta etapa, las tasas de crecimiento y ahorro de la economía se incrementan, la brecha de ingresos se amplía y hay mayor desigualdad. En la etapa final del crecimiento, la economía logra establecer una estructura sólida para la intermediación financiera. Aquí, la tasa de ahorro se reduce, la distribución del ingreso se estabiliza y la economía crece a una tasa mayor que en la etapa inicial. De esta manera, el crecimiento proporciona los medios para desarrollar una estructura financiera, mientras que esta estructura permite un mayor crecimiento (p. 1100).

Según Roubini y Sala-i-Martin (1995), los mercados financieros y la intermediación financiera determinan el desempeño económico de un país. Este sector asigna de manera eficiente los ahorros para proyectos de inversión productivos, con lo cual se facilita el crecimiento de una economía (p. 3). Sin embargo, muchos gobiernos han implementado políticas restrictivas a los mercados financieros, las cuales limitan su funcionamiento. Estas políticas reducen la cantidad de servicios proporcionados por el sector financiero, lo cual disminuye la inversión y afecta de manera negativa al crecimiento de largo plazo. (p. 29)

A lo largo del tiempo, los gobiernos han implementado políticas restrictivas al sector financiero. Estas políticas iniciaron con controles en las tasas de interés, para evitar que se cobre un interés excesivamente alto por un préstamo. Por otra parte, con la regulación del sistema bancario se esperaba tener un mayor control sobre la oferta monetaria. También, se pensaba que el gobierno podía asignar de mejor manera los recursos, desde una perspectiva social. (p. 1)

De acuerdo a los autores, el principal motivo para que los gobiernos intervengan es que el sector financiero es una fuente potencial de recursos "fáciles" para el presupuesto público. Por ejemplo, pueden regular las tasas de interés para conseguir 
financiamiento a un bajo costo. Los gobiernos tienen la capacidad de no permitir que el sector financiero funcione a su máximo potencial mediante la introducción de regulaciones, leyes y restricciones al comportamiento de los intermediarios financieros. (p. 2)

Según Merton (1995), la función principal de los sistemas financieros es facilitar la asignación y distribución de recursos económicos, dentro de un entorno cambiante. De manera desagregada, se pueden distinguir funciones más específicas, las cuales se refieren a los beneficios del sistema financiero: ofrece un sistema de pago para el intercambio de bienes y servicios; provee un mecanismo para concentrar fondos para llevar a cabo proyectos a gran escala; facilita la transferencia de recursos económicos a través del tiempo y del espacio; contribuye a gestionar la incertidumbre y de controlar riesgos; proporciona información que ayuda a coordinar la toma de decisiones en diversos sectores de la economía; y ayuda a enfrentar la información asimétrica y problemas de incentivos (p. 24).

Un marco de referencia para analizar la intermediación financiera es mediante una perspectiva funcional. Esta toma como dadas las funciones realizadas por el sistema financiero mencionadas y se pregunta cuál es la mejor estructura institucional para cumplir estas funciones. La perspectiva funcional se basa en que las funciones financieras son más estables que las instituciones financieras, y que la estructura institucional se vuelve más eficiente debido a la competencia. Este es el enfoque en el que se basa esta investigación, ya que, al ser las funciones aplicables a todas las economías, el enfoque funcional se puede utilizar de forma global, pudiendo ser útil para predecir la dirección de la innovación en instrumentos y los cambios en los mercados financieros (pp. 23-24).

\subsection{Investigaciones anteriores}

Debido a la importancia de este tema, se revisaron varios estudios acerca de la relación entre el mercado de capitales y el crecimiento económico.

En un estudio sobre el papel del mercado bursátil en el crecimiento económico de México, elaborado por el Centro de Estudios de las Finanzas Públicas del mismo país, se utiliza el enfoque funcional para explicar la relación entre el crecimiento y la calidad de las funciones que proporciona el sistema financiero. En este estudio se mencionan cinco 
funciones de los intermediarios financieros que contribuyen con el crecimiento económico (CEFP, 2010, p. 11):

- Reducción del riesgo: La incertidumbre de los inversionistas sobre el pago por parte de los emisores, genera que los primeros deban asumir costos de información y transacción. Esto hace necesario el establecimiento de mercados e instituciones financieras que faciliten el intercambio, la cobertura y control de los riesgos.

- Adquisición de información sobre inversiones y asignación de recursos: El alto costo de adquirir información hace que el capital fluya hacia las actividades más rentables. Los intermediarios financieros facilitan la obtención de esta información, lo cual mejora la asignación de recursos al dar a conocer las distintas oportunidades de inversión.

- Supervisión de administradores y control de empresas: Los mecanismos financieros permiten intensificar el control de las empresas, a través de contratos. De esta manera se reducen los costos de supervisión, promoviendo así la inversión.

- Movilización del Ahorro: La movilización de recursos consiste en la acumulación del capital de diversos ahorradores para invertirlo, lo cual permite la realización de proyectos de gran escala. Por otra parte, facilita la diversificación de carteras de pequeños inversionistas y aumentan la liquidez de los activos. El papel de los intermediarios financieros en este caso es reducir los costos que esta movilización puede implicar, mejorando la asignación de recursos.

- Facilitación del intercambio: Los intermediarios financieros, al reducir los costos de transacción y de información, facilitan la innovación tecnológica y fomentan el aumento de la productividad. Esto a su vez contribuye al desarrollo de los mercados financieros al incrementar el ingreso per cápita, ya que se reducen los costos fijos en proporción a este.

Debido a las características del sistema financiero, este contribuye en gran medida a la reducción del costo de información y de transacción. Según el estudio, estos costos tienen un impacto directo en las tasas de ahorro, las decisiones sobre inversión, la innovación tecnológica y las tasas de interés a largo plazo, por lo que la eficiencia del 
sistema financiero para reducirlos contribuye de forma positiva en el crecimiento económico.

En este estudio, se usan series de tiempo con data mensual, para el periodo de 1995 al 2008. Se toma como variable "proxy" del sector real de la economía toma el Índice del Volumen de la Producción Industrial, mientras que para estimar la actividad bursátil se usa el Índice de Precios y Cotizaciones de la Bolsa Mexicana de Valores. Por medio de pruebas de cointegración, mecanismos de corrección del error y de causalidad, se demostró que las series están cointegradas, es decir, que tienen una relación de equilibrio de largo plazo.

Según José Pablo Dapena (2009), en su estudio realizado sobre del rol del mercado de capitales en el crecimiento económico de Argentina, para lograr un desarrollo económico sostenido es necesaria la acumulación de capital, la cual se da en un ambiente propicio, donde los recursos de capital son canalizados eficientemente hacia la inversión productiva (p. 19). Estas condiciones están presentes en los mercados de capitales desarrollados.

En el caso de los países en vías de desarrollo, es muy importante la entrada de capitales del extranjero, ya que estos son invertidos en proyectos que mejoran la infraestructura y la calidad de vida de sus habitantes, además de brindar puestos de trabajo. En un contexto de perfecta movilidad de capitales, sería más atractivo invertir en estos países debido a que su producto marginal es mayor que el de los países desarrollados. Esto se debe a que los países emergentes cuentan con un menor stock de capital, lo que hace que un incremento de este sea altamente productivo.

Estudios realizados por Caballero y citados por Vial, mencionan la importancia de que los mercados de capitales sean tanto profundos como activos, con un alto número de transacciones. De esta manera, cumpliría un rol de estabilización, al ser un mercado más líquido y con variaciones menos pronunciadas. Sin embargo, el autor resalta la dificultad de lograr esto mientras las garantías de los deudores nacionales sean débiles en un contexto de riesgo cambiario. Además, no existe un mercado internacional donde se puedan transar los activos de respaldo, por lo que estas garantías se vuelven menos atractivas (como se citó en Vial, 2002, p. 4).

Mientras más desarrollado sea este mercado, habrá una mayor entrada de flujos de capital, la cual se incrementará hasta que las tasas de rendimiento de las inversiones 
se igualen con las de otros países. Según la condición de paridad de las tasas de interés, si hay una alta movilidad de capitales, "las tasas de interés y tipos de cambio tienden fuertemente a equilibrarse de manera que los rendimientos esperados se igualen entre países" (Thomas, 2006, p. 191). A partir de ahí es fundamental incentivar la inversión para no perder el dinamismo.

En un estudio realizado por Lahura y Vega (2013) para el Perú, se obtuvo que los indicadores de los mercados de acciones contribuyen a la predicción del crecimiento del PBI per cápita recién a partir de los años 90s. Por otra parte, un choque en el mercado de acciones tiene efectos de corto plazo significativos en su tasa de crecimiento. Esto implica que las políticas direccionadas al desarrollo de los mercados de capitales del país tendrán un impacto positivo en la dinámica del crecimiento económico, aunque podría incrementar su volatilidad (p. 3).

Vial (2002) identifica cuatro variables que generan inestabilidad en el crecimiento económico: los términos de intercambio, los flujos de capital privado, el tipo de cambio real y las políticas económicas (p. 6). En cuanto a los flujos privados de capitales financieros, menciona que son pro-cíclicos, por lo que, frente a una caída en los precios de productos de exportación, tienden a contraerse, limitando así las posibilidades de acceso al crédito internacional tanto a los gobiernos como al sector privado.

Otra investigación sobre este tema es la realizada por King y Levine (1993), en donde afirman que el desarrollo financiero está fuertemente correlacionado con el crecimiento económico al incrementar la acumulación de capital y al hacer más eficiente la asignación del mismo. Además, los intermediarios financieros, al lograr el financiamiento de proyectos riesgosos facilitan la innovación, la cual mejora la calidad del capital y lo hace más eficiente. Los autores concluyen en su investigación que las políticas que reducen los costos de transacción y mejoran la eficiencia del sistema financiero, ejercen una influencia directa en el crecimiento económico (p. 735).

En el caso de la intermediación financiera directa, el mercado de valores puede mejorar el desempeño del crecimiento económico. Esto se da a través de sus efectos positivos sobre los flujos de capital, la diversificación de riesgo de inversión, el financiamiento de proyectos industriales de largo plazo, y la provisión de liquidez (Wong, 2011, p. 111). 
Hassan, Sanchez y Yu, realizan un estudio que proporciona evidencia sobre el papel del desarrollo financiero en el crecimiento económico en países de bajos y medianos ingresos, clasificados por regiones geográficas. Para analizar esta relación, estimaron regresiones de panel data y vectores autorregresivos, para los años 1980 a 2007. Con los resultados, obtuvieron una relación positiva entre el desarrollo financiero y el crecimiento económico para los países en desarrollo. Sin embargo, en el corto plazo, usando el análisis multivariado, obtuvieron resultados mixtos. Por una parte, encontraron una relación de causalidad bidireccional entre el desarrollo financiero y el crecimiento económico para la mayoría de las regiones, mientras que para las regiones más pobres obtuvieron causalidad unidireccional del crecimiento al desarrollo financiero.

En el estudio de Nyasha y Odhiambo, se emplea un método de promedios restando las medias, para la elaboración de índices de desarrollo financiero basados en el desarrollo bancario y de mercado. Usan un enfoque de rezagos autorregresivos para analizar la relación entre estos índices y el crecimiento económico en Sudáfrica, con data anual para el periodo de 1980 a 2012. Los resultados que obtuvieron son que existe una relación positiva entre el desarrollo financiero basado en la banca y el crecimiento económico. Sin embargo, no encontraron una relación significativa entre el desarrollo financiero basado en el mercado y el crecimiento económico, para el caso de Sudáfrica.

Por otra parte, Al Nasser (2015) desarrolla un modelo de datos de panel para 14 países de Latinoamérica, con data de 1978 a 2011. Por medio del test de cointegración, demostró la existencia de una relación de largo plazo entre el crecimiento económico y el desarrollo del sistema financiero. Además, por medio de la prueba de causalidad de Granger, obtuvo que existe una relación unidireccional entre el crecimiento económico y el desarrollo del sector bancario, mientras que el crecimiento económico y el desarrollo del mercado de capitales presentan una relación bidireccional.

Para el caso de Perú, Lahura y Vega (2013) emplearon un modelo de vectores autorregresivos para estimar la relación dinámica entre la actividad económica real y los mercados de acciones. Usaron tres indicadores para explicar el PBI real per cápita: el ratio de valor transado sobre el PBI, la capitalización bursátil sobre el PBI y el ratio de rotación de acciones, con datos anuales de 1965 a 2011 (p. 1). Los autores obtuvieron que los indicadores bursátiles contribuyen en la predicción del crecimiento del PBI per cápita desde inicios de la década de los noventa, donde el rol del mercado de acciones se hizo más significativo (pp. 13-14). 
Más adelante, Lahura y Vargas (2016) realizaron un estudio también para Perú sobre la relación entre el sector bancario, el mercado de capitales y la actividad real para el periodo de 1992 a 2012, con datos mensuales. Emplearon una metodología de vectores autoregresivos con cointegración y realizaron pruebas de causalidad de Granger. Obtuvieron que el PBI per cápita y el volumen de negociación bursátil causan en el sentido de Granger al ratio de crédito sobre PBI, y que las variables están cointegradas (p. 66).

En este trabajo, a diferencia de los mencionados anteriormente, se estudian a los países del Mila, explicando las principales reformas que se dieron en el sistema financiero de la región, y la situación actual del mercado de capitales. Adicionalmente, se hace un análisis respecto a los costos de emisión de bonos en los países de estudio. Para el modelo se utilizaron datos de panel, empleando el método de Mínimos Cuadrados Completamente Modificados para evaluar la cointegración de las variables estudiadas. Este método se centra en medir la relación de las variables en el largo plazo, ya que en el corto plazo, la volatilidad puede sesgar los resultados. Adicionalmente se estiman funciones impulso-respuesta para analizar el comportamiento de las variables ante shocks de las mismas. El modelo explica el efecto de las variables que describen el desarrollo del mercado de capitales y el acceso al crédito sobre el crecimiento económico medido por el Producto Bruto Interno real per cápita. 


\section{CAPÍTULO II: SISTEMA FINANCIERO PERUANO}

\subsection{Historia del sistema financiero peruano}

Marchini (2004), en su publicación sobre el sistema financiero peruano, estudia cómo se ha ido desarrollando el sector financiero del país, resaltando los principales acontecimientos y reformas que se tomaron en el periodo de 1970 a 2004. Menciona que, en la década de los sesenta, el sistema financiero peruano era poco profundo y tenía escasa intervención del Estado. Se centraba alrededor de la banca comercial y de diversas instituciones públicas de banca de desarrollo, que atendían sectores económicos específicos (p. 43).

A partir de esos años, el sistema financiero tuvo una gran expansión, tanto por el crecimiento de sus activos como por el surgimiento de nuevas instituciones financieras. Además, la banca entró en un proceso de desnacionalización, con el cual la participación de capitales extranjeros en los activos bancarios pasó de 36\% en 1960 a $62 \%$ en 1968. En los años 70s, se fortaleció el rol del Estado en el sector financiero con el gobierno militar y se radicalizaron los controles cambiarios. A fines de la década, con el alza de la inflación, el gobierno tuvo que incrementar las tasas de interés máximas a 37.5\% en 1980, para luego subir hasta $92 \%$ a mediados de la década. Por otra parte, la hiperinflación de fines de los 80 s ocasionó la desmonetización de la economía y la reducción de la intermediación financiera agregada (Rojas, 1994, p. 152).

En esa misma década, Marchini menciona que el gobierno tuvo una alta participación en la asignación de recursos, mediante la banca de fomento y los bancos comerciales con participación pública. En 1990, se liquidó la banca estatal de fomento, que contaba con los bancos Hipotecario, Agrario, Industrial, Minero y De la Vivienda, los cuales eran una importante fuente del crédito a la pequeña empresa. A partir de esta liquidación, la Corporación Financiera de Desarrollo (Cofide) asumió las funciones de la banca de fomento y se convirtió en una institución de segundo piso, otorgando líneas de crédito a otras entidades del sistema financiero (p. 44). A ésta se agregó posteriormente un Banco Agropecuario (Agrobanco), el cual se centraba en dicho sector.

A partir de 1992, Cofide solo captaba fondos del extranjero, para luego colocarlos en el mercado doméstico a través de la banca múltiple. Rojas (1994) comenta que esto se 
dio hasta 1994, cuando la banca múltiple perdió interés en este tipo de líneas de crédito, por lo que se crearon Entidades de Desarrollo para la Pequeña y Micro Empresa. Estas entidades, al no estar autorizadas a recibir depósitos del público, eran financiadas a través de Cofide, instituciones de cooperación internacional, organismos multilaterales y entidades financieras (p. 178).

En la tabla 2.1 se mencionan las principales reformas financieras que se dieron en el país entre 1990 y 2004. Se puede observar que fue en 1990 cuando se empezaron a implementar reformas de liberalización del sistema financiero, reduciendo la influencia del Estado en el sector. Además, se facilitó a las empresas el acceso al financiamiento. 
Tabla 2.1

Perú: principales reformas financieras (1990-2004)

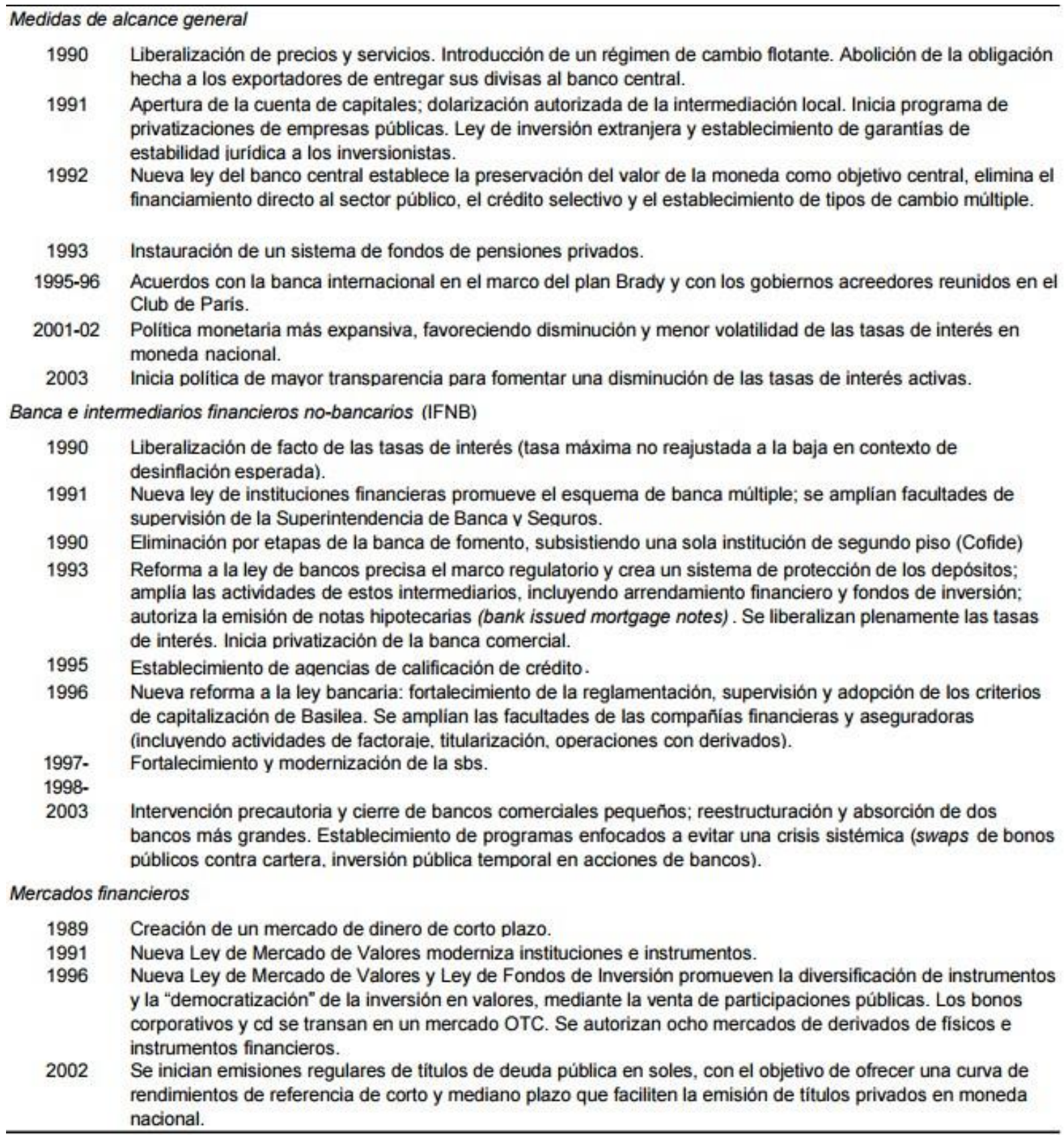

Fuente: Marchini, G (2004). El sistema financiero peruano: 1970-2004. México y la cuenca del pacífico. Recuperado de http://148.202.18.157/sitios/publicacionesite/pperiod/pacifico/Revista23/04Genevieve02.pdf

\subsection{Situación actual}

Según el Reporte de Estabilidad Financiera publicado por el BCRP (Banco Central de Reserva del Perú), el mercado de capitales peruano se caracteriza por tener poca liquidez y bajo grado de desarrollo de los inversionistas institucionales. Estos 
aspectos no han tenido mejoras significativas en los últimos años debido a que el mercado ha tenido un crecimiento lento y un bajo grado de profundización (p. 16).

De acuerdo con el reporte, solo 14 de las 100 acciones más líquidas se negocian más del 95\% de días. Esto refleja el bajo nivel de liquidez del mercado de capitales peruano. En el año 2007, el monto promedio de negociación diario de acciones alcanzaba los 108.8 millones de soles, para luego presentar una tendencia decreciente, llegando a 21.7 al 2015. Después se recuperó a 40.7 millones a setiembre del 2017, aunque aún falta más del doble de esa cifra para llegar a los niveles anteriores (p. 49).

Por el lado de los inversionistas institucionales, el portafolio administrado por los fondos de pensiones y compañías de seguros en Perú representa el 27.12\% del PBI, de acuerdo a los datos del Banco Mundial al 2015. En Colombia hay una proporción similar, representando el 27.17\% del PBI, mientras que en México es 20.18\%. Sin embargo, en Chile este número llega a $88.9 \%$. Esto quiere decir que, si bien Perú se encuentra en el promedio de los países del MILA, aún hay un amplio margen de crecimiento.

El grado de profundidad del mercado de capitales del país es bajo, sin embargo, ha tenido una mejora sostenida en los últimos años. Por ejemplo, la capitalización bursátil como porcentaje del PBI se ha incrementado en 14 puntos porcentuales de setiembre del 2016 a 2017, llegando a 75.9\%, acorde a datos del BCRP (p. 45).

En el indicador de deuda privada, el incremento ha sido moderado pero sostenido, pasando de $14.8 \%$ a $16.3 \%$ para la misma fecha. Según el Reporte, las emisiones de bonos en el mercado local de las empresas no financieras, llegaron a 2,495 millones de soles en el año 2017. De este monto, el $97.7 \%$ fue emitido en soles, debido a la preferencia de las empresas en endeudarse en moneda local (p. 46).

Según el informe de Equilibrium del Comportamiento de los Bonos Corporativos en el Mercado Peruano de abril de 2016, las empresas emisoras de bonos corporativos redujeron su exposición al riesgo cambiario, debido a la devaluación del sol respecto al dólar. De acuerdo con el reporte, la mayoría de las emisiones de años recientes ha sido en moneda nacional. Entre los años 2012 y 2015, la emisión en dólares en promedio representó menos del 7\% del total, mientras que del 2000 al 2011 este porcentaje era de $46 \%$ (p. 2). Según datos del Banco Mundial, las emisiones de estos instrumentos como porcentaje del PBI ha tenido una tendencia decreciente. Esta cifra representa el $0.18 \%$ del PBI en 2016, estando en su punto máximo de 2.14\% en 2013. 
Para el caso de los indicadores de deuda pública, se menciona que mejoraron por las operaciones de manejo de activos y pasivos del Ministerio de Economía y Finanzas (MEF). En julio de 2017, la entidad realizó una oferta internacional de bonos soberanos, para pagar créditos en dólares, euros y yenes. Esta estrategia tiene como objetivo desarrollar el mercado de deuda pública, además de mejorar el perfil de deuda, por tener un mayor porcentaje del portafolio en moneda nacional. También se está incrementando la duración de las obligaciones, lo que reduce el riesgo de refinanciamiento y genera ahorros por menores costos de financiamiento (p. 48).

En la siguiente tabla, se hace una comparación de los indicadores de profundidad para los países del MILA. Aquí resalta el mayor nivel de desarrollo relativo de México en los mercados de deuda, tanto pública como privada, mientras que Perú tiene el nivel de desarrollo más bajo. Por otra parte, se observa que Chile tiene el indicador de capitalización bursátil como porcentaje del PBI más alto, seguido por el Perú.

Tabla 2.2

Comparación de la profundidad del Mercado de Capitales en los países del MILA

\begin{tabular}{|c|c|c|c|c|}
\hline \multicolumn{5}{|c|}{$\begin{array}{c}\text { Cuadro } 3.2 \\
\text { COMPARACIÓN DE LA PROFUNDIDAD DEL MERCADO DE CAPITALES } \\
\text { EN LOS PAÍSES DE LA ALIANZA DEL PACÍFICO } \\
\text { (Diciembre de 2016) }\end{array}$} \\
\hline & México & Chile & Colombia & Perú \\
\hline Deuda Pública & & & & \\
\hline $\begin{array}{l}\text { Bonos Soberanos y Letras del Tesoro } \\
\text { (como \% de la deuda pública total) }\end{array}$ & $90,2 \%$ & $51,2 \%$ & $61,1 \%$ & $41,8 \%$ \\
\hline $\begin{array}{l}\text { Bonos Soberanos y Letras del Tesoro } \\
\text { (como \% del PBI) }\end{array}$ & $36,7 \%$ & $10,9 \%$ & $26,7 \%$ & $10,0 \%$ \\
\hline $\begin{array}{l}\text { Deuda Privada } \\
\text { Bonos Corporativos } \\
\text { (como \% de la deuda total de las empresas no financieras) * }\end{array}$ & $45,4 \%$ & $20,0 \%$ & $14,4 \%$ & $9.7 \%$ \\
\hline Capitalización Bursátil (\% del PBI) & $34,9 \%$ & $84,1 \%$ & $36,1 \%$ & $63,2 \%$ \\
\hline
\end{tabular}

Fuente: Banco Central de Reserva del Perú (2017). Reporte de Estabilidad Financiera. Recuperado de http://www.bcrp.gob.pe/publicaciones/reporte-de-estabilidad-financiera/ref-noviembre-2017.html

Por el lado del sistema bancario, se han logrado avances en el acceso a servicios financieros, sin embargo, los niveles de inclusión financiera aún son reducidos, según el Reporte de Indicadores de Inclusión Financiera de los Sistemas Financiero, de Seguros y de Pensiones de la SBS a junio de 2017. En el reporte se menciona que se incorporaron 
1,3 millones de deudores al sistema financiero de 2012 a 2017, llegando a 6.5 millones de personas naturales con crédito a junio de 2017 (p. 3). Con este incremento de deudores, el nivel de profundización financiera medido por los créditos del sistema financiero sobre el PBI, pasó de $32.33 \%$ a $39.7 \%$ en el mismo periodo (p. 7).

Debido a la mayor competencia entre las entidades financieras causada por el crecimiento del sector, las tasas activas de interés se han reducido, pasando de $19.24 \%$ en 2012 a 16.47\% en 2016, según datos del Banco Mundial (Indicadores de Desarrollo Mundial). Sin embargo, este nivel de tasas es alto comparado con los países del MILA. Por ejemplo, el promedio de las tasas activas en Chile al 2016 es de 5.41\%, y en México es de $6.92 \%$.

En el caso de las inversiones, en los últimos años se ha incrementado el porcentaje de financiamiento por medio de capital o venta de acciones. Según la base de datos del Desarrollo Financiero Mundial del Banco Mundial, al 2006 el 39.8\% de las inversiones en activo fijo en el país se financiaban por medio de préstamos bancarios, mientras que solo el $0.4 \%$ se financiaba por medio de venta de acciones o capital. En el año 2010, estas cifras pasaron a $34.7 \%$ y $5.4 \%$ respectivamente, lo que significa que el financiamiento por medio de capital está reemplazando parte del financiamiento por medio de bancos. Sin embargo, este último sigue siendo el predominante.

En términos generales, el capital en el mercado de acciones se acerca al capital destinado a créditos del sistema financiero. Según esta base de datos, al año 2015 la capitalización bursátil como porcentaje del PBI es de 33.6\%, mientras que el crédito al sector privado es el $37.4 \%$ del PBI.

Por otra parte, los instrumentos de deuda vigentes como porcentaje del PBI se han incrementado en los últimos años, pasando de $12.88 \%$ del PBI en 2000 a $16.89 \%$ en 2015. Este crecimiento ha sido impulsado por el incremento de la colocación de instrumentos en el mercado internacional. En este mercado, pasó de ser $0.37 \%$ del PBI en 2000, a $11.66 \%$ en 2015. Sin embargo, en el mercado local, este indicador se ha reducido, pasando de $12.51 \%$ del PBI en el año 2000 a 5.23\% en el año 2015, según los datos del Banco Mundial. Esto refleja la preferencia de las empresas a emitir instrumentos de deuda en el exterior, donde hay mayor demanda. El mercado nacional necesita desarrollarse para poder incrementar la demanda local de los instrumentos, y que sea rentable para las empresas emitir deuda en el país. 


\subsection{Principales leyes que regulan el mercado de capitales}

A lo largo de los años, las leyes que regulan el mercado de capitales en el Perú se han ido modificando para mejorar la regulación del mercado de capitales y promover su desarrollo. Entre los principales reglamentos y leyes que se aplican en el país se encuentran los siguientes:

- Ley Orgánica de la SMV: Describe y explica las funciones de la Superintendencia del Mercado de Valores.

- Ley del Mercado de Valores: Explica los requerimientos para la oferta de valores y para la protección del inversionista. Promueve el desarrollo adecuado y la transparencia del mercado de valores.

- Ley de Fondos de Inversión y sus Sociedades Administradoras: Describe las características de los Fondos de Inversión y establece los requerimientos que estos y las Sociedades Administradoras deben cumplir.

- Ley que fomenta la liquidez e integración del Mercado de Valores: Detalla la retención del impuesto a la renta de ganancias provenientes de la transacción de valores representativos de acciones, además de explicar las exoneraciones del impuesto a la renta.

- Ley que promueve el desarrollo del Mercado de Capitales: Su objetivo es fortalecer la infraestructura del mercado de capitales, principalmente la que está relacionada con la industria de fondos mutuos de inversión en valores, fondos de inversión, la de agentes de intermediación y las plataformas de negociación de facturas y otros instrumentos de emisión no masiva. Esta ley plantea modificaciones a la Ley de Mercado de Valores y a la Ley de Fondos de Inversión y sus Sociedades Administradoras.

- Reglamento de Bonos Soberanos: Explica cómo se emiten los bonos de la República del Perú y describe sus características, como el precio, rendimiento, moneda y plazo. También explica el procedimiento para la compra y reventa de estos bonos.

- Reglamento del Programa de Creadores de Mercado: Este programa busca promover el buen funcionamiento del mercado de valores para lograr una mayor liquidez y obtener una mayor base de inversionistas. En el reglamento se detalla 
los requisitos para ser parte del programa, así como los beneficios y las obligaciones de sus integrantes.

Si bien el mercado de capitales peruano tiene un bajo grado de desarrollo, principalmente debido a su poca liquidez, se están haciendo esfuerzos para mejorar los indicadores. En los últimos años se han implementado leyes que promueven el desarrollo de este mercado y que buscan mejorar su funcionamiento. Además, el MEF ha realizado operaciones que contribuyen al desarrollo del mercado de deuda pública. En el caso de la deuda privada, debido al bajo nivel de demanda nacional y a los altos costos, las empresas prefieren emitir deuda en el exterior, lo que dificulta el desarrollo del mercado nacional. A pesar de esto, hay una tendencia creciente de utilizar instrumentos de deuda, como bonos y papeles comerciales, para el financiamiento en las empresas. 


\section{CAPÍTULO III: MEDIDAS Y REFORMAS EN AMÉRICA LATINA}

\subsection{Reformas liberales en América Latina}

En 1989 surge el consenso de Washington, un conjunto de recomendaciones de política económica. Está orientado principalmente a los países de América Latina, por lo que propone medidas de política económica para orientar a los gobiernos de países en desarrollo. "El Consenso se elaboró para encontrar soluciones útiles sobre la forma de afrontar en la región la crisis de la deuda externa y establecer un ambiente de transparencia y estabilidad económica" (Casilda, 2004, p. 19).

De acuerdo con el consenso, América Latina requería de un modelo económico abierto y estable. Según Soto y Martínez (2012), la apertura económica tenía como objetivo impulsar el crecimiento económico de la región. Esto se logra por medio de medidas que faciliten el comercio internacional entre los países en vías de desarrollo y los países desarrollados. Por otro lado, estos países tendrían estabilidad económica por medio de la disciplina macroeconómica, que consiste en el control de las finanzas públicas del Estado. Con esto, según los autores, se generan efectos económicos, políticos y sociales positivos (p. 43).

Este consenso se centra en diez puntos:

1. Disciplina presupuestaria de los gobiernos

2. Cambios en las prioridades del gasto público (reorientación hacia gasto en educación y salud)

3. La reforma fiscal o tributaria

4. Tasas de interés libres de acuerdo al mercado

5. El tipo de cambio de acuerdo al mercado

6. Liberalización comercial

7. Política de apertura respecto a la inversión extranjera directa

8. Política de privatizaciones

9. Política desreguladora de los mercados

10. Derechos de propiedad 
La disciplina presupuestaria, según Casilda, tiene una gran importancia en la negociación de préstamos con el Fondo Monetario Internacional. Además, tuvo importancia en Washington, donde se aprobó la Ley Gramm-Rudman-Hollings en 1993, con el objetivo de establecer presupuestos equilibrados para el gasto público. Esto fue necesario debido a que los déficits fiscales grandes y persistentes en los países de América Latina, constituían una fuente básica de trastornos macroeconómicos en forma de inflación, desequilibrios en la balanza de pagos y evasión de capitales (p. 20).

Para la reforma fiscal, se llegó al acuerdo de tratar de instaurar una base imponible íntegra y amplia, manteniendo a la vez tasas impositivas marginales moderadas. En el caso de los tipos de interés, debían seguir dos principios fundamentales: ser determinados por el mercado, para evitar una asignación inadecuada de los recursos, y ser positivos en términos reales, para desincentivar las evasiones de capitales e incrementar el ahorro. De igual manera, el tipo de cambio debía ser determinado por el mercado (p. 21).

Fue por eso que, en Perú, a inicios de los 90s se eliminaron los controles sobre el tipo de cambio y la tasa de interés, permitiendo los depósitos y créditos en dólares. Según Rojas, la eliminación de estos controles favoreció la libre movilidad de capitales, lo cual incentivó la inversión extranjera (p. 153).

Soto menciona que es imprescindible que las economías de Latinoamérica se internacionalicen, abriendo sus fronteras al capital extranjero e impulsando la exportación de productos domésticos (p. 49). De esta manera, se logrará capitalizar estas economías de una manera más rápida y eficiente. Además, al abrir sus fronteras se da paso a la implementación de nuevas tecnologías para la industria nacional. Esto no solo contribuye a mejorar la rentabilidad de las empresas, sino que también incrementa su productividad.

Sin embargo, las reformas del Consenso de Washington expusieron a los países a un mayor riesgo. Stiglitz (2003) comenta que la imposición del programa de liberalización se hizo sin pensar en los riesgos que se incurrirían. Da como ejemplo el caso de Chile, donde se llegó a desregularizar el sector financiero. Además, menciona que las economías pequeñas y abiertas al comercio exterior son las más afectadas, ya que los choques externos las afectan en mayor escala (p. 21).

Por otra parte, menciona que las reformas de liberalización de los mercados de capitales tuvieron efectos adversos. Aunque estas reformas generarían un flujo constante de capital de los países más desarrollados a los países en desarrollo, no se tomó en cuenta 
el efecto sobre la volatilidad generado por los capitales de corto plazo, ya que en general son procíclicos (p. 22).

En la conferencia sobre el desarrollo de los mercados de capital en América Latina (2001) realizada por el Fondo Monetario Internacional, Aninat mencionó el caso de la implementación de medidas para el desarrollo de los mercados de capitales en los países de la región: "Brasil ha actuado para limitar el endeudamiento de los niveles locales de gobierno, problema que en el pasado ha generado pasivos contingentes para el gobierno central. México ha continuado desarrollando sus mercados financieros internos, recurriendo así en mayor grado al financiamiento a más largo plazo facilitado por residentes mexicanos". Mencionó también la importancia de aplicar medidas para incrementar la transparencia en los países de América Latina, para facilitar el acceso a información confiable. Esto atraería a una mayor cantidad de inversionistas.

Al final de la conferencia, Aninat explica que "con la implementación sostenida de medidas correctoras en el terreno macroeconómico y estructural y la provisión de financiamiento oficial, los países disponen de buenas probabilidades para recuperar con relativa rapidez el acceso a los mercados internacionales de capital”.

Sin embargo, estas medidas se tienen que implementar con cuidado, ya que pueden generar vulnerabilidad en los países de la región ante shocks externos. Stiglitz, en la revista de la Comisión Económica para América Latina y el Caribe (2003), realizó un estudio sobre las reformas implementadas en América Latina, entre las cuales estaba la liberalización del mercado de capitales. En el artículo afirma que las reformas "aumentaron la exposición de los países al riesgo, sin acrecentar su capacidad de hacer frente a ese riesgo". Con esto se puede ver que, tan importante como las medidas para la dinamización de los mercados de capitales, son las medidas para el control de riesgos.

Para lograr la participación en mercado de capitales internacional, se requiere que los que solicitan fondos trabajen con transparencia y den seguridad a los inversionistas. Según El-Erian, es importante que los prestatarios tengan tanto hojas de balance como perspectivas financieras sólidas, y necesidades de financiación para inversiones de alto rendimiento. Para reducir la exposición a choques externos, menciona que es importante considerar el uso de herramientas de gestión de riesgo financiero (p. 9).

Una medida aplicada en los países de América Latina para combatir la corrupción consiste en promover las sociedades anónimas abiertas que participan en el principio de 
la transparencia, al estar obligadas a publicar trimestralmente sus estados financieros (Arrarte, R., p. 139). De esta manera se facilita el acceso a la información para los inversionistas, lo cual fomenta la entrada de capitales para el financiamiento de empresas.

Sin embargo, las políticas que dan resultado en algunos países pueden resultar ser ineficientes en otros. Esto se debe principalmente a una diferencia en las condiciones iniciales en base a las que se aplica la política. Según Raju y Fitzpatrick (2010), una baja proporción de ahorro e inversión con respecto al PBI, puede resultar en un crecimiento económico débil.

Los autores concluyen en su estudio que Perú no tiene limitaciones en ahorro e inversión, debido a que el spread entre la tasa de interés doméstica y externa es relativamente bajo. Sin embargo, existe un déficit en la infraestructura del país, el cual genera altos costos de transporte, disminuyendo su competitividad (p. 51).

\subsection{Mercado Integrado Latinoamericano}

El MILA está conformado por las bolsas de valores de los mercados de Chile, Colombia, México y Perú. También hay un enlace entre las centrales de depósito de valores de estos países, para facilitar la compensación y liquidación de las operaciones realizadas en el mercado. En el año 2009, se inició el proceso de creación de un mercado regional para la negociación de títulos de renta variable de Chile, Colombia y Perú. En 2011, el MILA entró en operación, brindando más oportunidades de inversión y facilidades a los inversionistas y empresarios. En 2014, México se incorporó en este mercado, dándole un mayor impulso al ampliar la oferta de valores y las fuentes de financiamiento (http://www.mercadomila.com).

Las bolsas de valores de los cuatro países se integran mediante el uso de herramientas tecnológicas en el enrutamiento intermediado, que consiste en la canalización de propuestas entre los intermediarios locales y los extranjeros, permitiendo trasladar las propuestas de un sistema de negociación a otro. También fue necesario adecuar la regulación sobre la negociación en los mercados de capitales y sobre la custodia de títulos en los países de este mercado (Reglamento del Mercado Integrado Latinoamericano, 2014).

La integración bursátil de estos países trae beneficios al brindar más alternativas de inversión y financiamiento, ya que se pueden negociar los valores de cualquier país 
desde un intermediario local. Esto facilita la diversificación del riesgo del portafolio de los inversionistas y reduce el costo de financiamiento para los empresarios al ampliarse la demanda de valores. Además, facilita la compensación y liquidación de operaciones y reduce los costos de transacción porque evita la duplicidad de procesos en cada país. Por otra parte, al integrar los mercados de los países integrantes, se logra un incremento de la liquidez al tener un mayor flujo de capitales (http://www.mercadomila.com).

El objetivo del Mercado Integrado Latinoamericano es atraer inversión hacia la región, ofreciendo a emisores, intermediarios e inversionistas atractivas oportunidades de acceso al mercado. Dadas las complementariedades de los países de la región, se busca el crecimiento en conjunto del mercado integrado, sin que cada uno de estos pierda su independencia ni autonomía regulatoria. Actualmente, el MILA busca mejorar y ampliar la oferta de valores que pueden ofrecer los intermediarios, para aprovechar las ventajas específicas de los mercados de cada país. Para esto se requiere incluir nuevos tipos de instrumentos que cumplan con las necesidades de los inversionistas, empresarios e intermediarios (Informe Especial MILA, BVC, s. f.).

El MILA representa una integración financiera que genera apertura respecto a la inversión extranjera, con lo que se puede incrementar la liquidez del mercado gracias a un mayor flujo de capitales. Sin embargo, esta apertura debe ser regulada, para evitar los capitales de corto plazo que generan volatilidad en la economía. Además, la integración de los mercados de estos países amplía la demanda de valores, lo que reduce el costo de financiamiento para las empresas. Esto contribuye a un mayor crecimiento económico, al incentivar la inversión. 


\section{CAPÍTULO IV: COSTOS DE EMISIÓN DE DEUDA EN LOS PAÍSES DEL MILA}

\subsection{Costos en Perú}

En el Perú, la emisión de deuda en el mercado de capitales no es una alternativa de financiamiento muy utilizada debido a los costos que implica realizar una emisión. Según el Reporte de Estabilidad Financiera de mayo del año 2011 del BCRP, las empresas que buscan emitir instrumentos de deuda por primera vez, se ven desmotivadas a ingresar al mercado de capitales. Esto es debido a varios factores, como la complejidad y multiplicidad de los procesos que se deben hacer para efectuar una emisión. Esto se traduce en un sobrecosto de horas-hombre, requeridas únicamente a realizar los procesos administrativos, además del costo de asesores legales (p. 48).

En el reporte se mencionan los costos de emisión de bonos corporativos. Los más importantes son los gastos de estructuración, los gastos legales, la comisión del agente colocador y el costo de contratar a dos clasificadoras de riesgo para que clasifiquen el bono. Adicionalmente está el gasto de mantenimiento por el tiempo que la deuda siga vigente. Este se compone principalmente de la auditoría externa anual, el costo del Representante Bursátil y las contribuciones mensuales a la Conasev, Bolsa de Valores de Lima y Cavali (p. 50).

En el siguiente recuadro, tabla 4.1, se detallan los costos de emisión y mantenimiento de bonos corporativos en el Perú. Se observa que estos disminuyen a medida que el monto emitido es mayor, ya que gran parte de los costos son fijos. Entre los gastos de emisión, los únicos que son variables son la inscripción en la BVL y la comisión de colocación. Los costos fijos suman en total 127,747 soles. Esto hace que solo sea rentable emitir deuda por montos altos. En el recuadro se realiza una comparación de los costos en los que se incurre al emitir bonos, en cuatro escalas de montos. Se observa que el costo de una emisión de 50 millones es de solo $0.44 \%$ del monto, mientras que, en el caso de una emisión de 5 millones, el costo es de $2.74 \%$, más de seis veces que el anterior. 
Tabla 4.1

Costo de emisión de bonos corporativos en el Mercado de Capitales peruano.

COSTO DE EMISIÓN DE BONOS CORPORATIVOS EN EL MERCADO PERUANO DE CAPITALES (EN US\$)

\begin{tabular}{|c|c|c|c|c|c|}
\hline Supuestos & Monto emisión & $\begin{array}{l}\text { Escala } 1 \\
5000000\end{array}$ & $\begin{array}{r}\text { Escala } 2 \\
10000000\end{array}$ & $\begin{array}{c}\text { Escala } 3 \\
20000000\end{array}$ & $\begin{array}{c}\text { Escala } 4 \\
50000000\end{array}$ \\
\hline $\begin{array}{l}\text { Gastos de } \\
\text { preparación } \\
\text { de la } \\
\text { emisión }\end{array}$ & $\begin{array}{l}\text { Estructuración } \\
\text { Gastos legales } \\
\text { Auditoría externa } \\
\text { Contratación de un representante de obligacionistas } \\
\text { Contratación de } 2 \text { clasificadoras de riesgo } \\
\text { Otros gastos } 1 /\end{array}$ & $\begin{array}{r}50000 \\
25000 \\
20000 \\
5000 \\
20000 \\
3100\end{array}$ & $\begin{array}{r}50000 \\
25000 \\
20000 \\
5000 \\
20000 \\
3100\end{array}$ & $\begin{array}{r}50000 \\
25000 \\
20000 \\
5000 \\
20000 \\
3100\end{array}$ & $\begin{array}{r}50000 \\
25000 \\
20000 \\
5000 \\
20000 \\
3100\end{array}$ \\
\hline $\begin{array}{l}\text { Gastos para } \\
\text { efectuar } \\
\text { la Oferta } \\
\text { Pública } \\
\text { Primaria }\end{array}$ & $\begin{array}{l}\text { Inscripción Conasev } \\
\text { Publicación Resolución en El Peruano } \\
\text { Inscripción BVL: } 0,0375 \% \\
\text { Inscripción Cavali } \\
\text { Gastos de publicación, registrales y de impresión } 2 \text { / } \\
\text { Comisión de colocación: } 0,15 \%\end{array}$ & $\begin{array}{r}1286 \\
246 \\
1875 \\
100 \\
3015 \\
7500 \\
\end{array}$ & $\begin{array}{r}1286 \\
246 \\
3750 \\
100 \\
3015 \\
15000 \\
\end{array}$ & $\begin{array}{r}1286 \\
246 \\
7500 \\
100 \\
3015 \\
30000\end{array}$ & $\begin{array}{r}1286 \\
246 \\
18750 \\
100 \\
3015 \\
75000 \\
\end{array}$ \\
\hline $\begin{array}{l}\text { Gasto anual de } \\
\text { mantenimiento } \\
\text { de la emisión }\end{array}$ & $\begin{array}{l}\text { Conasev: } 0,0035 \% \text { mensual } \\
\text { BVL: } 0,002 \% \text { mensual } \\
\text { Cavali: } 0,001 \% \text { mensual (Min US\$ 100; Máx US\$ 300) } \\
\text { Clasificadoras } \\
\text { Representante de Obligacionistas: } 0,035 \% \text { anual } \\
\text { Auditoria externa } \\
\text { Representante bursátil 3/ }\end{array}$ & $\begin{array}{r}2100 \\
1200 \\
1200 \\
36000 \\
1750 \\
20000 \\
15000\end{array}$ & $\begin{array}{r}4200 \\
2400 \\
1200 \\
36000 \\
3500 \\
20000 \\
15000\end{array}$ & $\begin{array}{r}8400 \\
4800 \\
2400 \\
36000 \\
7000 \\
20000 \\
15000\end{array}$ & $\begin{array}{r}21000 \\
12000 \\
3600 \\
36000 \\
17500 \\
20000 \\
15000\end{array}$ \\
\hline Costos totales & $\begin{array}{l}\text { Costo total de efectuar la emisión } \\
\text { (En \% de la emisión) } \\
\text { Gasto anual de mantemiento de la emisión } \\
\text { (En \% de la emisión) }\end{array}$ & $\begin{array}{r}137122 \\
2,74 \% \\
77250 \\
1,55 \%\end{array}$ & $\begin{array}{r}146497 \\
1,46 \% \\
82300 \\
0,82 \%\end{array}$ & $\begin{array}{r}165247 \\
0,83 \% \\
93600 \\
0,47 \%\end{array}$ & $\begin{array}{r}221497 \\
0,44 \% \\
125100 \\
0,25 \%\end{array}$ \\
\hline
\end{tabular}

1/ Gastos registrales, costo del certificado para el sistema MvNet, gastos de impresión del Prospecto Marco y de preparación de información. 2/ Gastos de publicación de la OPP en EI Peruano y en uno de los diarios de mayor circulación, gasto de registro del Contrato de Emisión Complementario y de impresión del Prospecto Marco Complementario.

3/ Costo del personal asignado para el cumplimiento de los requerimientos de información.

Fuente: Conasev, Bolsa de Valores de Lima, Cavali, etc.

Fuente: Banco Central de Reserva del Perú (2011). Reporte de Estabilidad Financiera. Recuperado de http://www.bcrp.gob.pe/docs/Publicaciones/Reporte-Estabilidad-Financiera/Reporte-de-EstabilidadFinanciera-Mayo-2011.pdf

\subsection{Costos en Chile}

Para poder ofrecer públicamente bonos en Chile, estos deben ser inscritos en el registro de emisión de títulos de deuda de largo plazo. El costo de este trámite, según datos de la Superintendencia de Valores y Seguros de Chile (SVS), es de 20 Unidades de Fomento (UF), más 0.5 por mil de capital, este último tiene un costo límite de 200 UF. En total, el costo máximo es de 220 UF. Una Unidad de Fomento equivale a 44.25 dólares, por lo que el pago inicial sería de 885 dólares, y el costo máximo sería de 9,735 dólares.

Por ejemplo, si se quiere emitir un bono por 5 millones de dólares, el costo sería el siguiente:

- Costo fijo: $20(\mathrm{UF})=20$ x $44.25=885$ dólares

- Costo variable: 0.5 x 5,000,000/1,000 =2,500 dólares 
Esto significaría un costo total de 3,385 dólares, lo que equivale al $0.068 \%$ del nominal del bono.

Si la emisión fuera de 20 millones de dólares, el costo sería:

- Costo fijo: $20(\mathrm{UF})=20$ x $44.25=885$ dólares

- Costo variable: 0.5 x 20,000,000/1,000 = 10,000 dólares. En este caso, se supera el límite máximo de 200 UF, por lo que el costo sería solo 8,850 dólares.

En total sería 9,735 dólares. Esto sería equivalente al 0.049\% del nominal.

\subsection{Costos en Colombia}

En caso de Colombia, según datos de la Bolsa de Valores de Colombia, la inscripción en la Bolsa de Valores de Colombia (BVC) tiene un costo del $0.059 \%$ del monto de emisión. Para la inscripción el Registro Nacional de Valores y Emisores (RNVE), el costo es de $0.008 \%$ del patrimonio del emisor. Además, se debe hacer un pago por derechos para realizar la oferta pública, lo que tiene un costo del $0.035 \%$ del monto de emisión. Estos dos últimos costos tienen una tarifa mínima de 6 salarios mínimos y una tarifa máxima de 300 salarios mínimos cada uno. Un salario mínimo equivale a 269 dólares, por lo que la tarifa mínima es 1,614 y la máxima es 80,700 dólares.

Para el caso de una empresa con patrimonio de 20 millones de dólares, el costo de emitir un bono por 5 millones de dólares sería el siguiente:

- Inscripción BVC: 0.059\% x 5,000,000 = 2,950 dólares.

- Inscripción RNVE: 0.008\% x 20,000,000 = 1,600 dólares. Como este monto está por debajo de la tarifa mínima, el pago sería de 1,614 dólares.

- Derechos para realizar la oferta pública: $0.035 \%$ x 5,000,000 = 1,750 dólares.

En total, el pago sería de 6,314 dólares, equivalente al 0.126\% del nominal.

Si fuera una empresa con patrimonio de 50 millones de dólares, y un bono por 20 millones de dólares, el costo sería el siguiente:

- Inscripción BVC: 0.059\% x 20,000,000 = 11,800 dólares.

- Inscripción RNVE: $0.008 \%$ x 50,000,000 = 4,000 dólares.

- Derechos para realizar la oferta pública: $0.035 \%$ x 20,000,000 =7,000 dólares.

Esto sumaría 22,800 dólares, equivalente al $0.114 \%$ del nominal. 
Adicionalmente, se debe pagar una cuota anual para el Registro Nacional de Valores y Emisores, que tiene un costo de $0.01 \%$ del patrimonio del emisor.

\subsection{Costos en México}

En México, según la Bolsa de Valores de México (BVM), para la solicitud de listado de valores se paga 200 Unidades de Inversión por estudio y trámite inicial. Una UDI equivale a aproximadamente 0.3258 dólares, por lo que este pago inicial sería de 1,042.51 dólares.

Para el listado de valores, el costo depende del rango en el que se encuentre el monto de emisión. Si es menor a 5 millones de pesos, no hay costo fijo, pero se paga 0.18\% sobre el monto emitido. Si está entre 5 y 10 millones, se pagan 2,050 UDIs, que equivale a 12,395 pesos (667.9 dólares), además del 0.15\% sobre el límite. Es decir, si la emisión es de 8 millones, se paga el $0.15 \%$ de 3 millones. A continuación, en la tabla 4.2 se presentan los pagos que se deben hacer, por rango de monto de emisión. A la derecha están los montos referenciales en dólares, considerando un tipo de cambio de 18.56 pesos por dólar.

Tabla 4.2

Costo para el listado de valores de deuda en México

\begin{tabular}{|rrrr|rrr|}
\hline \multicolumn{2}{|c}{ pesos } & $\begin{array}{c}\text { UDI } \\
\text { fijo }\end{array}$ & $\begin{array}{c}\text { \% sobre } \\
\text { límite }\end{array}$ & USD & \multicolumn{2}{c|}{$\begin{array}{c}\text { Costo } \\
\text { fijo USD }\end{array}$} \\
\hline- & $5,000,000$ & - & $0.18 \%$ & - & 269,397 & - \\
$5,000,000$ & $10,000,000$ & 2,050 & $0.15 \%$ & 269,397 & 538,793 & 667.9 \\
$10,000,000$ & $40,000,000$ & 3,750 & $0.12 \%$ & 538,793 & $2,155,172$ & $1,221.7$ \\
$40,000,000$ & a más & 12,000 & $0.09 \%$ & $2,155,172$ & a más & $3,909.4$ \\
\hline
\end{tabular}

Fuente: Bolsa Mexicana de Valores (s. f.). Recuperado de https://www.bmv.com.mx/es/listados-yprospectos/aranceles-y-calculos-de-cuotas Elaboración propia

El pago mínimo por este concepto es de 2,781 pesos (150 dólares) y el pago máximo es de 695,354 pesos (37,465 dólares).

Por ejemplo, para una emisión de 5 millones de dólares, el pago por el listado de valores sería el siguiente:

- Costo fijo: 1,042.51 + 3,909.4 = 4,952 dólares.

- Costo variable: de $0.09 \%$ x $(5,000,000-2,155,172)=2,560$ dólares.

Estos dos costos suman 7,512, lo que equivale al $0.150 \%$ del nominal. 
En el caso de una emisión de 20 millones de dólares, el pago sería:

- Costo fijo: 1,042.51 + 3,909.4 = 4,952 dólares. Sería el mismo que en el caso anterior, ya que el monto está en el mismo rango.

- Costo variable: $0.09 \% \times(20,000,000-2,155,172)=16,060$.

En total, el costo sería de 21,012 dólares, equivalente a $0.105 \%$ del nominal.

Adicionalmente, se realiza un pago anual por mantenimiento, en base al monto en circulación. Al igual que con el pago para el listado de valores, en base al rango en el que esté el monto de circulación, se paga un monto fijo y un porcentaje sobre la diferencia del monto con el límite inferior del rango, como se puede ver en la siguiente tabla.

Tabla 4.3

Costos de mantenimiento de valores de deuda en México

\begin{tabular}{|rrrr|rrr|}
\hline \multicolumn{2}{|c}{ pesos } & $\begin{array}{c}\text { UDI } \\
\text { fijo }\end{array}$ & $\begin{array}{c}\text { \% sobre } \\
\text { límite }\end{array}$ & USD & \multicolumn{2}{r|}{$\begin{array}{r}\text { Costo } \\
\text { fijo USD }\end{array}$} \\
\hline- & $5,000,000$ & - & $0.14 \%$ & - & 269,397 & - \\
$5,000,000$ & $10,000,000$ & 1,700 & $0.11 \%$ & 269,397 & 538,793 & 554 \\
$10,000,000$ & $40,000,000$ & 3,100 & $0.09 \%$ & 538,793 & $2,155,172$ & 1,010 \\
$40,000,000$ & a más & 9,200 & $0.58 \%$ & $2,155,172$ & a más & 2,997 \\
\hline
\end{tabular}

Fuente: Bolsa Mexicana de Valores. Recuperado de https://www.bmv.com.mx/es/listados-yprospectos/aranceles-y-calculos-de-cuotas

Elaboración propia

Como en el caso anterior, el pago mínimo por mantenimiento es de 2,781 pesos (150 dólares), y el pago máximo es de 695,354 pesos (37,465 dólares).

\subsection{Comparación de costos}

Considerando solo los gastos de emisión y, en el caso de Perú, solo los gastos para efectuar la Oferta Pública Primaria, se obtiene el siguiente cuadro resumen en la tabla 4.4. Se observa que, en los cuatro países, los costos disminuyen cuando el monto de emisión es mayor. El país con menor costo, tanto variable como fijo, es Chile. Luego sigue Colombia para el costo fijo y México para el costo variable. 
Tabla 4.4

Costos de emisión de valores de deuda privada en los países del MILA (en US\$)

\begin{tabular}{|c|rcrr|}
\hline Monto de emisión & \multicolumn{1}{|c}{ Chile } & Colombia & Mexico & \multicolumn{1}{c|}{ Perú } \\
\hline $\mathbf{5 , 0 0 0 , 0 0 0}$ & $\mathbf{0 . 0 6 8 \%}$ & $\mathbf{0 . 1 2 6 \%}$ & $\mathbf{0 . 1 5 0 \%}$ & $\mathbf{0 . 2 8 0 \%}$ \\
costo fijo & 885 & $1,614^{*}$ & 4,952 & 4,647 \\
costo variable & 2,500 & 4,700 & 2,560 & 9,375 \\
Total & 3,385 & 6,314 & 7,512 & 14,022 \\
\hline $\mathbf{2 0 , 0 0 0 , 0 0 0}$ & $\mathbf{0 . 0 4 9 \%}$ & $\mathbf{0 . 1 1 4 \%}$ & $\mathbf{0 . 1 0 5 \%}$ & $\mathbf{0 . 2 1 1 \%}$ \\
costo fijo & 885 & $4,000 *$ & 4,952 & $4,647.0$ \\
costo variable & 8,850 & 18,800 & 16,060 & 37,500 \\
Total & 9,735 & 22,800 & 21,012 & 42,147 \\
\hline
\end{tabular}

Nota: En el caso de Colombia, el costo fijo es sobre el patrimonio de la empresa.

Elaboración propia

Por otra parte, se observa que Perú es el país con el costo de emisión más alto entre los países del MILA. Esto es principalmente por la comisión de colocación, que es el $0.15 \%$ del monto de emisión, seguido de los gastos de publicación, registrales y de impresión, que es un costo fijo de 3,015 dólares. Esto concuerda con que Perú es el país con menor porcentaje de bonos corporativos respecto a la deuda total de las empresas, como se vio anteriormente en el capítulo 2. 


\section{CAPÍTULO V: EVALUACIÓN EMPÍRICA}

Para el desarrollo del modelo se analizaron los países del Mercado Integrado Latinoamericano: Chile, Colombia, México y Perú, con un periodo de análisis del año 1994 al año 2016. Se utilizan los datos de panel, el cual combina series temporales y sección transversal, para poder tener un mayor número de observaciones. De esta manera se mejora la eficiencia de las estimaciones (Mayorga y Muñoz; 2000, p. 5). El panel trabajado es de tipo macropanel, es decir que hay más observaciones como serie de tiempo que como corte transversal, ya que se trabaja con 23 años y 4 países.

Se quiere medir la relación de largo plazo de las variables, ya que, como se mencionó en el marco teórico, el mercado de capitales contribuye al crecimiento económico de largo plazo. Para esto se emplea un modelo de cointegración, usando Mínimos Cuadrados Ordinarios Completamente Modificados (FMOLS por sus siglas en inglés). Este método incrementa la robustez de las pruebas de hipótesis, ya que considera correcciones para los problemas de autocorrelación de los errores y posible endogeneidad de los regresores, que resultan de la relación de cointegración (Phillips, 1995, p. 1023).

Adicionalmente, se analizó cómo responde cada variable ante shocks individuales de las otras variables del modelo, con lo que se puede ver su reacción tanto en el corto como en el largo plazo. Esto se logra obteniendo las funciones impulso-respuesta, que se obtienen luego de estimar el Modelo de Corrección de Errores (VECM). Este es un modelo que permite estudiar la dinámica entre la variable endógena y las variables exógenas al calcular un término de corrección del error, el cual regresa a la variable endógena al equilibrio ante desviaciones en el corto plazo (Wooldrige; 2016, p. 643)

La data utilizada fue obtenida del Banco de Datos del Banco Mundial, en las bases de datos de Indicadores de Desarrollo Mundial y Desarrollo Financiero Mundial. Las variables se presentan a continuación:

- PBI per cápita, en dólares constantes del 2010 (PBIPC)

- Crédito interno al sector privado, como porcentaje del PBI (CRED)

- Spread de tasas de interés, en porcentaje (SPREAD)

- Capitalización del Mercado de acciones, como porcentaje del PBI (CAP)

- Valor total de acciones tranzadas, como porcentaje del PBI (SMVT) 
A continuación, se presentan los gráficos de las variables empleadas en el modelo.

Figura 5.1

Gráficos de las variables para Chile (1) y Colombia (2): PBI per cápita, Crédito Interno, Spread de Tasas de Interés, Capitalización de Mercado y Valor Total de Acciones

Tranzadas.

1 - PBIPC

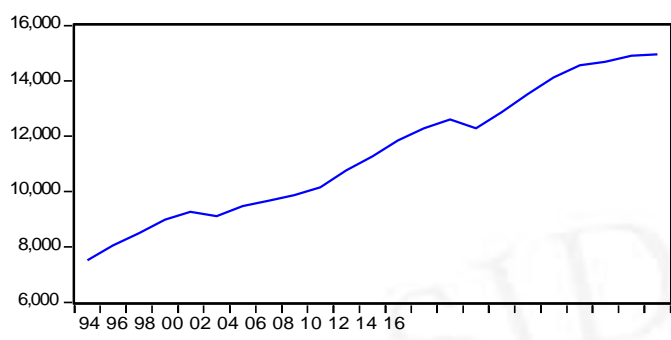

1 - CRED

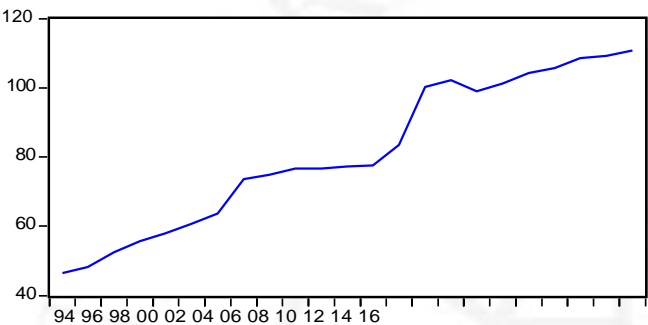

1 - SPREAD

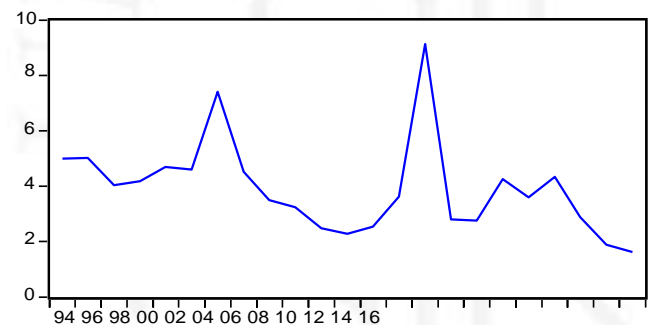

1 - CAP

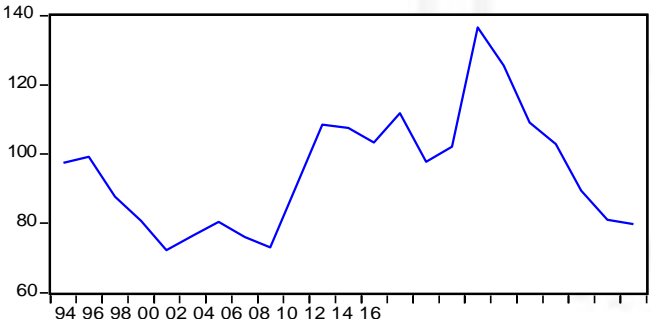

1 - SMVT

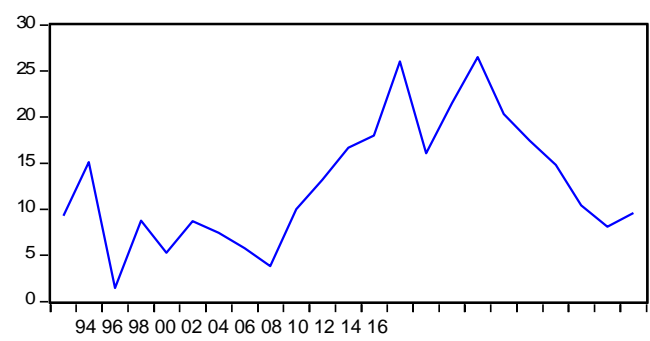

2 - PBIPC

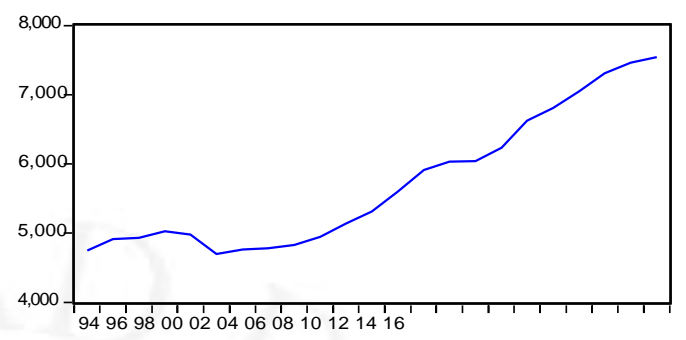

2 - CRED
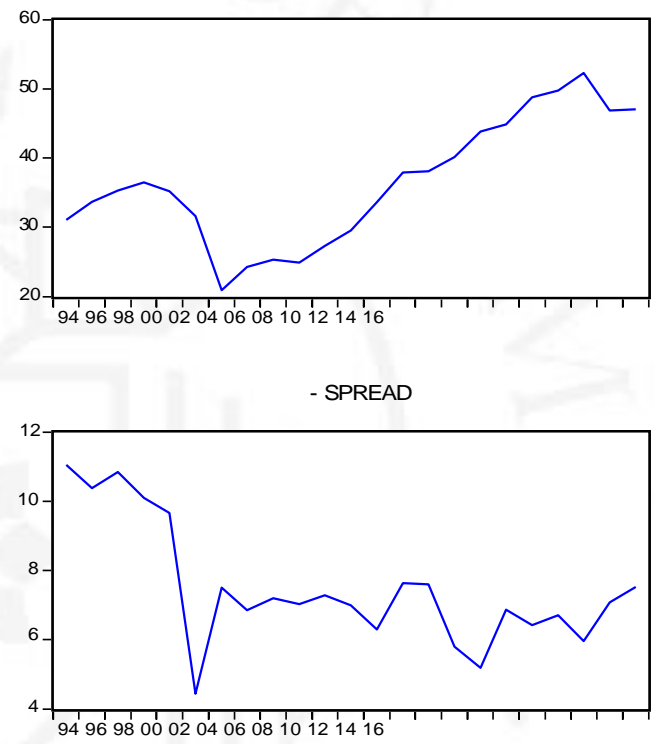

2 - CAP

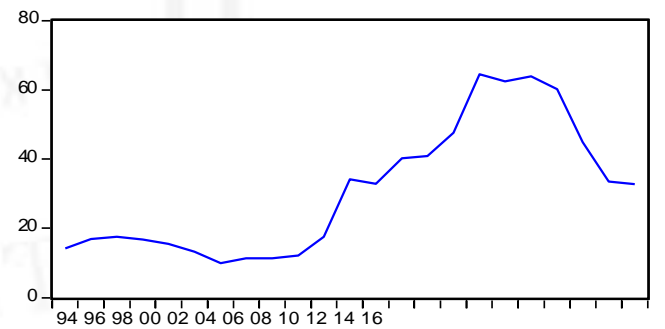

2

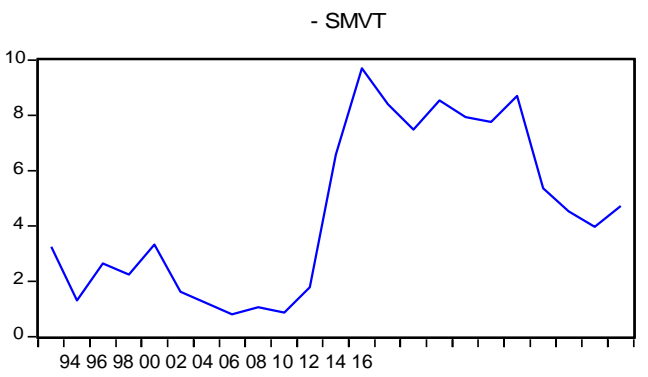

Fuente: Banco de Datos del Banco Mundial (s. f.). Recuperado de https://databank.bancomundial.org Elaboración propia 
Figura 5.2

Gráficos de las variables para México (3) y Perú (4): PBI per cápita, Crédito Interno, Spread de Tasas de Interés, Capitalización de Mercado y Valor Total de Acciones

Tranzadas.

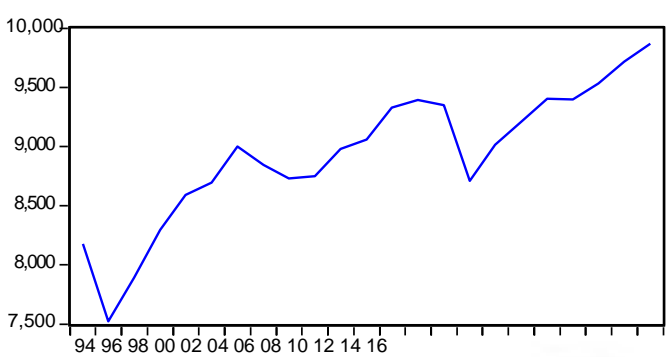

3 - CRED

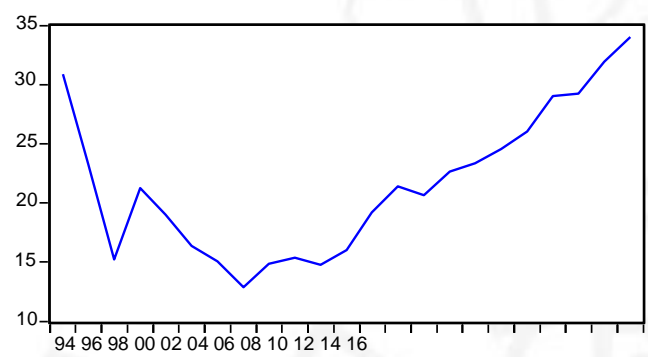

3 - SPREAD

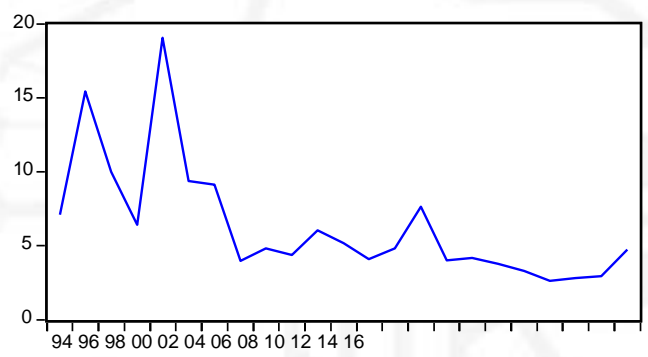

3- CAP

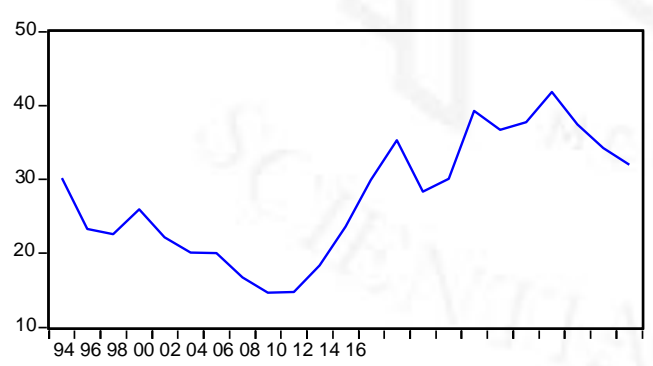

3 - SMVT

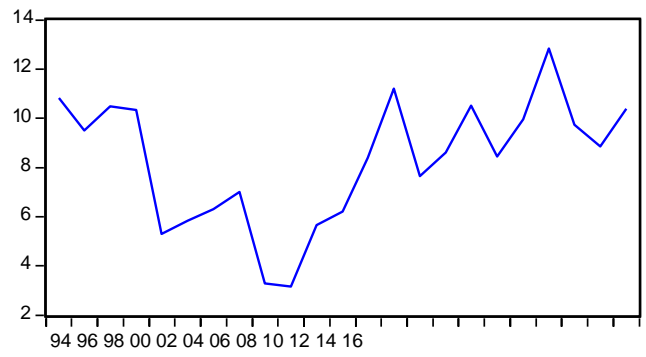

4 - PBIPC

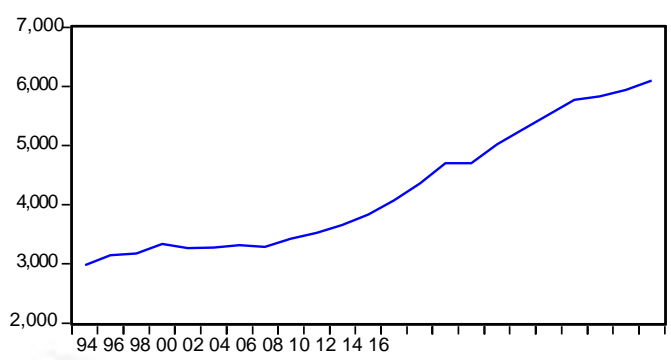

4
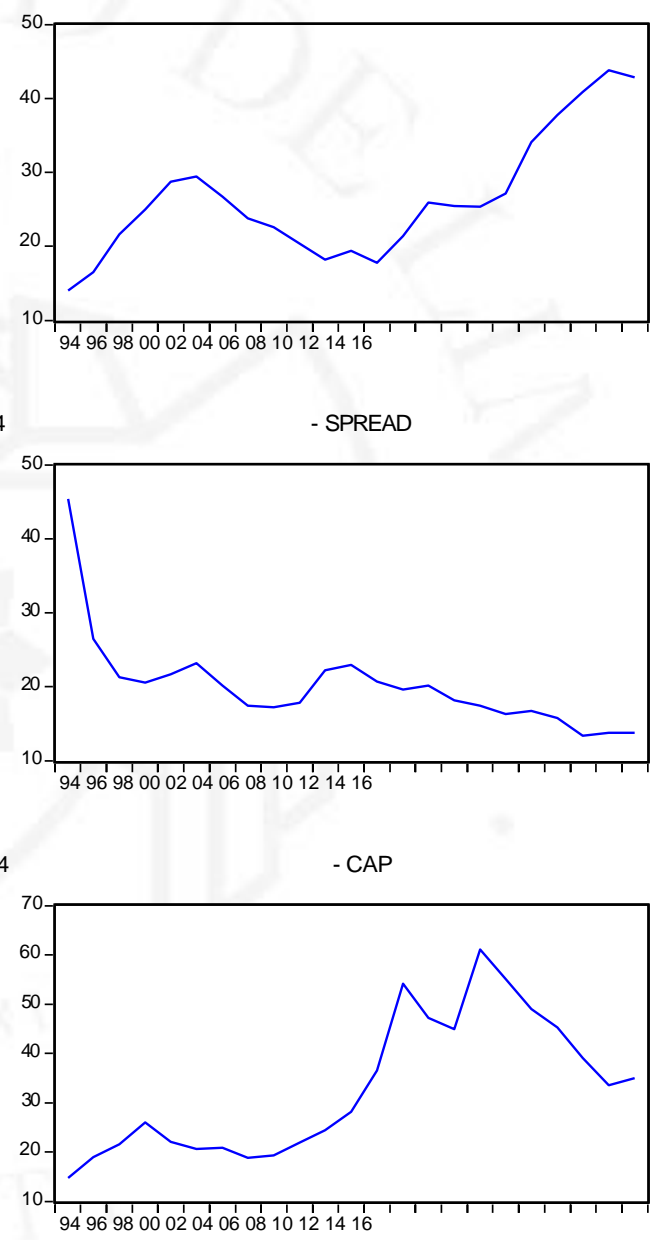

4

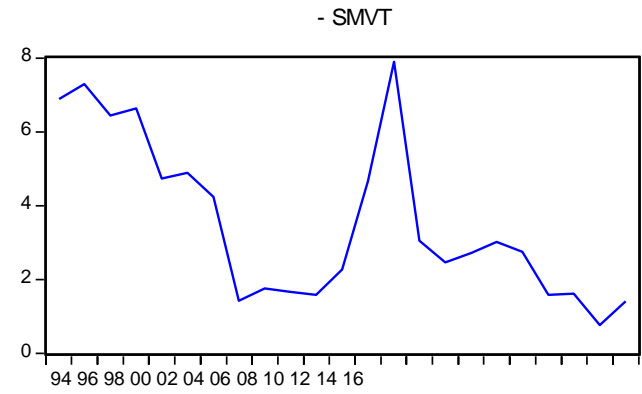

Fuente: Banco de Datos del Banco Mundial (s. f.). Recuperado de https://databank.bancomundial.org Elaboración propia 
En la figura 5.3 está la matriz de correlación, donde se observa que las variables están correlacionadas entre sí. La única variable que presenta correlación negativa es el spread de tasas de interés, que se relaciona de manera negativa con todas las variables del modelo. El resto de variables se correlaciona de manera positiva, lo que se confirma al observar las gráficas de las variables, que se muestran en el punto 5.2. Esto va de acuerdo a lo explicado en el marco teórico.

Figura 5.3

Matriz de correlación de las variables.

\begin{tabular}{|c|c|c|c|c|c|}
\multicolumn{5}{|c|}{ Correlation } \\
\hline & PBIPC & CRED & SPREAD & \multicolumn{1}{c|}{ CAP } & \multicolumn{1}{c|}{ SMVT } \\
\hline PBIPC & 1.000000 & 0.742489 & -0.703399 & 0.692283 & 0.703613 \\
\hline CRED & 0.742489 & 1.000000 & -0.457238 & 0.861708 & 0.602781 \\
\hline SPREAD & -0.703399 & -0.457238 & 1.000000 & -0.421989 & -0.408065 \\
\hline CAP & 0.692283 & 0.861708 & -0.421989 & 1.000000 & 0.721771 \\
\hline SMVT & 0.703613 & 0.602781 & -0.408065 & 0.721771 & 1.000000 \\
\hline
\end{tabular}

Fuente: Banco de Datos del Banco Mundial (s. f.). Recuperado de https://databank.bancomundial.org Elaboración propia

Para poder llevar a cabo el modelo de cointegración, las variables deben estar integradas en el mismo orden. Para comprobar esto, se procedió a realizar la prueba de raíz unitaria de Fisher para las variables, siendo la hipótesis nula que esta presenta raíz unitaria. Se obtuvo que las variables no rechazan la hipótesis nula en primeras diferencias, es decir, tienen raíz unitaria. Se procedió a realizar la prueba en primeras diferencias, donde se obtuvo que se rechaza la hipótesis nula, siendo estacionarias en primeras diferencias. Esto quiere decir que las variables son integradas de primer orden, a un nivel de confianza del 95\%, por lo que se puede realizar la prueba de cointegración. En la tabla 5.1 se observa un cuadro resumen con el estadístico de las pruebas realizadas. En el Anexo 1 se encuentran estas pruebas detalladas para cada variable.

Tabla 5.1

Resultados de pruebas de raíz unitaria para las variables del modelo

\begin{tabular}{|l|cc|cc|cc|}
\cline { 2 - 7 } \multicolumn{1}{c|}{} & \multicolumn{2}{c|}{ En niveles } & \multicolumn{2}{c|}{ En primeras diferencias } & \multicolumn{2}{c|}{ Resultados } \\
\cline { 2 - 7 } \multicolumn{1}{c|}{} & Estadístico & p-value & Estadístico & p-value & criterio & orden \\
\hline PBIPC & 3.8867 & 0.8672 & 18.6300 & 0.0170 & $<0.05$ & $\mathrm{I}(1)$ \\
CRED & 2.3428 & 0.9687 & 37.4772 & 0.0000 & $<0.05$ & $\mathrm{I}(1)$ \\
SPREAD & 12.7984 & 0.1190 & 51.0297 & 0.0000 & $<0.05$ & $\mathrm{I}(1)$ \\
CAP & 5.4039 & 0.7137 & 27.7511 & 0.0005 & $<0.05$ & $\mathrm{I}(1)$ \\
SMVT & 8.0282 & 0.4307 & 37.0695 & 0.0000 & $<0.05$ & $\mathrm{I}(1)$ \\
\hline
\end{tabular}

Fuente: Banco de Datos del Banco Mundial (s. f.). Recuperado de https://databank.bancomundial.org Elaboración propia 


\subsection{Modelo de mínimos cuadrados completamente modificados (FMOLS)}

El modelo desarrollado es el siguiente:

$$
\mathrm{PBIPC}=\beta_{1} \mathrm{CRED}+\beta_{2} \mathrm{SPREAD}+\beta_{3} \mathrm{CAP}+\beta_{4} \mathrm{SMVT}
$$

Se espera que la variable crédito interno tenga un impacto positivo sobre el PBI per cápita, ya que el crédito facilita el consumo y la inversión. Por otra parte, la variable spread de tasas debe tener una relación negativa con el crecimiento económico, debido a que representa un costo adicional para el financiamiento de las empresas.

Por el lado del mercado de capitales, las variables capitalización de mercado y valor total tranzado deben tener una relación positiva con el PBI per cápita, debido a que un alto nivel de estas representa un mercado de capitales desarrollado, el cual facilita la inversión y mejora la asignación de recursos. Esto a su vez se traduce en un mayor consumo de bienes de capital por parte de las empresas.

Para la estimación del modelo, primero se debe realizar la prueba de cointegración, ya que un supuesto necesario para la validez de los resultados es que las variables empleadas cointegren. Al realizar esta prueba se obtuvo que las variables cointegran a un nivel de confianza del 95\%, lo cual significa que existe una relación de largo plazo en el comportamiento de las variables. Si bien pueden existir desequilibrios en el corto plazo, hay una relación de equilibrio en el largo plazo. En la figura 5.4 se puede ver el resultado de la prueba, donde también se observa que los residuos no presentan autocorrelación, con un indicador de Durbin-Watson de 2.0444. 
Figura 5.4

Prueba de cointegración de Kao

Kao Residual Cointegration Test

Series: PBIPC CRED SPREAD CAP SMVT

Date: 04/28/19 Time: $20: 45$

Sample: 19942016

Included observations: 92

Null Hypothesis: No cointegration

Trend assumption: No deterministic trend

User-specified lag length: 1

Newey-West automatic bandwidth selection and Bartlett kernel

\begin{tabular}{|c|c|c|}
\hline ADF & $\begin{array}{c}\text { t-Statistic } \\
-3.144474\end{array}$ & $\frac{\text { Prob. }}{0.0008}$ \\
\hline $\begin{array}{l}\text { Residual variance } \\
\text { HAC variance }\end{array}$ & $\begin{array}{l}68101.56 \\
110002.0\end{array}$ & \\
\hline
\end{tabular}

\begin{tabular}{|c|c|c|c|c|}
\hline $\begin{array}{c}\text { RESID }(-1) \\
\text { D(RESID }(-1))\end{array}$ & $\begin{array}{r}-0.356639 \\
0.242911\end{array}$ & $\begin{array}{l}0.077929 \\
0101145\end{array}$ & $\begin{array}{r}-4.576438 \\
2401607\end{array}$ & $\begin{array}{l}0.0000 \\
0.0186\end{array}$ \\
\hline R-squared & 0.205115 & Mean depen & ent var & 33.55759 \\
\hline Adjusted R-squared & 0.195422 & S.D. depend & ht var & 389.2790 \\
\hline S.E. of regression & 349.1766 & Akaike info o & erion & 14.57255 \\
\hline Sum squared resid & 9997793. & Schwarz crit & ion & 14.63043 \\
\hline Log likelihood & -610.0473 & Hannan-Qui & criter. & 14.59582 \\
\hline Durbin-Watson stat & 2.044430 & & & \\
\hline
\end{tabular}

Fuente: Banco de Datos del Banco Mundial (s. f.). Recuperado de https://databank.bancomundial.org Elaboración propia

Luego de obtener este resultado, se procedió a estimar el modelo utilizando mínimos cuadrados completamente modificados (FMOLS) para datos de panel. Se utilizó el estimador de Newey-West, el cual corrige posibles problemas de autocorrelación y heterocedasticidad en los términos de error. Con esto se obtuvo lo presentado en la figura 5.5, donde se observa el modelo resultante. Este presenta un $\mathrm{R}$ cuadrado elevado, lo que significa que el modelo es explicativo. 
Figura 5.5

Estimación del modelo con el método de FMOLS

\begin{tabular}{|c|c|c|c|c|}
\hline $\begin{array}{l}\text { Dependent Variable: } \\
\text { Method: Panel Fully } \\
\text { Date: } 04 / 30 / 19 \text { Time } \\
\text { Sample (adjusted): } 1 \\
\text { Periods included: } 22 \\
\text { Cross-sections inclu } \\
\text { Total panel (balance } \\
\text { Panel method: Poole } \\
\text { Cointegrating equati } \\
\text { Additional regressor } \\
\text { First-stage residuals } \\
\text { Coefficient covarianc } \\
\text { Long-run covariance } \\
\text { maxlags = - } 1, \mathrm{~Pa} \\
\text { automatic lag ler }\end{array}$ & $\begin{array}{l}22 \\
2016 \\
4 \\
\text { servations: } 8 \\
\text { timation } \\
\text { terministics: } \\
\text { rministics: @ } \\
\text { heterogenec } \\
\text { mputed usin } \\
\text { nates (Prewl } \\
\text { kernel, New }\end{array}$ & $\begin{array}{l}8 \\
\text { C } \\
\text { TREND } \\
\text { us long-run c } \\
\text { sandwich m } \\
\text { itening with Ia } \\
\text { y-West auton }\end{array}$ & $\begin{array}{l}\text { efficients } \\
\text { hod } \\
s=-1 \text { from } A \\
\text { tic bandwidt }\end{array}$ & $\begin{array}{l}\text { AIC } \\
\text { ith, NW }\end{array}$ \\
\hline Variable & Coefficient & Std. Error & t-Statistic & Prob. \\
\hline CRED & 93.45659 & 2.073629 & 45.06910 & 0.0000 \\
\hline SPREAD & -33.40268 & 8.149852 & -4.098563 & 0.0001 \\
\hline CAP & 10.13397 & 2.413125 & 4.199521 & 0.0001 \\
\hline SMVT & -9.379643 & 8.060597 & -1.163641 & 0.2480 \\
\hline R-squared & 0.971700 & Mean depen & ent var & 7638.954 \\
\hline Adjusted R-squared & 0.969224 & S.D. depend & t var & 3131.905 \\
\hline S.E. of regression & 549.4348 & Sum square & resid & 24150284 \\
\hline Long-run variance & 129754.0 & & & \\
\hline
\end{tabular}

Fuente: Banco de Datos del Banco Mundial (s. f.). Recuperado de https://databank.bancomundial.org Elaboración propia

Se realizó la prueba de normalidad de Jarque-Bera para contrastar que los residuos del modelo siguen una distribución normal. El resultado fue que se acepta la hipótesis nula de normalidad de los residuos. Se puede ver el resultado de esta prueba en la figura 5.6.

Figura 5.6

Prueba de normalidad de los residuos para el modelo FMOLS.

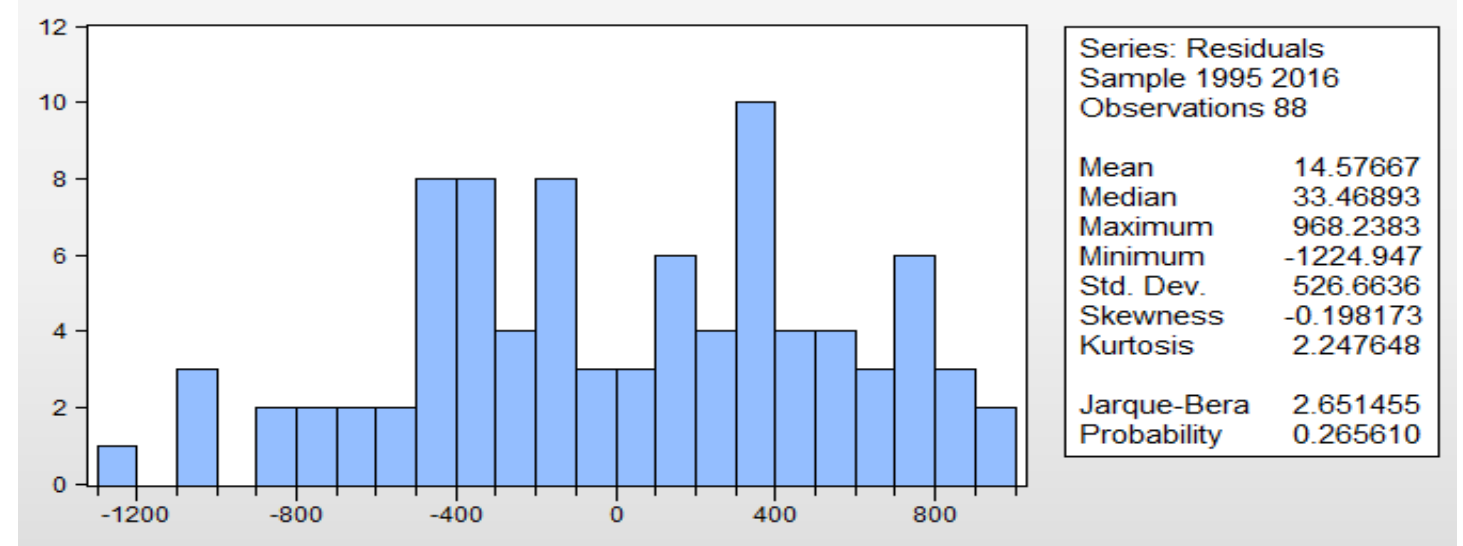

Fuente: Banco de Datos del Banco Mundial (s. f.). Recuperado de https://databank.bancomundial.org Elaboración propia 


\subsection{Discusión de resultados}

La variable crédito interno (CRED) es significativa y presenta un coeficiente positivo de 93.46, lo cual va acorde a lo esperado. Esto quiere decir que por cada punto porcentual que se incremente el crédito interno con respecto al PBI, el PBI per cápita se incrementa en 93.46 dólares, a precios de 2010. A mayor crédito interno, mayor financiamiento para las empresas, lo que facilita la inversión. Además, un alto nivel de crédito implica mayor acceso al crédito para las familias, facilitando así sus decisiones de consumo intertemporal.

De igual manera, la variable capitalización de mercado (CAP) también es significativa y presenta un coeficiente positivo de 10.13. Esto quiere decir que por cada punto porcentual con respecto al PBI que se incremente el valor total de acciones listadas, el PBI per cápita se incrementa en 10.13 dólares de 2010. El resultado va acorde a lo revisado en el marco teórico, ya que mientras más empresas listen sus acciones en la bolsa, mayor será el crecimiento económico, ya que estas empresas podrán financiar sus inversiones de largo plazo. Además, esto genera mayor actividad en el mercado de valores, lo que favorece la asignación de recursos de manera eficiente.

Por otra parte, la variable spread de tasas de interés es significativa y de coeficiente negativo de 33.40. Esto significa que una reducción del spread de tasas de interés en un punto incrementa el PBI per cápita en 33.40 dólares, por lo que un menor diferencial entre la tasa activa y pasiva contribuye al crecimiento económico. Como es una variable que mide principalmente el costo de pedir un préstamo, si tiene un nivel alto, los inversionistas pueden perder incentivos a invertir, ocasionando una reducción de la actividad económica.

La variable valor total de acciones tranzadas resultó no significativa en el modelo, al presentar una probabilidad de $24.8 \%$, mayor al $5 \%$ aceptado. Es por esto que no se considera el coeficiente obtenido.

A continuación, en la figura 5.7 se presentan las gráficas de la variable PBI per cápita respecto a las variables explicativas. Aquí se observa claramente una relación positiva entre PBIPC y CRED y una relación negativa con la variable SPREAD. 
Para el caso de las variables del mercado de capitales, CAP y SMVT, su relación con el PBI per cápita es positiva, sin embargo, esta relación no es tan clara como en el caso de las otras variables.

Esto reafirma los resultados obtenidos en el modelo estimado, donde la variable CRED es la más significativa y presenta el coeficiente más alto, comparando con las otras variables, seguida por la variable SPREAD. En el caso de la variable SMVT, los puntos están más dispersos. Si bien la relación con PBIPC es positiva, no es tan clara, por lo que esta variable no es significativa en el modelo.

Figura 5.7

Gráficas de la variable PBIPC respecto a las variables explicativas.
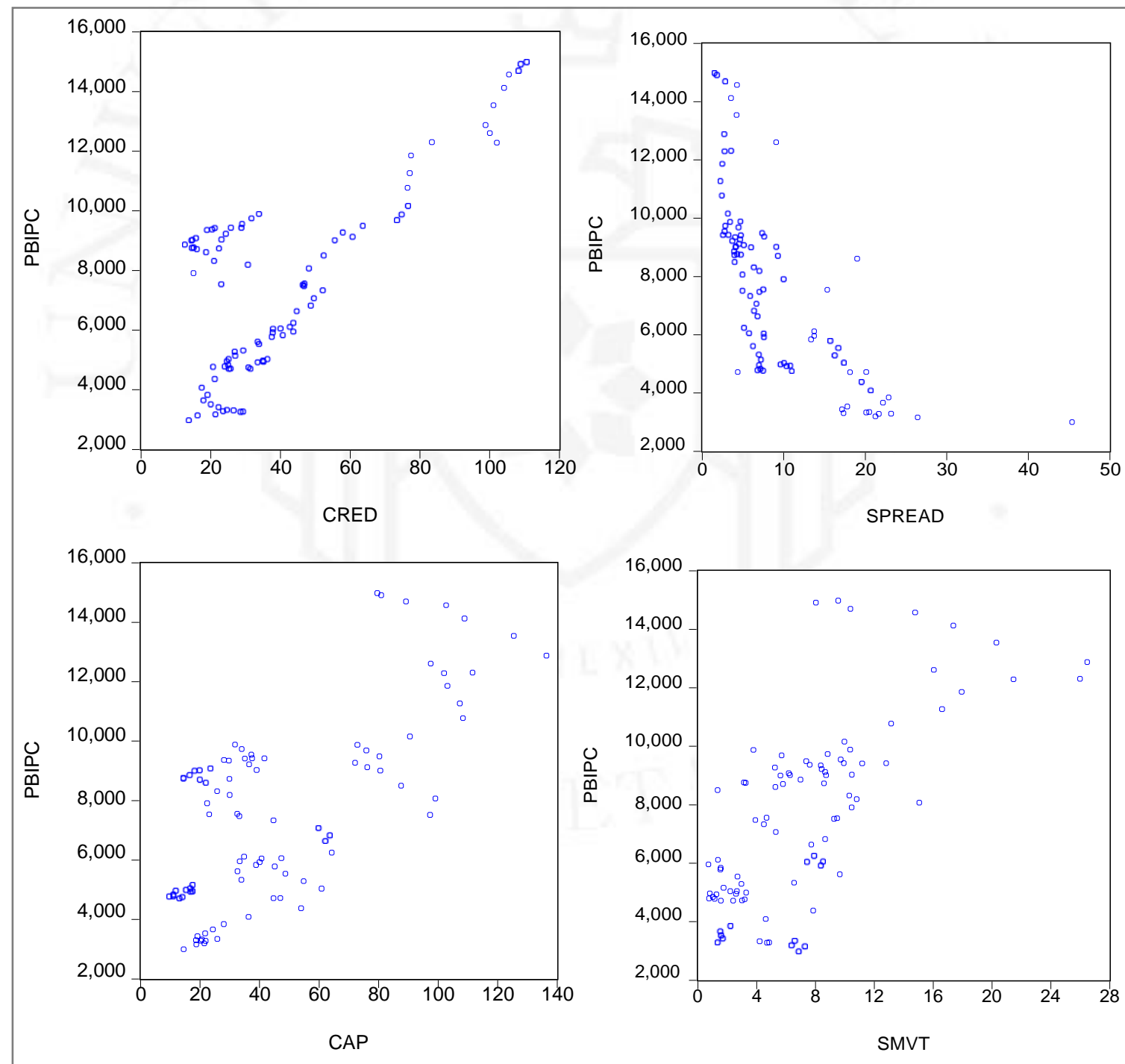

Fuente: Banco de Datos del Banco Mundial (s. f.). Recuperado de https://databank.bancomundial.org Elaboración propia 


\subsection{Modelo de corrección de errores (VECM)}

Para poder obtener las funciones impulso-respuesta, primero se debe estimar un modelo de corrección de errores. Este es un modelo de vectores autorregresivos (VAR) restringido, que se aplica cuando las variables presentan cointegración. El primer paso para estimar este modelo es verificar que las variables estén cointegradas Esto se realizó para el modelo anterior, encontrando que las variables sí están cointegradas.

Luego, se estableció la cantidad de rezagos que debe tener el modelo. Para esto, se estimó un modelo VAR sin restricciones para cada variable para poder hacer la prueba de longitud de los rezagos. Estas pruebas se encuentran en el Anexo 2 y el resumen de los resultados se encuentra en la tabla 5.2. Se elige el número de rezagos que resulte en un menor indicador de Akaike o Schwarz. En este caso, el indicador Akaike resultó ser menor en todas las aplicaciones, por lo que se toma como referencia este criterio. Como es data anual, el número de rezagos debería estar entre 1 y 2 . El resultado fue que el modelo debe tener 2 rezagos.

Tabla 5.2

Resultado de las pruebas de longitud de rezagos.

\begin{tabular}{|l|ccc|c|}
\cline { 2 - 4 } \multicolumn{1}{c|}{} & \multicolumn{3}{c|}{ Akaike Information Criterion } & N óptimo \\
\hline$N^{\circ}$ de rezagos & 0 & 1 & 2 & de rezagos \\
\hline PBIPC & 18.9617 & 13.5078 & 13.4753 & 2 \\
CRED & 9.4880 & 5.3183 & 5.2837 & 2 \\
SPREAD & 6.5447 & 4.7270 & 4.6933 & 2 \\
CAP & 9.7513 & 7.0242 & 7.0169 & 2 \\
SMVT & 6.2738 & 5.1076 & 5.0575 & 2 \\
\hline
\end{tabular}

Fuente: Banco de Datos del Banco Mundial (s. f.). Recuperado de https://databank.bancomundial.org Elaboración propia

Con esto, se procedió a estimar el modelo de Corrección de Errores (VECM), el cual se presenta en la figura 5.8. 
Figura 5.8

Estimación del modelo con el método de VECM.

Vector Error Correction Estimates

Date: 04/30/19 Time: 11:23

Sample (adjusted): 19972016

Included observations: 80 after adjustments

Standard errors in () \& t-statistics in []

\begin{tabular}{|c|c|c|c|c|c|}
\hline Cointegrating Eq: & CointEq1 & & & & \\
\hline PBIPC(-1) & 1.000000 & & & & \\
\hline CRED $(-1)$ & $\begin{array}{c}193.1774 \\
(103.394) \\
{[1.86836]}\end{array}$ & & & & \\
\hline SPREAD $(-1)$ & $\begin{array}{c}143.5092 \\
(193.284) \\
{[0.74248]}\end{array}$ & & & & \\
\hline $\mathrm{CAP}(-1)$ & $\begin{array}{r}-444.4778 \\
(105.163) \\
{[-4.22655]}\end{array}$ & & & & \\
\hline SMVT(-1) & $\begin{array}{r}-222.6447 \\
(313.893) \\
{[-0.70930]}\end{array}$ & & & & \\
\hline C & 5769.864 & & & & \\
\hline Error Correction: & $\mathrm{D}(\mathrm{PBIPC})$ & $\mathrm{D}(\mathrm{CRED})$ & D(SPREAD) & $\mathrm{D}(\mathrm{CAP})$ & $\mathrm{D}(\mathrm{SMVT})$ \\
\hline CointEq1 & $\begin{array}{r}-0.013015 \\
(0.00298) \\
{[-4.36544]}\end{array}$ & $\begin{array}{r}-0.000141 \\
(6.0 \mathrm{E}-05) \\
{[-2.36951]}\end{array}$ & $\begin{array}{r}-3.39 E-05 \\
(4.5 E-05) \\
{[-0.75446]}\end{array}$ & $\begin{array}{c}0.000145 \\
(0.00015) \\
{[0.98004]}\end{array}$ & $\begin{array}{c}6.34 \mathrm{E}-05 \\
(5.6 \mathrm{E}-05) \\
{[1.13620]}\end{array}$ \\
\hline $\mathrm{D}(\mathrm{PBIPC}(-1))$ & $\begin{array}{c}0.127506 \\
(0.11355) \\
{[1.12291]}\end{array}$ & $\begin{array}{c}0.001892 \\
(0.00227) \\
{[0.83353]}\end{array}$ & $\begin{array}{r}-0.000817 \\
(0.00171) \\
{[-0.47712]}\end{array}$ & $\begin{array}{r}-0.009535 \\
(0.00564) \\
{[-1.69002]}\end{array}$ & $\begin{array}{c}0.000502 \\
(0.00213) \\
{[0.23627]}\end{array}$ \\
\hline $\mathrm{D}(\mathrm{PBIPC}(-2))$ & $\begin{array}{c}0.035526 \\
(0.09952) \\
{[0.35698]}\end{array}$ & $\begin{array}{r}-0.002673 \\
(0.00199) \\
{[-1.34364]}\end{array}$ & $\begin{array}{c}0.001906 \\
(0.00150) \\
{[1.26971]}\end{array}$ & $\begin{array}{c}0.001759 \\
(0.00494) \\
{[0.35573]}\end{array}$ & $\begin{array}{c}0.000741 \\
(0.00186) \\
{[0.39757]}\end{array}$ \\
\hline $\mathrm{D}(\mathrm{CRED}(-1))$ & $\begin{array}{r}-7.327184 \\
(5.69982) \\
{[-1.28551]}\end{array}$ & $\begin{array}{c}0.184567 \\
(0.11394) \\
{[1.61984]}\end{array}$ & $\begin{array}{c}0.117303 \\
(0.08596) \\
{[1.36456]}\end{array}$ & $\begin{array}{r}-0.132204 \\
(0.28319) \\
{[-0.46683]}\end{array}$ & $\begin{array}{r}-0.096306 \\
(0.10667) \\
{[-0.90280]}\end{array}$ \\
\hline $\mathrm{D}(\mathrm{CRED}(-2))$ & $\begin{array}{r}-5.608361 \\
(5.59040) \\
{[-1.00321]}\end{array}$ & $\begin{array}{r}-0.101036 \\
(0.11175) \\
{[-0.90409]}\end{array}$ & $\begin{array}{r}-0.241554 \\
(0.08431) \\
{[-2.86495]}\end{array}$ & $\begin{array}{l}0.715100 \\
(0.27776) \\
{[2.57457]}\end{array}$ & $\begin{array}{c}0.263828 \\
(0.10463) \\
{[2.52161]}\end{array}$ \\
\hline $\mathrm{D}(\mathrm{SPREAD}(-1))$ & $\begin{array}{r}-15.37209 \\
(7.24564) \\
{[-2.12156]}\end{array}$ & $\begin{array}{c}0.139988 \\
(0.14484) \\
{[0.96648]}\end{array}$ & $\begin{array}{r}-0.290516 \\
(0.10928) \\
{[-2.65851]}\end{array}$ & $\begin{array}{r}-0.221874 \\
(0.36000) \\
{[-0.61632]}\end{array}$ & $\begin{array}{r}-0.076721 \\
(0.13561) \\
{[-0.56576]}\end{array}$ \\
\hline $\mathrm{D}(\mathrm{SPREAD}(-2))$ & $\begin{array}{c}4.846649 \\
(5.08310) \\
{[0.95348]}\end{array}$ & $\begin{array}{c}0.019882 \\
(0.10161) \\
{[0.19566]}\end{array}$ & $\begin{array}{r}-0.124561 \\
(0.07666) \\
{[-1.62480]}\end{array}$ & $\begin{array}{c}0.361510 \\
(0.25255) \\
{[1.43143]}\end{array}$ & $\begin{array}{c}0.151536 \\
(0.09513) \\
{[1.59290]}\end{array}$ \\
\hline $\mathrm{D}(\mathrm{CAP}(-1))$ & $\begin{array}{l}7.966337 \\
(3.45075) \\
{[2.30858]}\end{array}$ & $\begin{array}{r}-0.103491 \\
(0.06898) \\
{[-1.50026]}\end{array}$ & $\begin{array}{c}0.000845 \\
(0.05204) \\
{[0.01623]}\end{array}$ & $\begin{array}{c}0.244688 \\
(0.17145) \\
{[1.42718]}\end{array}$ & $\begin{array}{c}0.053973 \\
(0.06458) \\
{[0.83572]}\end{array}$ \\
\hline $\mathrm{D}(\mathrm{CAP}(-2))$ & $\begin{array}{l}2.992216 \\
(2.64343) \\
{[1.13194]}\end{array}$ & $\begin{array}{r}-0.042361 \\
(0.05284) \\
{[-0.80164]}\end{array}$ & $\begin{array}{r}-0.036183 \\
(0.03987) \\
{[-0.90757]}\end{array}$ & $\begin{array}{c}0.006627 \\
(0.13134) \\
{[0.05046]}\end{array}$ & $\begin{array}{c}0.005765 \\
(0.04947) \\
{[0.11653]}\end{array}$ \\
\hline
\end{tabular}

(continúa) 
(continuación)

\begin{tabular}{|c|c|c|c|c|c|}
\hline $\mathrm{D}(\mathrm{SMVT}(-1))$ & $\begin{array}{r}-8.938821 \\
(8.03903) \\
{[-1.11193]}\end{array}$ & $\begin{array}{c}0.368949 \\
(0.16070) \\
{[2.29584]}\end{array}$ & $\begin{array}{l}0.212840 \\
(0.12124) \\
{[1.75547]}\end{array}$ & $\begin{array}{r}0.108753 \\
(0.39941) \\
{[0.27228]}\end{array}$ & $\begin{array}{r}-0.298234 \\
(0.15045) \\
{[-1.98223]}\end{array}$ \\
\hline $\mathrm{D}(\operatorname{SMVT}(-2))$ & $\begin{array}{r}-22.42025 \\
(7.66418) \\
{[-2.92533]}\end{array}$ & $\begin{array}{l}0.233490 \\
(0.15321) \\
{[1.52399]}\end{array}$ & $\begin{array}{c}0.044847 \\
(0.11559) \\
{[0.38798]}\end{array}$ & $\begin{array}{r}-0.060857 \\
(0.38079) \\
{[-0.15982]}\end{array}$ & $\begin{array}{r}0.078422 \\
(0.14344) \\
{[0.54673]}\end{array}$ \\
\hline $\mathrm{C}$ & $\begin{array}{r}153.0695 \\
(34.3059) \\
{[4.46190]}\end{array}$ & $\begin{array}{r}1.574810 \\
(0.68579) \\
{[2.29635]}\end{array}$ & $\begin{array}{r}-0.376567 \\
(0.51740) \\
{[-0.72781]}\end{array}$ & $\begin{array}{c}1.038194 \\
(1.70447) \\
{[0.60910]}\end{array}$ & $\begin{array}{r}-0.387217 \\
(0.64205) \\
{[-0.60309]}\end{array}$ \\
\hline R-squared & 0.573319 & 0.305118 & 0.342399 & 0.295921 & 0.192112 \\
\hline Adj. R-squared & 0.504297 & 0.192711 & 0.236022 & 0.182026 & 0.061424 \\
\hline Sum sq. resids & 1526105. & 609.8526 & 347.1310 & 3767.255 & 534.5445 \\
\hline S.E. equation & 149.8089 & 2.994732 & 2.259396 & 7.443172 & 2.803738 \\
\hline F-statistic & 8.306320 & 2.714397 & 3.218736 & 2.598191 & 1.470010 \\
\hline Log likelihood & -507.7632 & -194.7627 & -172.2221 & -267.5981 & -189.4906 \\
\hline Akaike AIC & 12.99408 & 5.169068 & 4.605553 & 6.989952 & 5.037265 \\
\hline Schwarz SC & 13.35138 & 5.526372 & 4.962857 & 7.347256 & 5.394569 \\
\hline Mean dependent & 174.7479 & 1.375319 & -0.231393 & 0.374428 & 0.064318 \\
\hline S.D. dependent & 212.7780 & 3.333062 & 2.584948 & 8.229782 & 2.894029 \\
\hline \multicolumn{2}{|c|}{ Determinant resid covariance (dof adj.) } & $1.88 \mathrm{E}+08$ & & & \\
\hline \multicolumn{2}{|c|}{ Determinant resid covariance } & 83294296 & & & \\
\hline \multicolumn{2}{|c|}{ Log likelihood } & -1297.091 & & & \\
\hline \multicolumn{2}{|c|}{ Akaike information criterion } & 34.05228 & & & \\
\hline \multicolumn{2}{|c|}{ Schwarz criterion } & 35.98767 & & & \\
\hline
\end{tabular}

Fuente: Banco de Datos del Banco Mundial (s. f.). Recuperado de https://databank.bancomundial.org Elaboración propia

Para este trabajo, solo se calculó el modelo VECM para poder obtener las funciones impulso-respuesta, por lo que no se entrará en detalle sobre los resultados del modelo. Sin embargo, para que las funciones impulso respuesta muestren resultados válidos, el modelo debe cumplir con tener residuos que no presenten autocorrelación ni heterocedasticidad.

Se calculó el test de autocorrelación, el cual se muestra en la figura 5.9. Los residuos no están correlacionados, al aceptar la hipótesis nula de no correlación serial.

Figura 5.9

Test de autocorrelación de los residuos para el modelo VECM

VEC Residual Serial Correlation LM T...
Null Hypothesis: no serial correlation ...
Date: 04/28/19 Time: 21:08
Sample: 19942016
Included observations: 80
\begin{tabular}{ccc}
\hline Lags & LM-Stat & Prob \\
\hline \hline 1 & 35.61156 & 0.0777 \\
2 & 21.18084 & 0.6825 \\
3 & 27.90199 & 0.3124 \\
\hline \hline
\end{tabular}

Probs from chi-square with $25 \mathrm{df}$.

Fuente: Banco de Datos del Banco Mundial (s. f.). Recuperado de https://databank.bancomundial.org Elaboración propia 
Luego se procedió a realizar el test de heterocedasticidad, el cual se observa en la figura 5.10. El modelo no presenta heterocedasticidad, al aceptar la hipótesis nula de no heterocedasticidad. Estos resultados reafirman la validez del modelo.

Figura 5.10

Test de heterocedasticidad para el modelo VECM.

VEC Residual Heteroskedasticity Tests: Includes Cross Terms

Date: 04/28/19 Time: 21:09

Sample: 19942016

Included observations: 80

\begin{tabular}{|c|c|c|c|c|c|}
\hline \multicolumn{6}{|l|}{ Joint test: } \\
\hline Chi-sq & df & Prob. & & & \\
\hline 1162.276 & 1155 & 0.4345 & & & \\
\hline \multicolumn{6}{|c|}{ Individual components: } \\
\hline Dependent & R-squared & $F(77,2)$ & Prob. & Chi-sq(77) & Prob. \\
\hline res1*res1 & 0.984246 & 1.622717 & 0.4574 & 78.73965 & 0.4236 \\
\hline res2*res2 & 0.997396 & 9.950009 & 0.0955 & 79.79171 & 0.3913 \\
\hline res3*res 3 & 0.995116 & 5.292104 & 0.1718 & 79.60927 & 0.3968 \\
\hline res $4^{\star}$ res 4 & 0.903976 & 0.244522 & 0.9795 & 72.31812 & 0.6297 \\
\hline res5*res5 & 0.984333 & 1.631856 & 0.4555 & 78.74660 & 0.4233 \\
\hline res2*res1 & 0.998170 & 14.16981 & 0.0681 & 79.85362 & 0.3894 \\
\hline res3*res1 & 0.993813 & 4.171901 & 0.2126 & 79.50501 & 0.4000 \\
\hline res $3^{\star}$ res 2 & 0.997879 & 12.22004 & 0.0785 & 79.83032 & 0.3901 \\
\hline res $4^{\star}$ res 1 & 0.983570 & 1.554905 & 0.4716 & 78.68559 & 0.4252 \\
\hline res $4^{*}$ res 2 & 0.990125 & 2.604402 & 0.3175 & 79.21003 & 0.4090 \\
\hline res $4^{*}$ res 3 & 0.965202 & 0.720452 & 0.7443 & 77.21617 & 0.4716 \\
\hline res5*res1 & 0.997460 & 10.19968 & 0.0933 & 79.79679 & 0.3912 \\
\hline res5*res2 & 0.993393 & 3.905420 & 0.2252 & 79.47145 & 0.4010 \\
\hline res5*res 3 & 0.989241 & 2.388152 & 0.3406 & 79.13927 & 0.4112 \\
\hline res5res 4 & 0.918645 & 0.293295 & 0.9619 & 73.49162 & 0.5922 \\
\hline
\end{tabular}

Fuente: Banco de Datos del Banco Mundial (s. f.). Recuperado de https://databank.bancomundial.org Elaboración propia

También se calculó la prueba de normalidad. En este modelo, los residuos no son normales al rechazar la hipótesis nula de normalidad en los residuos. Independientemente, las variables CAP y SMVT presentan residuos normales, de acuerdo con el indicador de Jarque-Bera. Los resultados están en la figura 5.11. 
Figura 5.11

Test de normalidad de los residuos para el modelo VECM.

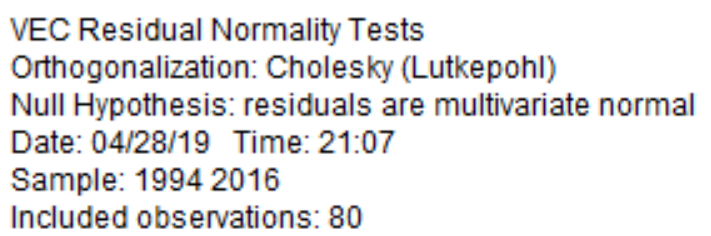

\begin{tabular}{|c|c|c|c|c|}
\hline Component & Skewness & Chi-sq & df & Prob. \\
\hline 1 & -1.034194 & 14.26078 & 1 & 0.0002 \\
\hline 2 & -0.168291 & 0.377625 & 1 & 0.5389 \\
\hline 3 & 0.366286 & 1.788875 & 1 & 0.1811 \\
\hline 4 & 0.442707 & 2.613192 & 1 & 0.1060 \\
\hline 5 & 0.310025 & 1.281544 & 1 & 0.2576 \\
\hline Joint & & 20.32201 & 5 & 0.0011 \\
\hline Component & Kurtosis & Chi-sq & df & Prob. \\
\hline 1 & 5.591224 & 22.38148 & 1 & 0.0000 \\
\hline 2 & 4.396140 & 6.497356 & 1 & 0.0108 \\
\hline 3 & 5.543665 & 21.56744 & 1 & 0.0000 \\
\hline 4 & 2.636722 & 0.439902 & 1 & 0.5072 \\
\hline 5 & 3.153544 & 0.078586 & 1 & 0.7792 \\
\hline Joint & & 50.96476 & 5 & 0.0000 \\
\hline Component & Jarque-Bera & df & Prob. & \\
\hline 1 & 36.64225 & 2 & 0.0000 & \\
\hline 2 & 6.874982 & 2 & 0.0321 & \\
\hline 3 & 23.35632 & 2 & 0.0000 & \\
\hline 4 & 3.053094 & 2 & 0.2173 & \\
\hline 5 & 1.360130 & 2 & 0.5066 & \\
\hline Joint & 71.28678 & 10 & 0.0000 & \\
\hline
\end{tabular}

Fuente: Banco de Datos del Banco Mundial (s. f.). Recuperado de https://databank.bancomundial.org Elaboración propia

El hecho que los residuos no sean normales no le quita validez al modelo, ya que se cumplen las otras pruebas de no autocorrelación y no heterocedasticidad (Rummel, 2015, p. 15). Luego de esto se procedió a calcular las funciones impulso-respuesta, las cuales se muestran a continuación.

En la figura 5.12 se muestran las funciones de respuesta de la variable PBIPC ante impulsos de las demás variables. En la figura 5.13 se muestran las funciones de respuesta de las variables CRED y SPREAD, y en la figura 5.14 se muestran las funciones de respuesta de las variables CAP y SMVT. 
Figura 5.12

Funciones impulso-respuesta para la variable PBIPC

Response to Cholesky One S.D. Innovations

Response of PBIPC to PBIPC

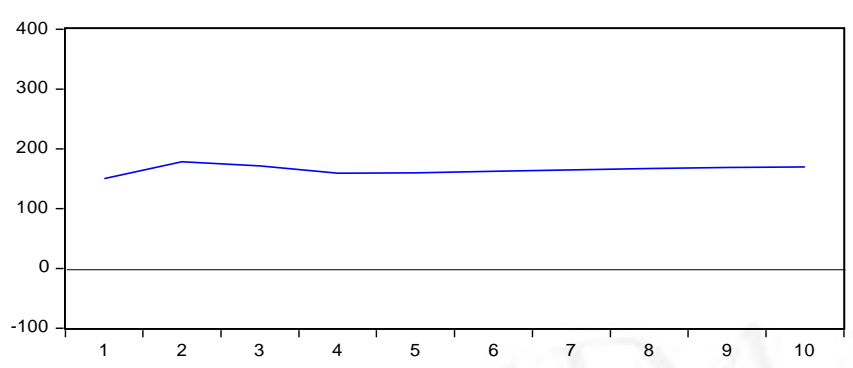

Response of PBIPC to CRED

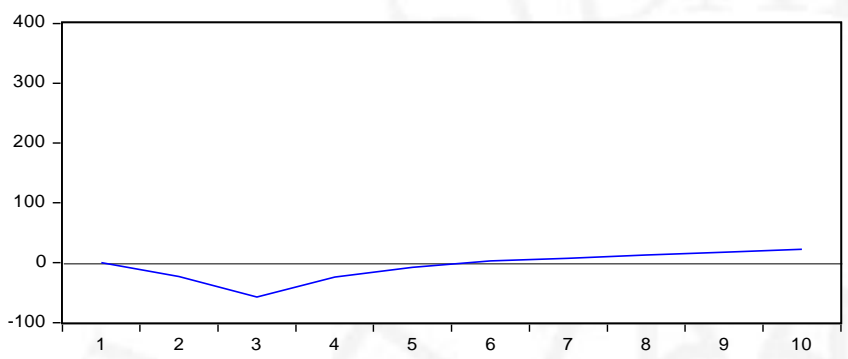

Response of PBIPC to SPREAD

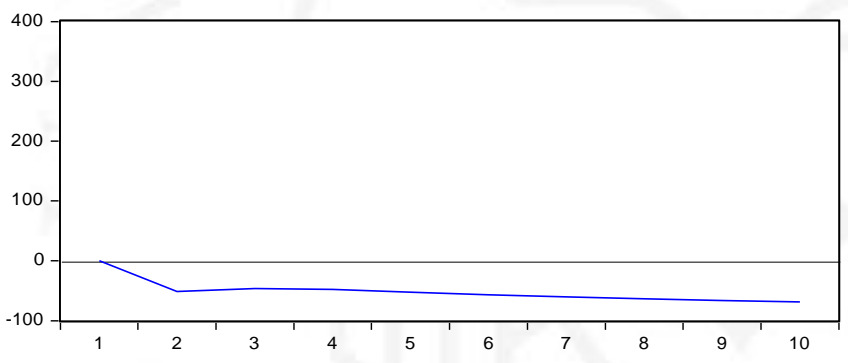

Response of PBIPC to CAP

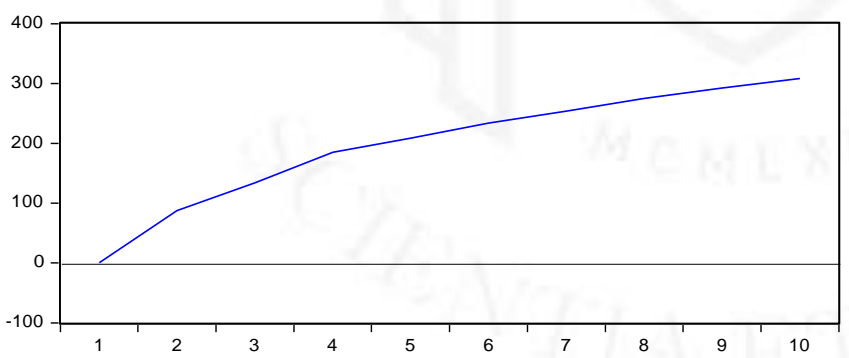

Response of PBIPC to SMVT

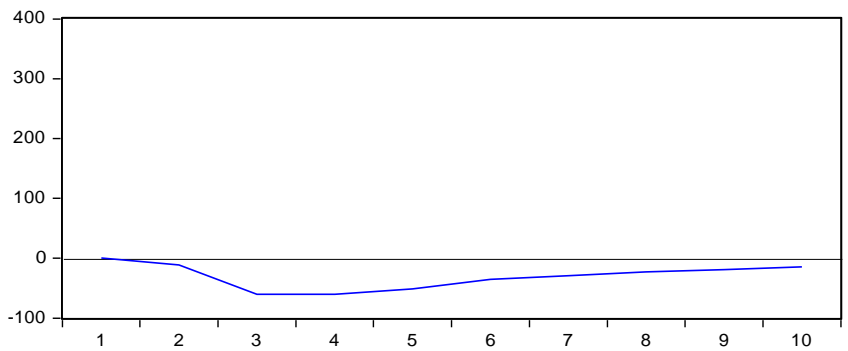

Fuente: Banco de Datos del Banco Mundial (s. f.). Recuperado de https://databank.bancomundial.org Elaboración propia 
Figura 5.13

Funciones impulso-respuesta para las variables CRED y SPREAD.

Response to Cholesky One S.D. Innovations

Response of CRED to PBIPC

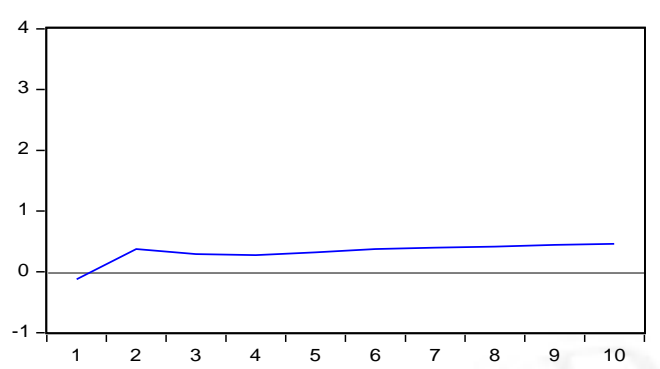

Response of CRED to CRED

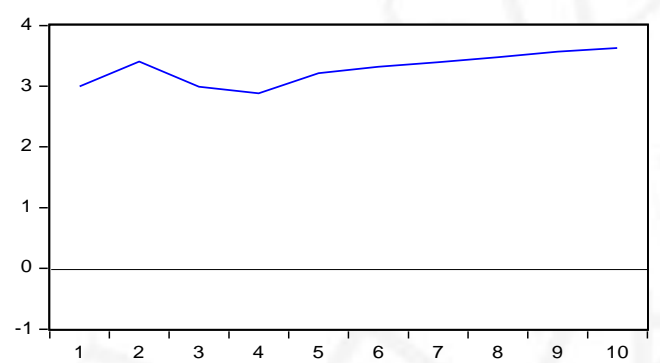

Response of CRED to SPREAD

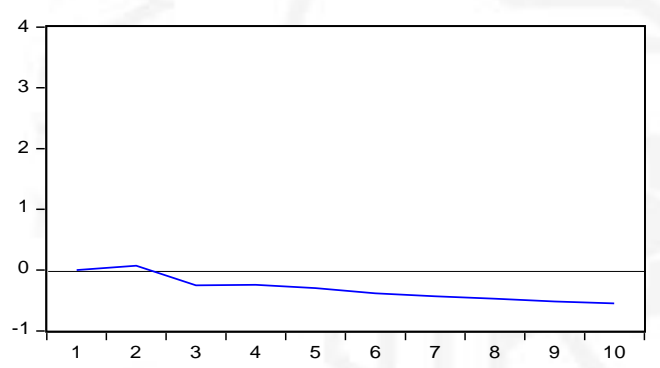

Response of CRED to CAP

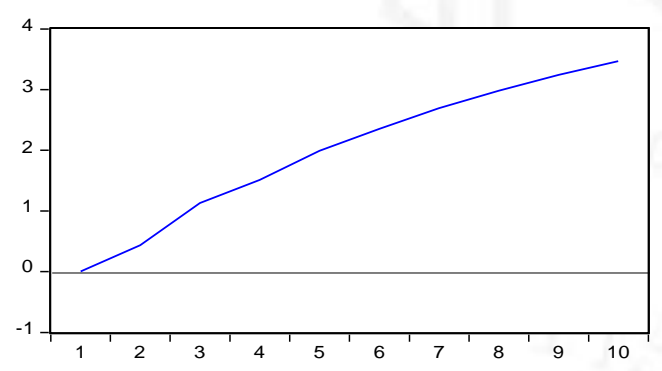

Response of CRED to SMVT

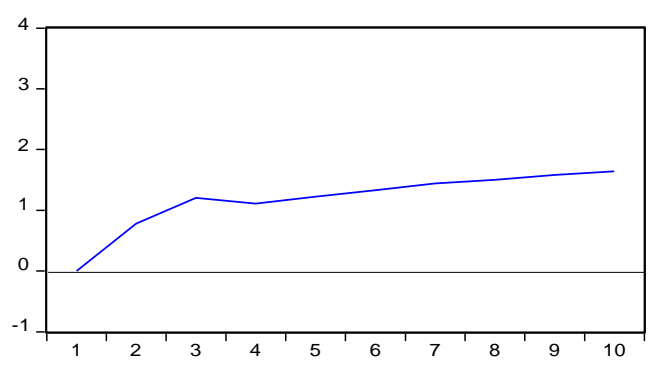

Response to Cholesky One S.D. Innovations

Response of SPREAD to PBIPC

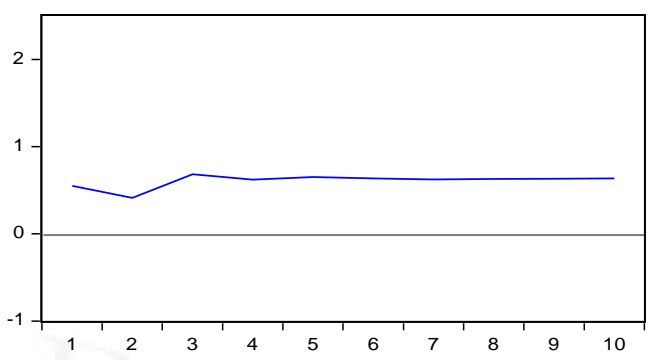

Response of SPREAD to CRED

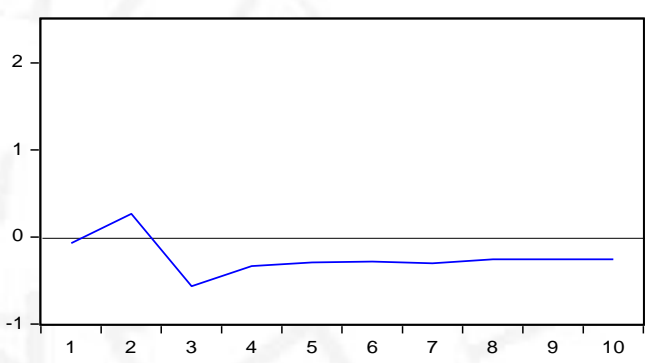

Response of SPREAD to SPREAD

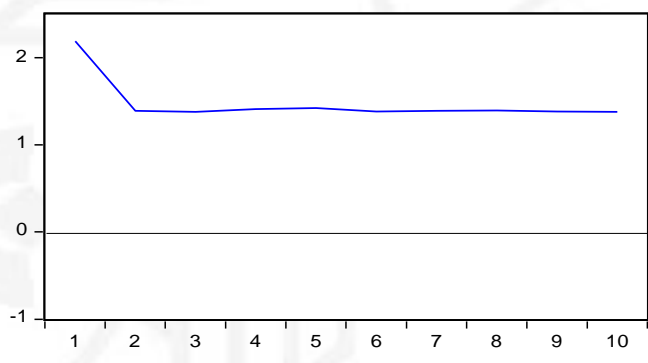

Response of SPREAD to CAP

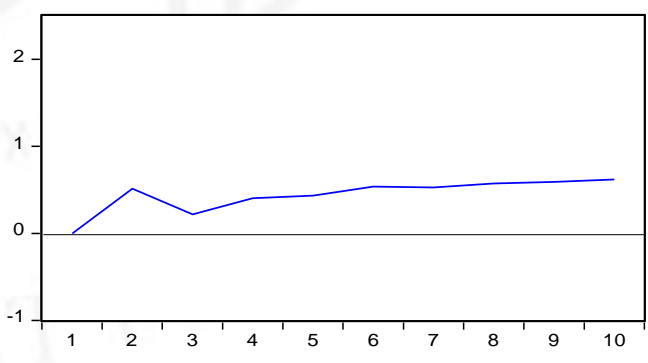

Response of SPREAD to SMVT

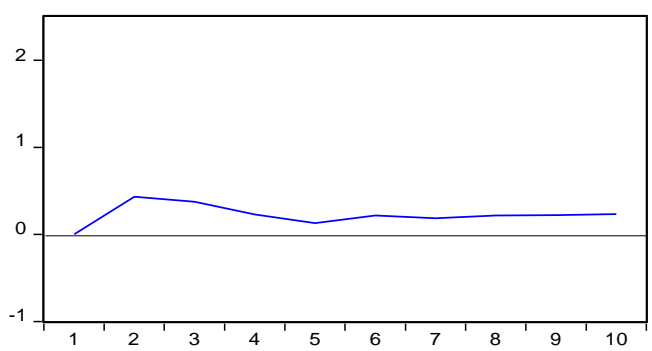

Fuente: Banco de Datos del Banco Mundial (s. f.). Recuperado de https://databank.bancomundial.org Elaboración propia 
Figura 5.14

Funciones impulso-respuesta para las variables CAP y SMVT.

Response to Cholesky One S.D. Innovations Response of CAP to PBIPC

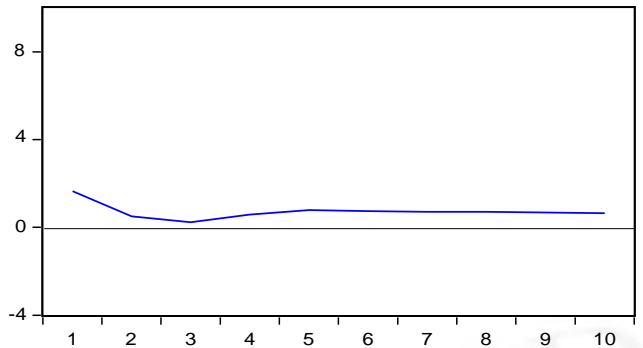

Response of CAP to CRED
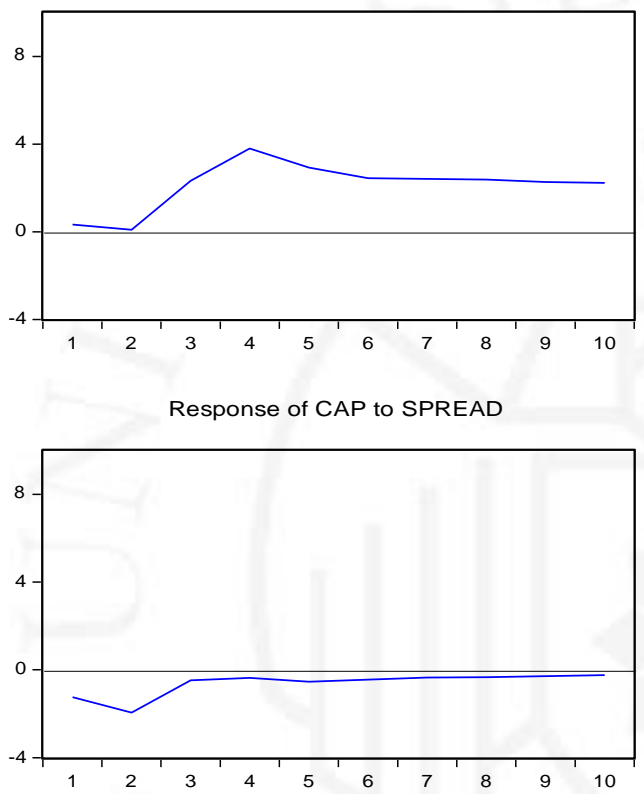

Response of CAP to CAP

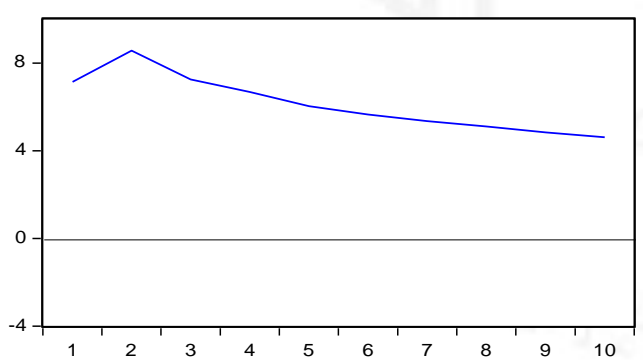

Response of CAP to SMVT

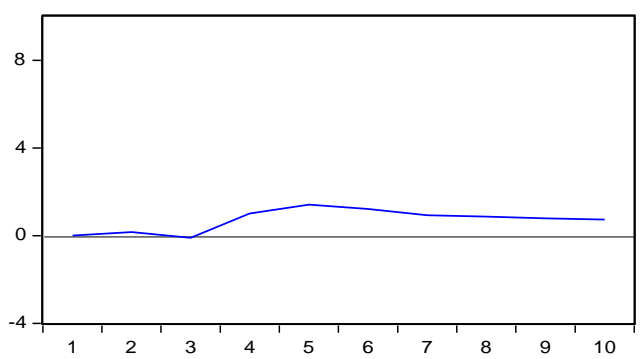

Response to Cholesky One S.D. Innovations Response of SMVT to PBIPC

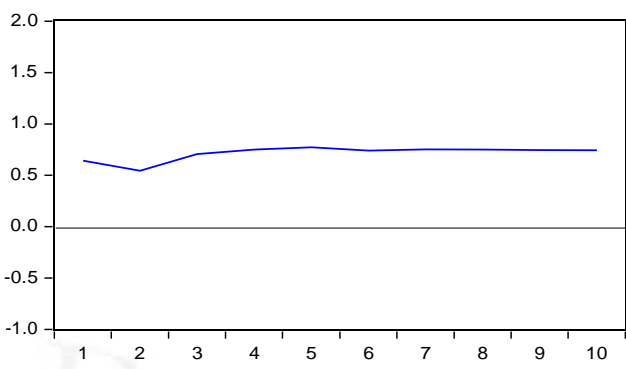

Response of SMVT to CRED

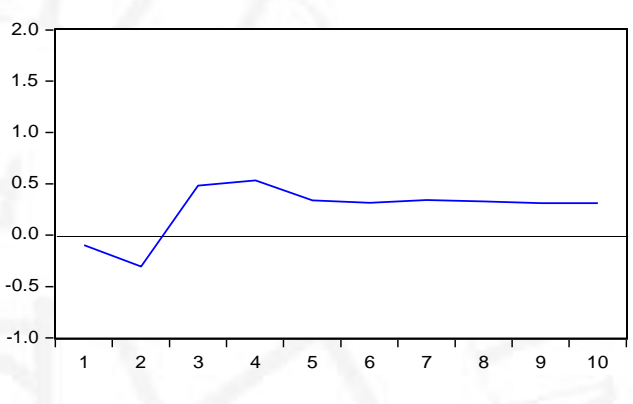

Response of SMVT to SPREAD

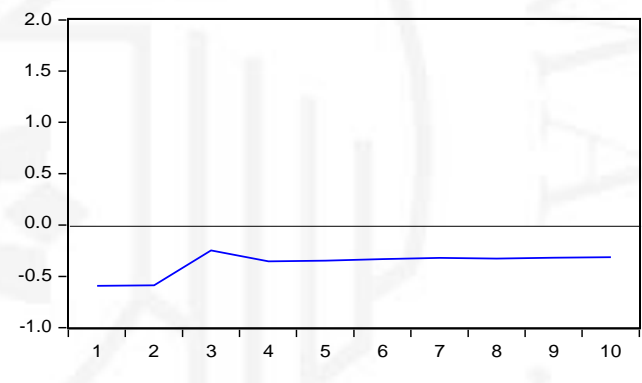

Response of SMVT to CAP

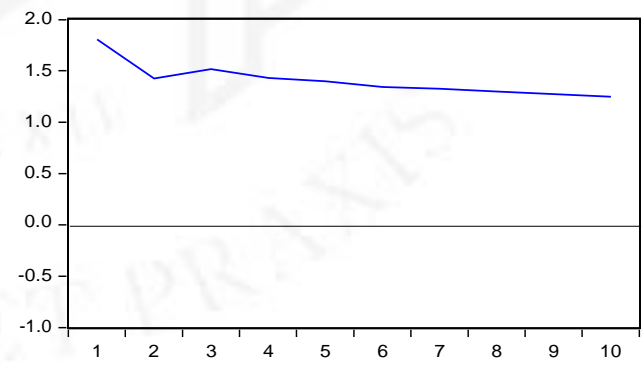

Response of SMVT to SMVT

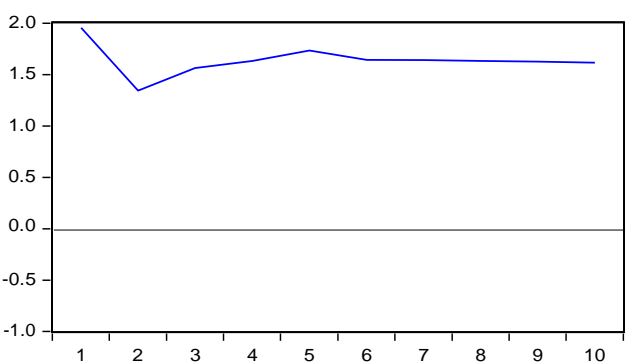

Fuente: Banco de Datos del Banco Mundial (s. f.). Recuperado de https://databank.bancomundial.org Elaboración propia 
Un shock en la variable CRED tiene inicialmente un efecto negativo en la variable PBIPC. A partir del periodo 3 el efecto se revierte y empieza a tener un efecto positivo en el periodo 6. Esto quiere decir que el impacto es negativo en el corto plazo, mientras que, en el largo plazo, el impacto es positivo. Un shock en la variable SPREAD siempre tendrá un impacto negativo en la variable PBIPC, pero presenta un efecto más pronunciado en el corto plazo. En el caso de un shock la variable CAP, la respuesta de PBIPC siempre será positiva, con un efecto ligeramente más pronunciado en los primeros periodos. Por otra parte, un shock la variable SMVT tendrá un efecto negativo en PBIPC hasta el periodo 3, donde el efecto se vuelve positivo, aunque se mantiene en la región negativa. Tanto las variables CRED como SMVT tienen impactos asimétricos en PBIPC entre el corto plazo y el largo plazo.

La respuesta de la variable CRED ante un shock en la variable SPREAD es casi nula en el corto plazo. Recién a partir del periodo 3 se observa una respuesta negativa. Cuando se da un shock en la variable CAP, la respuesta de CRED es positiva y prolongada en el tiempo. Ante un choque de SMVT, la respuesta de CRED es positiva, con una pendiente más pronunciada en el corto plazo.

Para la variable SPREAD, la respuesta ante un shock en CRED es positiva en el corto plazo, luego se revierte y se vuelve negativa, de manera más pronunciada en el periodo 3. Cuando hay un shock en CAP y SMVT, la respuesta de SPREAD es ligeramente positiva, con una pendiente negativa para los periodos 2 y 3 , pero permaneciendo en el área positiva.

En el caso de la variable CAP, responde de forma positiva ante un shock en CRED recién a partir del periodo 2 . Se puede decir que la respuesta de CAP está rezagada. Ante un shock en la variable SPREAD, CAP responde de manera negativa en el corto plazo, mientras que en el largo plazo la respuesta tiende a cero, pero permanece en la zona negativa.

La respuesta de la variable SMVT ante un shock en CRED es ligeramente negativa en el corto plazo, se vuelve positiva a partir del periodo 3 . Ante un shock en SPREAD, SMVT responde de manera negativa, de forma más notoria en el corto plazo. Ante un shock en CAP, SMVT tiene una respuesta positiva bastante pronunciada, con una ligera tendencia decreciente. 
En resumen, la variable CAP es la que más afecta de manera positiva a las otras variables. PBIPC, CRED y SMVT. En todos los casos, un shock en una variable tiene una respuesta positiva en la misma variable, la cual se mantiene constante en el tiempo.

Los efectos de un shock de la variable CRED van de acorde a lo esperado, según el marco teórico, recién en el largo plazo. En el caso del PBI, la respuesta es ligeramente positiva recién desde el periodo 6. Este resultado es similar al obtenido por Hassan, Sanchez y $\mathrm{Yu}$, quienes calcularon funciones impulso respuesta del crecimiento ante shocks en el crédito, con data anual de 1980 a 2007. En la función calculada para los países de Latinoamérica y el Caribe, la respuesta del crecimiento del PBI per cápita ante un shock en el crédito al sector privado es negativa en el corto plazo y se vuelve ligeramente positiva recién desde el periodo 5, como se puede ver en la figura 5.15.

Figura 5.15

Respuesta del crecimiento del PBI per cápita ante un shock en el crédito al sector privado (1980 - 2007).

Growth response to DCPS shock

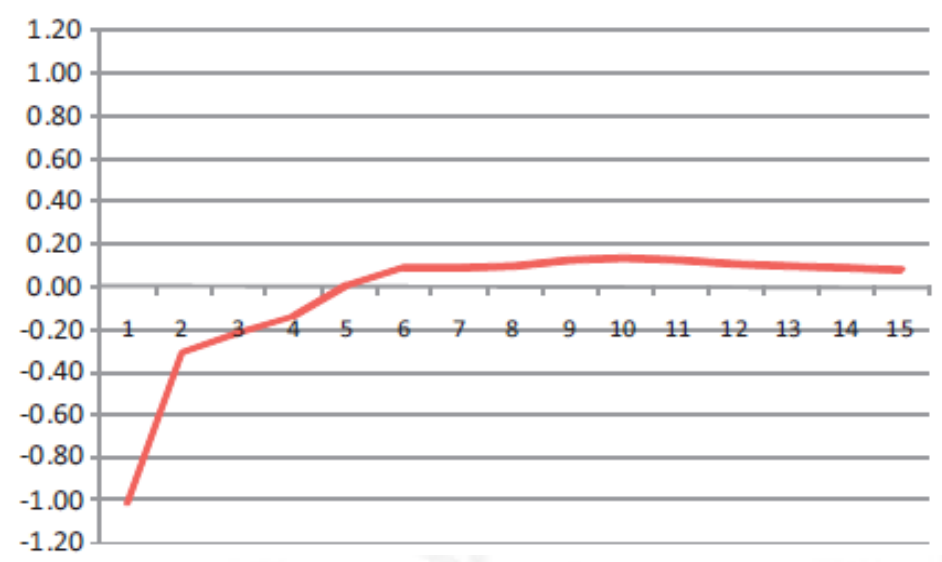

Fuente: Hassan, Sanchez y Yu (2011). Financial development and economic growth: New evidence from panel data, p. 97.

Por otra parte, ante un shock en SPREAD, todas las variables responden de forma negativa, teniendo un mayor impacto en el corto plazo en las variables CAP y SMVT. Esto último quiere decir que el diferencial de tasas de interés tiene un efecto negativo en el mercado de capitales, el cual es más pronunciado en el corto plazo. 


\section{CONCLUSIONES}

En este trabajo se estudió el impacto del mercado de capitales y el acceso al crédito por parte de las empresas en el Producto Bruto Interno real per cápita, en los países que conforman el Mercado Integrado Latinoamericano por el periodo de 1994 a 2016. Se utilizó un enfoque empírico de cointegración en un contexto de datos de panel, basado en aplicaciones pasadas mencionadas en el marco teórico, pero adaptado para los países del MILA.

Para realizar las estimaciones se usaron como indicadores del desarrollo del mercado de capitales la capitalización de mercado y el valor total de acciones tranzadas para cada país. Para el caso del acceso al crédito de las empresas, se usó como indicador el crédito doméstico al sector privado, mientras que se usó el spread de tasas de interés para reflejar el costo de transacción para obtener financiamiento. Se obtuvieron los efectos esperados según la literatura revisada, y se obtuvo una relación de largo plazo significativa entre estas variables.

La hipótesis general se cumple, al demostrarse la existencia de un impacto positivo del desarrollo de los mercados de capitales en el crecimiento económico de los países del MILA, en el periodo de estudio. En el modelo presentado, la variable capitalización de mercado resultó altamente significativa con un coeficiente positivo. Sin embargo, la variable valor total de acciones tranzadas resultó no significativa. El resultado se reafirma al observar las funciones impulso respuesta estimadas, donde la capitalización de mercado tiene un impacto positivo y creciente en el tiempo sobre el PBI per cápita.

La capitalización de mercado es un indicador de desarrollo del mercado de capitales, ya que un alto nivel de esta variable significa un mercado de gran tamaño. Esto quiere decir que, mientras más empresas coticen sus acciones en el mercado, estas podrán obtener el financiamiento necesario para llevar a cabo sus proyectos. Con esto se incentiva la inversión tanto local como extranjera, favoreciendo el crecimiento económico.

Por otra parte, las hipótesis específicas también se cumplen. Se planteó que el acceso al financiamiento de las empresas tiene un efecto positivo en el crecimiento 
económico. Un mayor acceso al crédito significa que las empresas pueden financiar sus operaciones, posibilitando un mayor crecimiento de las mismas. Además, mayor crédito interno significa mayor inversión, ya que los bancos poseen la capacidad de obtener recursos de los superavitarios y facilitárselos a los deficitarios, favoreciendo una asignación eficiente de recursos. En el modelo, esta variable es la que representa un mayor impacto sobre el PBI per cápita, al tener el coeficiente más alto.

En el caso de la variable spread, un nivel alto del diferencial de tasas de interés significa que es caro para las empresas pedir préstamos, lo que limita su acceso al financiamiento en términos absolutos. En los países del MILA, especialmente en Perú, este spread es muy alto, lo cual desincentiva la inversión.

También se planteó que los costos de transacción ejercen un impacto negativo en el desarrollo del mercado de capitales. De acuerdo a lo analizado en el marco teórico, estos costos influyen de manera directa en las decisiones de inversión y financiamiento. Por el lado de los inversionistas, mayor costo se traduce en una mala asignación de activos, ya que solo las inversiones con un retorno que compense estos costos serán atractivas.

Por el lado de las empresas, altos costos de financiamiento desincentivan la inversión. En el capítulo IV se vio que, en el Perú, los costos asociados a la emisión de bonos son en gran parte fijos, mientras que en los otros países del MILA, los costos fijos son menores. Mientras más alto sea el costo fijo, solo será rentable emitir bonos por montos mayores, por lo que el mercado de deuda no crece. Esto se traduce en que el porcentaje de financiamiento de las empresas mediante bonos corporativos en Perú, sea el más bajo de los cuatro países.

Este trabajo apoya a la literatura revisada, lo cual fortalece la idea de que el desarrollo del mercado de capitales favorece al crecimiento económico, en especial en los países en desarrollo, que tienen alta dependencia de la inversión extranjera. Es por esto que la integración bursátil de Chile, Colombia, México y Perú es de gran importancia para el crecimiento de estos países, ya que no solo favorece la asignación de recursos de manera interna, sino que también facilita la inversión extranjera, proporcionando un mayor flujo de capitales a la zona. 


\section{RECOMENDACIONES}

Una primera recomendación es incrementar la transparencia en las empresas para evitar problemas de información asimétrica. Para esto se puede exigir que las empresas que coticen en bolsa o emitan bonos cuenten con estados financieros auditados de manera trimestral, disponibles para el público en sus páginas web y en la página de la Superintendencia de Mercado de Valores. De esta manera, los inversionistas podrán informarse sobre la situación de las empresas, lo que les dará seguridad a la hora de invertir.

Además, se puede ampliar este requerimiento para las empresas que buscan financiamiento bancario, con lo que se lograría reducir los costos de evaluación en los que incurre el banco. Esto se puede traducir en una disminución de las tasas de interés activas. De esta manera se podría lograr la reducción del spread de tasas de interés a través del incremento de la transparencia en las empresas.

También se debe incentivar a las empresas a emitir acciones y bonos para incrementar la oferta de valores, con lo que se puede mejorar la liquidez del mercado. Esto se lograría reduciendo los costos de emisión y haciendo que estos no sean fijos, para que las pequeñas y medianas empresas puedan emitir instrumentos. Por parte del Estado, se puede utilizar la emisión de bonos como medio de financiamiento de obras públicas para las municipalidades regionales. Con esto se puede acceder a mayores recursos a un menor costo, además de mejorar la asignación de recursos públicos.

Por otra parte, instituciones estatales como la Superintendencia de Mercado de Valores, pueden realizar seminarios o charlas gratuitas a empresas sobre el financiamiento a través de este mercado. Además, pueden brindar asesoría personalizada para facilitar las primeras emisiones de deuda o colocaciones de acciones de las empresas. De esta manera se puede incentivar el uso del mercado de capitales y promover su crecimiento. 


\section{REFERENCIAS}

Aghion, P. y Howitt, P. (1992). A Model of Growth Through Creative Destruction. Econometrica, 60(2), 323-351.

Al Nasser, O. (2015). Stock Markets, Banks, and Economic Growth: Evidence from Latin American Countries. International Journal of Economics and Finance, 7(2), 100112.

Aninat, E. (2001). Desarrollo de los mercados de capital en América Latina. Fondo Monetario Internacional. Recuperado de https://www.imf.org/external/np/speeches/2001/020501s.htm

Arestis, P., Demetriades, P., y Luintel, K. (2001). Financial Development and Economic Growth: The Role of Stock Markets. Journal of Money, Credit and Banking, 33, $16-41$.

Arrarte, R. (2011). Financiamiento de inversiones estratégicas y el mercado de capitales en el Perú. Revista de la Facultad de Ciencias Contables de la UNMSM, 18, 117141.

Banco Centra de Reserva del Perú (2010). Guía Metodológica de la Nota Semanal. Recuperado de http://www.bcrp.gob.pe/docs/Publicaciones/Guia-Metodologica/ Guia-Metodologica-04.pdf

Banco Centra de Reserva del Perú (2017). Reporte de Estabilidad Financiera Noviembre 2017. Recuperado de http://www.bcrp.gob.pe/publicaciones/reportede-estabilidad-financiera/ref-noviembre-2017.html

Banco Mundial. Banco de Datos. Base de datos: Desarrollo Financiero Mundial.

Recuperado de

http://databank.bancomundial.org/data/source/global-financial-development

Banco Mundial. Banco de Datos. Base de datos: Indicadores de Desarrollo Mundial.

Recuperado de

http://databank.bancomundial.org/data/source/world-development-indicators

Bolsa Mexicana de Valores (2016). Aranceles para el cobro de cuotas por concepto de listado y mantenimiento de valores que cotizan en la BMV. Recuperado de 
https://www.bmv.com.mx/es/listados-y-prospectos/aranceles-y-calculos-decuotas

Bolsa de Valores de Colombia (2018). Simulador de bonos ordinarios. Recuperado de https://bvc.com.co/pps/tibco/portalbvc/Home/Empresas

Bencivenga, V. y Smith, B. (1991). Financial intermediation and endogenous growth. The Review of Economic Studies, 58 (194), 195.

Borges, M., Landaberry, M., y Licandro, G. (2012). Determinantes del desarrollo de Mercados de Capitales: Estudios de casos de Chile, Colombia y Perú. Banco Central del Uruguay, (008), 54.

Bucacos, E. (2003). El financiamiento inflacionario del déficit fiscal”. Banco Central del Uruguay, (001), 17.

Casilda, R. (2004). América Latina y el Consenso de Washington. Boletín Económico de Ice, (2803), 19-38.

Dapena, J. (2009). Rol del mercado de capitales en el crecimiento de la economía: Literatura y evidencia para Argentina. Serie Documentos de Trabajo, Universidad del CEMA: Área: economía y finanzas, (393).

El-Erian, M. (1992). Restoration of access to voluntary capital market financing: The recent Latin American experience. Staff Papers - International Monetary Fund, 39(1), 175.

Equilibrium (2016). Comportamiento de los Bonos Corporativos en el Mercado Peruano. Recuperado de http://www.equilibrium.com.pe/InformeBCorp.pdf

Greenwood, J. y Jovanovic, B. (1990). Financial Development, Growth, and the Distribution of Income. The Journal of Political Economy, 98(5), 1076-1107.

Grossman, G. y Helpman, E. (1991). Quality Ladders in the Theory of Growth. The Review of Economic Studies, 58(1), 43-61.

Hassan, M., Sanchez, B y Yu, J. (2011). Financial development and economic growth: New evidence from panel data. The Quarterly Review of Economics and Finance, $51,88-104$. 
Informe Especial MILA. Bolsa de Valores de Colombia (s. f.). Recuperado de http://www.bvc.com.co/pps/tibco/portalbvc/Home/Mercados/informesbursatiles ?com

Instituto Nacional de Estadística e Informática (2014). Resumen ejecutivo, Perú:

Estructura Empresarial. Recuperado de https://www.inei.gob.pe/media/Menu

Recursivo/publicaciones_digitales/Est/Lib1262/resumen.pdf

King, R. y Levine, R. (1993). Finance and Growth: Schumpeter Might Be Right. The Quarterly Journal of Economics, 108 (3), 717.

Lahura, E. y Vargas, M. (2016). Sector bancario, mercado de capitales y actividad real en el Perú: Un análisis de causalidad empírica”. Banco Central de Reserva del Perú: Revista Estudios Económicos, 31, 59-69.

Lahura, E. y Vega, M. (2013). The dynamic relationship between stock market development and economic activity: evidence from Peru, 1965-2011. Departamento de Economía PUCP, (369). Recuperado de http://www.pucp.edu.pe/departamento/economia/images/documentos/DDD369. pdf

Lucas, R. (1988). On the Mechanics of Economic Development. Journal of Monetary Economics, 22, 3-42.

Marchini, G. (2004). El sistema financiero peruano: 1970-2004. México y la cuenca del pacífico, 7(23), 43-57.

Martínez, R y Soto, E. (2012). El Consenso de Washington: la instauración de las políticas neoliberales. Política y Cultura, (37), 35-64.

Mayorga, M. y Muñoz S., E. (2000). La técnica de datos de panel, una técnica para su uso e interpretación. Banco Central de Costa Rica - Departamento de Investigaciones Económicas, (05-2000), 20.

Mercado Integrado Latinoamericano. Reseña Histórica (s. f.). Recuperado de http://www.mercadomila.com

Merton, R. (1995). A Functional Perspective of Financial Intermediation. Financial Management, 24(2), 23-41. 
Ministerio de Economía y Finanzas. Capitulo I. Conceptos Básicos sobre el Mercado de Valores. Recuperado de http://www.mef.gob.pe/index.php?option=com_ contentyview $=$ articleyid $=2186 \% 3$ Acapitulo-i-conceptos-basicos-sobre-elmercado-de-valores-yItemid=100143ylang=es

Nyasha, S. y Odhiambo, N. (2015). The Impact of Banks and Stock Market Development on Economic Growth in South Africa: an ARDL-bounds Testing Approach. Contemporary Economics, 9(1), 93-108.

Ouandlous, A. (2010). Capital Markets and Economic Development: A Framework for Newly Liberalized Economies. Journal of Business y Economics Research, 8(6), 9-16.

Peraza, L. (2010). El papel del mercado bursátil en el crecimiento económico de México. Centro de Estudios de las Finanzas Públicas, (001), 60.

Phillips, P. (1995). Fully Modified Least Squares and Vector Autoregression. Econometrica, 63(5), 1023-1078.

Raju, S. y Fitzpatrick, B. (2010). Financial Market Development, Economic Development and Growth Diagnostics: An Application to Peru. International Business y Economics Research Journal, 9, 9-39.

Rebelo, S. (1991). Long-Run Policy Analysis and Long-Run Growth. The Journal of Political Economy, 99(3), 500-521.

Reglamento del Mercado Integrado Latinoamericano. (2014). Recuperado de: http://www.cavali.com.pe/userfiles/cms/pagina/documento/reglamentomilamayo 2016.pdf

Rojas, J. (1994). La reforma del sistema financiero peruano, 1990- 1995. Economía, 17(33), 149-198.

Romer, P. (1986). Increasing Returns and Long-Run Growth. The Journal of Political Economy, 94(5), 1002-1037.

Romer, P. (1990). Endogenous Technological Change. The Journal of Political Economy, 98(5), 71-102.

Roubini, N. y Sala-i-Martin, X. (1992) A Growth Model of Inflation, Tax Evasion and Financial Repression. Economic Growth Center, Yale University, (658), 1-37. 
Rummel, O. (2015). Economic Modelling and Forecasting: Subset VAR, SVAR and VECM modelling. Centre for Central Banking Studies - Bank of England, 54.

Solow, R. (1956). A Contribution to the Theory of Economic Growth. The Quarterly Journal of Economics, 70(1), 65-94.

Stiglitz, J. (2003). El rumbo de las reformas. Hacia una nueva agenda para América Latina. Revista de la CEPAL - Repositorio Digital de la Comisión Económica para América Latina y el Caribe, 7.

Superintendencia de Banca y Seguros (2017). Reporte de Indicadores de Inclusión Financiera de los Sistemas Financiero, de Seguros y de Pensiones de la SBS. Recuperado de http://www.sbs.gob.pe/Portals/4/jer/PLANTILLA-REPORTEINDICADORES/CIIF_0001_jn2017.pdf

Superintendencia de Valores y Seguros de Chile (2018). Inscripción en el Registro de emisión de títulos de deuda de largo plazo. Recuperado de http://www.svs.cl/portal/principal/605/w3-article-14626.html

Thomas, L. (2006). Money, Banking and Financial Markets (4. ${ }^{\mathrm{a}}$ ed.). Kansas: South Western.

Vial, J. (2002). Dependencia de Recursos Naturales y Vulnerabilidad en los Países Andinos. Center for International Development, Harvard University, 33.

Wong, A. (2011). Development of Financial Market and Economic Growth: Review of Hong Kong, China, Japan, the United States and the United Kingdom. International Journal of Economics and Finance,3(2), 111-115.

Wooldridge, J. (2016). Introducción a la econometría, un enfoque moderno (4. $\left.{ }^{\mathrm{a}} \mathrm{ed}.\right)$. México, D.F.: Cengage Learning. 
ANEXOS 


\section{ANEXO 1: PRUEBAS DE RAÍZ UNITARIA}

Prueba en niveles para la variable PBI per cápita

\section{ADF Fisher Unit Root Test on PBIPC}

Null Hypothesis: Unit root (individual unit root process)

Series: PBIPC

Date: 04/14/19 Time: $18: 51$

Sample: 19942016

Exogenous variables: Individual effects

User-specified lags: 1

Total (balanced) observations: 84

Cross-sections included: 4

\begin{tabular}{lcc}
\hline \hline Method & Statistic & Prob.** \\
\hline ADF - Fisher Chi-square & 3.88666 & 0.8672 \\
ADF - Choi Z-stat & 2.64602 & 0.9959 \\
\hline \hline
\end{tabular}

** Probabilities for Fisher tests are computed using an asymptotic Chi -square distribution. All other tests assume asymptotic normality.

Fuente: Banco de Datos del Banco Mundial (s. f.). Recuperado de https://databank.bancomundial.org. Elaboración propia

Prueba en diferencias para la variable PBI per cápita

\section{ADF Fisher Unit Root Test on D(PBIPC)}

Null Hypothesis: Unit root (individual unit root process)

Series: D(PBIPC)

Date: 04/14/19 Time: 18:51

Sample: 19942016

Exogenous variables: Individual effects

User-specified lags: 1

Total (balanced) observations: 80

Cross-sections included: 4

\begin{tabular}{lrc}
\hline \hline Method & Statistic & Prob. $^{* *}$ \\
\hline ADF - Fisher Chi-square & 18.6300 & 0.0170 \\
ADF - Choi Z-stat & -2.36791 & 0.0089 \\
\hline \hline
\end{tabular}

** Probabilities for Fisher tests are computed using an asymptotic Chi -square distribution. All other tests assume asymptotic normality.

Fuente: Banco de Datos del Banco Mundial (s. f.). Recuperado de https://databank.bancomundial.org. Elaboración propia 
Prueba en niveles para la variable Crédito interno

\section{ADF Fisher Unit Root Test on CRED}

Null Hypothesis: Unit root (individual unit root process)

Series: CRED

Date: 04/14/19 Time: 18:51

Sample: 19942016

Exogenous variables: Individual effects

User-specified lags: 1

Total (balanced) observations: 84

Cross-sections included: 4

\begin{tabular}{lcc}
\hline \hline Method & Statistic & Prob. $^{* *}$ \\
\hline ADF - Fisher Chi-square & 2.34280 & 0.9687 \\
ADF - Choi Z-stat & 1.54257 & 0.9385 \\
\hline \hline
\end{tabular}

** Probabilities for Fisher tests are computed using an asymptotic Chi -square distribution. All other tests assume asymptotic normality.

Fuente: Banco de Datos del Banco Mundial (s. f.). Recuperado de https://databank.bancomundial.org. Elaboración propia

Prueba en diferencias para la variable Crédito interno

\section{ADF Fisher Unit Root Test on D(CRED)}

Null Hypothesis: Unit root (individual unit root process)

Series: D(CRED)

Date: 04/14/19 Time: 18:52

Sample: 19942016

Exogenous variables: Individual effects

User-specified lags: 1

Total (balanced) observations: 80

Cross-sections included: 4

\begin{tabular}{lcc}
\hline \hline Method & Statistic & Prob. $^{* *}$ \\
\hline ADF - Fisher Chi-square & 37.4772 & 0.0000 \\
ADF - Choi Z-stat & -4.20611 & 0.0000 \\
\hline \hline
\end{tabular}

** Probabilities for Fisher tests are computed using an asymptotic Chi -square distribution. All other tests assume asymptotic normality.

Fuente: Banco de Datos del Banco Mundial (s. f.). Recuperado de https://databank.bancomundial.org. Elaboración propia 
Prueba en niveles para la variable Spread de tasas de interés

\section{ADF Fisher Unit Root Test on SPREAD}

Null Hypothesis: Unit root (individual unit root process)

Series: SPREAD

Date: 04/14/19 Time: 18:52

Sample: 19942016

Exogenous variables: Individual effects

User-specified lags: 1

Total (balanced) observations: 84

Cross-sections included: 4

\begin{tabular}{lrc}
\hline \hline Method & Statistic & Prob. $^{* *}$ \\
\hline ADF - Fisher Chi-square & 12.7984 & 0.1190 \\
ADF - Choi Z-stat & -1.45025 & 0.0735 \\
\hline
\end{tabular}

** Probabilities for Fisher tests are computed using an asymptotic Chi -square distribution. All other tests assume asymptotic normality.

Fuente: Banco de Datos del Banco Mundial (s. f.). Recuperado de https://databank.bancomundial.org. Elaboración propia

Prueba en diferencias para la variable Spread de tasas de interés

\section{ADF Fisher Unit Root Test on D(SPREAD)}

Null Hypothesis: Unit root (individual unit root process)

Series: D(SPREAD)

Date: 04/14/19 Time: 18:52

Sample: 19942016

Exogenous variables: Individual effects

User-specified lags: 1

Total (balanced) observations: 80

Cross-sections included: 4

\begin{tabular}{lcc}
\hline \hline Method & Statistic & Prob. ${ }^{* \star}$ \\
\hline ADF - Fisher Chi-square & 51.0297 & 0.0000 \\
ADF - Choi Z-stat & -5.79596 & 0.0000 \\
\hline \hline
\end{tabular}

** Probabilities for Fisher tests are computed using an asymptotic Chi -square distribution. All other tests assume asymptotic normality.

Fuente: Banco de Datos del Banco Mundial (s. f.). Recuperado de https://databank.bancomundial.org. Elaboración propia 
Prueba en niveles para la variable Capitalización de mercado

\section{ADF Fisher Unit Root Test on CAP}

Null Hypothesis: Unit root (individual unit root process)

Series: CAP

Date: 04/14/19 Time: 18:53

Sample: 19942016

Exogenous variables: Individual effects

User-specified lags: 1

Total (balanced) observations: 84

Cross-sections included: 4

\begin{tabular}{lcc}
\hline \hline Method & Statistic & Prob. $^{* *}$ \\
\hline ADF - Fisher Chi-square & 5.40392 & 0.7137 \\
ADF - Choi Z-stat & 0.12810 & 0.5510 \\
\hline \hline
\end{tabular}

** Probabilities for Fisher tests are computed using an asymptotic Chi -square distribution. All other tests assume asymptotic normality.

Fuente: Banco de Datos del Banco Mundial (s. f.). Recuperado de https://databank.bancomundial.org. Elaboración propia

Prueba en diferencias para la variable Capitalización de mercado

\section{ADF Fisher Unit Root Test on D(CAP)}

Null Hypothesis: Unit root (individual unit root process)

Series: D(CAP)

Date: 04/14/19 Time: $18: 53$

Sample: 19942016

Exogenous variables: Individual effects

User-specified lags: 1

Total (balanced) observations: 80

Cross-sections included: 4

\begin{tabular}{lcc}
\hline \hline Method & Statistic & Prob.** \\
\hline ADF - Fisher Chi-square & 27.7511 & 0.0005 \\
ADF - Choi Z-stat & -3.54308 & 0.0002 \\
\hline \hline
\end{tabular}

** Probabilities for Fisher tests are computed using an asymptotic Chi -square distribution. All other tests assume asymptotic normality.

Fuente: Banco de Datos del Banco Mundial (s. f.). Recuperado de https://databank.bancomundial.org. Elaboración propia 
Prueba en niveles para la variable Valor total de acciones tranzadas

\section{ADF Fisher Unit Root Test on SMVT}

Null Hypothesis: Unit root (individual unit root process)

Series: SMVT

Date: 04/28/19 Time: $20: 41$

Sample: 19942016

Exogenous variables: Individual effects

User-specified lags: 1

Total (balanced) observations: 84

Cross-sections included: 4

\begin{tabular}{lcc}
\hline \hline Method & Statistic & Prob. $^{\star *}$ \\
\hline ADF - Fisher Chi-square & 8.02823 & 0.4307 \\
ADF - Choi Z-stat & -0.54157 & 0.2941 \\
\hline \hline
\end{tabular}

** Probabilities for Fisher tests are computed using an asymptotic Chi -square distribution. All other tests assume asymptotic normality.

Fuente: Banco de Datos del Banco Mundial (s. f.). Recuperado de https://databank.bancomundial.org. Elaboración propia

Prueba en diferencias para la variable Valor total de acciones tranzadas

\section{ADF Fisher Unit Root Test on D(SMVT)}

Null Hypothesis: Unit root (individual unit root process)

Series: D(SMVT)

Date: 04/28/19 Time: 20:42

Sample: 19942016

Exogenous variables: Individual effects

User-specified lags: 1

Total (balanced) observations: 80

Cross-sections included: 4

\begin{tabular}{lcc}
\hline \hline Method & Statistic & Prob. $^{* *}$ \\
\hline ADF - Fisher Chi-square & 37.0695 & 0.0000 \\
ADF - Choi Z-stat & -4.56875 & 0.0000 \\
\hline \hline
\end{tabular}

** Probabilities for Fisher tests are computed using an asymptotic Chi -square distribution. All other tests assume asymptotic normality.

Fuente: Banco de Datos del Banco Mundial (s. f.). Recuperado de https://databank.bancomundial.org. Elaboración propia 


\section{ANEXO 2: PRUEBAS DE SELECCIÓN DE NÚMERO DE REZAGOS}

Prueba de selección de número de rezagos para la variable PBI per cápita

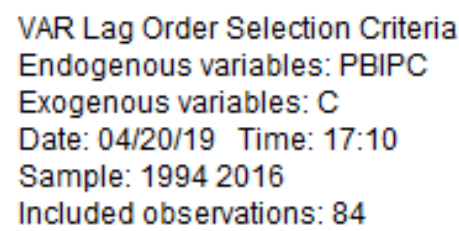

\begin{tabular}{ccccccc}
\hline \hline Lag & LogL & LR & FPE & AIC & SC & HQ \\
\hline \hline 0 & -795.3912 & NA & 10057409 & 18.96170 & 18.99063 & 18.97333 \\
1 & -565.3262 & 449.1746 & 43040.56 & 13.50777 & 13.56564 & 13.53103 \\
2 & -562.9623 & $4.558889^{\star}$ & $41666.24^{\star}$ & $13.47529^{*}$ & $13.56211^{*}$ & $13.51019^{*}$ \\
\hline \hline
\end{tabular}

* indicates lag order selected by the criterion

LR: sequential modified LR test statistic (each test at $5 \%$ level)

FPE: Final prediction error

AIC: Akaike information criterion

SC: Schwarz information criterion

$\mathrm{HQ}$ : Hannan-Quinn information criterion

Fuente: Banco de Datos del Banco Mundial (s. f.). Recuperado de https://databank.bancomundial.org. Elaboración propia

Prueba de selección de número de rezagos para la variable Crédito interno

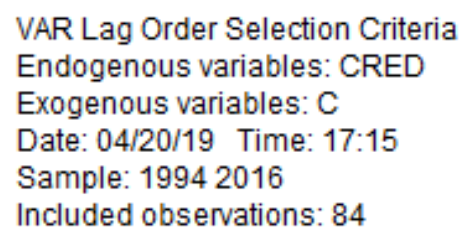

\begin{tabular}{ccccccc}
\hline \hline Lag & LogL & LR & FPE & AIC & SC & HQ \\
\hline \hline 0 & -397.4973 & NA & 772.9043 & 9.488031 & 9.516969 & 9.499664 \\
1 & -221.3671 & 343.8733 & 11.94598 & 5.318263 & 5.376140 & 5.341529 \\
2 & -218.9173 & $4.724486^{\star}$ & $11.54092^{\star}$ & $5.283746^{\star}$ & $5.370561^{\star}$ & $5.318645^{\star}$ \\
\hline \hline
\end{tabular}

* indicates lag order selected by the criterion

LR: sequential modified LR test statistic (each test at $5 \%$ level)

FPE: Final prediction error

AIC: Akaike information criterion

SC: Schwarz information criterion

$H Q$ : Hannan-Quinn information criterion

Fuente: Banco de Datos del Banco Mundial (s. f.). Recuperado de https://databank.bancomundial.org. Elaboración propia 
Prueba de selección de número de rezagos para la variable Spread de tasas de interés

\begin{tabular}{l} 
VAR Lag Order Selection Criteria \\
Endogenous variables: SPREAD \\
Exogenous variables: C \\
Date: 04/20/19 Time: 17:14 \\
Sample: 1994 2016 \\
Included observations: 84 \\
\hline \hline \\
\hline \hline
\end{tabular}

Fuente: Banco de Datos del Banco Mundial (s. f.). Recuperado de https://databank.bancomundial.org. Elaboración propia

Prueba de selección de número de rezagos para la variable Capitalización de mercado

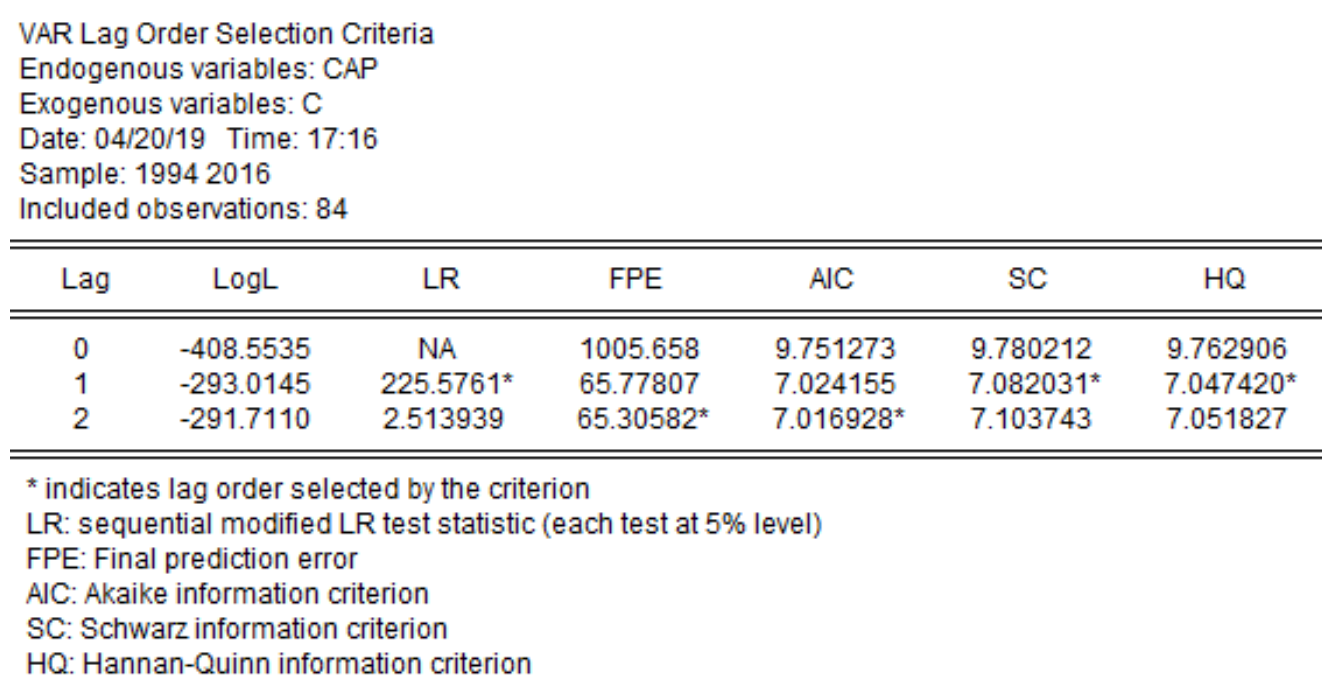

Fuente: Banco de Datos del Banco Mundial (s. f.). Recuperado de https://databank.bancomundial.org. Elaboración propia 
Prueba de selección de número de rezagos para la variable Valor total de acciones tranzadas

VAR Lag Order Selection Criteria

Endogenous variables: SMVT

Exogenous variables: $\mathrm{C}$

Date: 04/28/19 Time: $21: 00$

Sample: 19942016

Included observations: 84

\begin{tabular}{ccccccc}
\hline \hline Lag & LogL & LR & FPE & AIC & SC & HQ \\
\hline \hline 0 & -262.5012 & NA & 31.06126 & 6.273837 & 6.302776 & 6.285470 \\
1 & -212.5182 & 97.58578 & 9.676577 & 5.107576 & 5.165453 & 5.130842 \\
2 & -209.4130 & $5.988692^{*}$ & $9.203692^{*}$ & $5.057451^{\star}$ & $5.144266^{\star}$ & $5.092350^{*}$ \\
\hline \hline
\end{tabular}

* indicates lag order selected by the criterion

LR: sequential modified LR test statistic (each test at $5 \%$ level)

FPE: Final prediction error

AIC: Akaike information criterion

SC: Schwarz information criterion

$\mathrm{HQ}$ : Hannan-Quinn information criterion

Fuente: Banco de Datos del Banco Mundial (s. f.). Recuperado de https://databank.bancomundial.org. Elaboración propia 